\author{
UNIVERSIDADE DE BRASÍLIA \\ FACULDADE DE CIÊNCIAS DA SAÚDE \\ PROGRAMA DE PÓS-GRADUAÇÃO EM SAÚDE COLETIVA
}

ELISA GOULART MACHADO KOVALSKI

DEPRESSÃO EM ADOLESCENTES: UM ESTUDO DE PREVALÊNCIA NO DISTRITO FEDERAL

Dissertação apresentada como requisito parcial para a obtenção do Título de Mestre em Saúde Coletiva pelo Programa de PósGraduação em Saúde Coletiva da Universidade de Brasília

Orientadora: Elza Maria de Souza, Ph.D.

Brasília 
ELISA GOULART MACHADO KOVALSKI

\title{
DEPRESSÃO EM ADOLESCENTES: UM ESTUDO DE PREVALÊNCIA NO DISTRITO FEDERAL
}

\begin{abstract}
Dissertação apresentada como requisito parcial para a obtenção do Título de Mestre em Saúde Coletiva pelo Programa de Pós-

Graduação em Saúde Coletiva da Universidade de Brasília
\end{abstract}

Aprovado em 28/08/2015

\author{
BANCA EXAMINADORA \\ Elza Maria de Souza (Presidente) \\ Universidade de Brasília \\ Dapnhe Rattner (Examinadora Interna ao Programa) \\ Universidade de Brasília \\ Maria da Glória Lima (Examinadora Externa do Programa) \\ Universidade deBrasília
}


Aos meus filhos: Pedro e Tiago, minhas fontes de vida e motivação. 


\section{AGRADECIMENTOS}

Agradeço a Deus, em primeiro lugar, por me guiar, iluminar e me dar tranquilidade para concluir esse mestrado, apesar de todas as dificuldades.

Ao meu esposo, Simão, que sempre me incentivou e torceu pela minha vitória.

Aos meus amados pais, Ednardo e Luzdalma, principais responsáveis pela minha vida; e a quem devo o meu caráter e a minha disciplina no trabalho.

Ao meu querido irmão, Bruno, sempre paciente e generoso; e tão presente nos meus momentos de desânimo e falta de estímulo.

À minha querida madrinha e tia Ilma, minha fonte de inspiração acadêmica, em quem me espelho e referencio como profissional, esposa e mãe.

À minha professora e orientadora, Dra Elza Maria de Souza, pela confiança em minha capacidade para desenvolver este trabalho, além da paciência e tranquilidade para me transmitir os ensinamentos necessários.

À minha professora e coordenadora do curso de Pós Graduação em Saúde Coletiva, Dra Helena Eri Shimizu, pela compreensão e apoio ao longo do mestrado.

Ao colega Tiago Alencar, pelo fundamental apoio estatístico, necessário para o desenvolvimento dessa dissertação.

E, por fim, aos professores e colegas da Pós Graduação em Saúde Coletiva, que me proporcionaram um maravilhoso convívio, além de amadurecimento profissional. 
"Somos meninos brincando no teatro do tempo; todo o conhecimento que temos ainda não nos levou ao subsolo do nosso inconsciente."

(Augusto Cury) 


\section{RESUMO}

Os sintomas depressivos na população adolescente são muitas vezes atribuídos às características próprias da idade, dificultando a possiblidade de estudar e tratar os transtornos mentais desta faixa etária. Por outro lado, há uma carência de instrumentos adequados que definam os graus de depressão. Os estudos referentes à adolescência no Brasil são escassos e predominantemente relativos à mortalidade, gravidez precoce, violência, infecção por HIV e uso de drogas. No entanto, pouco se sabe sobre outros agravos neste grupo populacional e sobre como os adolescentes percebem o seu estado de saúde. Tudo isso corrobora para alimentar o mito de que na adolescência existem poucos agravos à saúde física e mental. Nesse sentido, o objetivo do presente estudo foi investigar a prevalência dos sintomas depressivos em uma amostra de adolescentes matriculados em escolas públicas e privadas do Distrito Federal. Para tanto, desenvolveu-se um estudo transversal com 1470 adolescentes entre 10 e 19 anos de idade. Para a seleção da amostra, foram utilizadas as técnicas de amostragem por múltiplos estágios. Em seguida, realizou-se um estudo do "ranking" de renda per capita de todas as Regiões Administrativas (RA's) do DF de acordo com os dados da Companhia de Planejamento do Distrito Federal (CODEPLAN - DF), com vistas à obtenção de uma amostra que fosse representativa de adolescentes pertencentes a todos as faixas de renda do Distrito Federal. Após a seleção das regionais, foi obtida uma lista das escolas públicas junto à Secretaria de Estado de Educação do Distrito Federal (SEEDF). Dessa forma, seria possível obter, em um mesmo ambiente, adolescentes de todas as faixas de idade, de acordo com a definição da OMS. A classificação dos níveis de gradação da depressão foi realizada segundo o Inventário de Depressão de Beck (BDI). Os achados dessa pesquisa evidenciaram que 68\% dos adolescentes pesquisados apresentaram-se deprimidos, sendo que $45 \%$ apresentou depressão leve, 19\% depressão moderada e 4\% depressão grave. As prevalências de depressão de acordo com o gênero, idade e com a renda per capita apresentaram diferenças estatisticamente significativas, sendo que as maiores prevalências de depressão grave e moderada ocorreram nas regiões de menor renda. Já a prevalência de depressão leve foi mais evidente na Região do Plano Piloto, que detém a maior renda do DF e com maiores proporções na única escola 
particular participante da pesquisa. Portanto, os resultados desta pesquisa sugerem a necessidade de mais estudos, incluindo análises de triangulação metodológica sobre depressão em adolescentes, com abrangência nacional, a fim de aprofundar o conhecimento deste agravo e possibilitar a proposição de estratégias de Saúde Coletiva mais amplas, com vistas à prevenção e intervenção neste transtorno junto a esta faixa etária da população brasileira.

PALAVRAS - CHAVE: depressão; adolescentes; prevalência. 


\begin{abstract}
\end{abstract}
Depressive symptoms in teenagers are often attributed to age features, what hinders the possibility to study and treat mental disorders in this group. On the other hand, there is a lack of suitable instruments that define the degrees of depression, without, however, establishing its severity. The studies among teenagers in Brazil are predominantly related to mortality, pregnancy, violence, HIV infection and use of drugs. However, it is necessary to research about other health problems in this population and how teenagers realize their health status. All this supposes that there are a few hazards to physical and mental health in teenagers. Therefore, the aim of this study was to investigate the prevalence of depressive symptoms in teenagers enrolled in public and private schools in the Federal District. Accordingly, a crosssectional study was developed within 1470 teenagers between 10 and 19 years. For the selection, sampling techniques were used by multiple stages. Then, there was a study of the "ranking" of per-capita income of all the administrative regions (RA's) of DF according to data from the Federal District's Planning Company (CODEPLAN$D F)$, in order to obtain a representative sample of teenagers of all income ranges of the state. After the selection of the Regions, a list of public schools from the State Department of Education of Federal District (SEE-DF) was obtained. In this way, it would become possible to take, in the same environment, tennagers from all age ranges, according to WHO's definition. The classification for the depression levels was performed according to the Beck Depression Inventory (BDI). As a result, the findings of this research showed that $68 \%$ of the teenagers evaluated had become depressed, and 45\% had light depression, 19\% moderate depression and 4\% severe depression. The prevalence of depression according to gender and age showed statistically significant differences, as well as income ranges. The highest rates of depressive symptoms were evidenced in the female population. According to depression levels, the higher prevalences of severe and moderate depression occurred in regions with lower incomes and light depression was more prevalent in Plano Piloto Region, which had the highest income of the Distrito Federal, which occurred in the only private school. Therefore, the results of this research suggest the need for further studies, including analyses of methodological triangulation on depression in teenagers, with national scope, in order to deepen the knowledge of 
the interlocutory appeal and make the proposition of broader public health strategies, with a view to prevention and intervention in this trouble with this age group of the Brazilian population.

Key Words: depression; teenagers; prevalence. 


\section{LISTA DE FIGURAS E QUADROS}

Figura 1 - Fluxograma da coleta de dados .28

Figura 2 -llustração do Teste Qui Quadrado. 38

Figura 3- Distribuição dos adolescentes por sexo. .40

Figura 4 -Gradação dos níveis de depressão por sexo. .55

Figura 5 - Distribuição da gradação dos estados depressivos por sexo .55

Figura 6- Prevalência de depressão por escola. .57

Figura 7 - Gradação dos níveis de depressão por escola .57

Figura 8 - Prevalência de depressão segundo o estado conjugal dos pais. 61

Figura 9 - Gradação dos níveis de depressão segundo o estado conjugal dos pais. 61

Quadro 1- Escolas selecionadas aleatoriamente para o estudo. 32 


\section{LISTA DE TABELAS}

Tabela 1-População adolescente do Distrito Federal por Regiões Administrativas.

Tabela 2- Ranking das Regiões Administrativas do Distrito Federal por renda per capita

Tabela 3- Total de adolescentes entrevistados por escola por sexo

Tabela 4- Distribuição das características sóciodemográficas dos adolescentes relativas ao sexo, idade, local de residência e arranjo familiar.

Tabela 5 - Distribuição das características sóciodemográficas dos pais dos adolescentes segundo o estado conjugal e a escolaridade.

Tabela 6 - Distribuição dos aspectos avaliados para a classificação da auto avaliação dos adolescentes sobre seus estados de saúde.

Tabela 7 - Distribuição dos sintomas de depressão referidos pelos estudantes por sexo.

Tabela 8- Gradação da depressão segundo o sexo .54

Tabela 9- Classificação dos níveis de depressão por escola .56

Tabela 10- Classificação dos níveis de depressão por idade. .58 
Tabela 11- Classificação dos níveis de depressão segundo o estado conjugal dos pais. 


\section{LISTA DE ABREVIATURAS E SIGLAS}

ABEP Associação Brasileira de Estudos Populacionais

APA American Psychiatric Association, Associação Americana de Psiquiatria

BAI Beck Anxiety Inventory, Inventário de Ansiedade de Beck

BDI Beck Depression Inventory, Inventário de Depressão de Beck

BHS Beck Hopelessness Scale, Escala de Desesperança de Beck

BSI Beck Scale for Suicide Ideation, Escala de Ideação Suicida de Beck

Box Plot - Gráfico de Caixa

CCHD Carolina Consortium on Human Development, Centro de Desenvolvimento Humano Carolina Consortium

CES-D Center for Epidemiologic Studies Depression Scale

CEP Comitê de Ética e Pesquisa

CID Código Internacional de Doenças

CODEPLAN Companhia de Planejamento do Distrito Federal

CRS Carroll Rating Scale

ESCS Escola Superior em Ciências da Saúde

et al e outros

FEPECS Fundação de Ensino e Pesquisa em Ciências da Saúde

FREE-R The "R" Project for Statistical Computing

DSM The Diagnostic and Statistical Manual of Mental Disorders, Manual Diagnóstico e Estatístico de Transtornos Mentais

GBD Global Burden of Diseases

HAM-D The Hamilton Rating Scale for Depression, Escala de Avaliação de Hamilton IBGE Instituto Brasileiro de Geografia e Estatística

LIDO Longitudinal Investigation of Depression Outcomes 
ONU Organização das Nações Unidas

PIBIC Programa Institucional de Bolsas de Iniciação Científica

PIC Programa de Iniciação Científica

PDAD Pesquisa Distrital de Amostras por Domicílio

RA Região Administrativa do Distrito Federal

SEE/DF Secretaria de Estado de Educação do Distrito Federal

SES/DF Secretaria de Estado de Saúde do Distrito Federal

SIA Setor de Indústria e Abastecimento

SPSS Statistical Package for the Social Sciences

SQR Self Report Questionnaire

YLL Years of Life Lost

YLD Years Lived with Disability

$\%$ porcentagem 


\section{SUMÁRIO}

\section{INTRODUÇÃO}

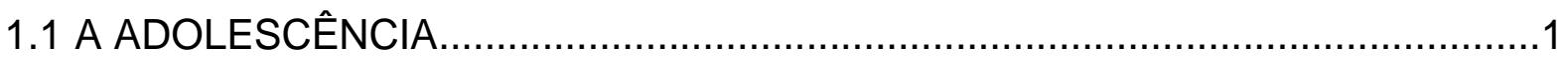

1.2 ADOLESCÊNCIA E AS TEORIAS DO DESENVOLVIMENTO_............................

1.2.1. Primeira Fase: A Descrição dos processos de Desenvolvimento na Adolescência.

1.2.2. Segunda Fase: A Visão Contextualista do Desenvolvimento do Adolescente.7

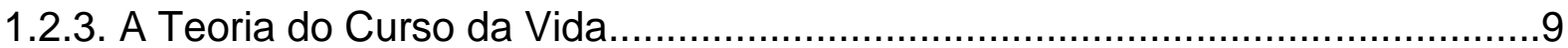

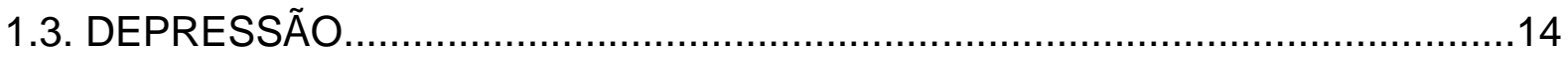

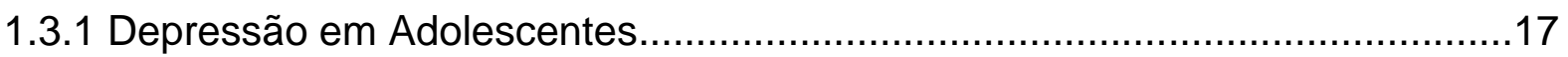

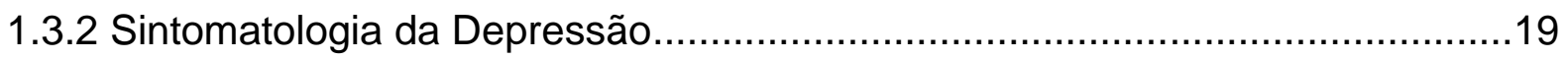

1.3.3 As Escalas de Classificação da Depressão..................................................21

1.4 A POPULAÇÃO ADOLESCENTE NO CONTEXTO MUNDIAL..........................24

2. OBJETIVOS

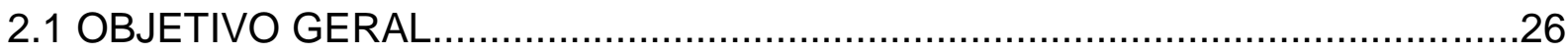

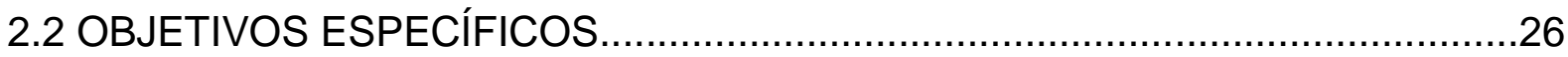

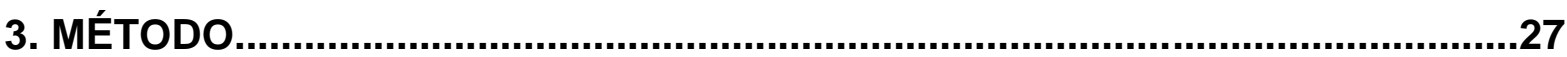

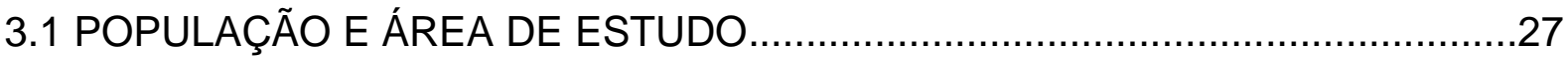

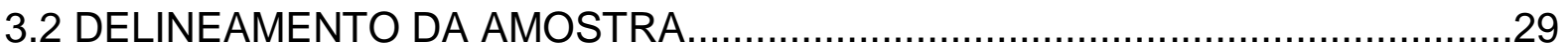

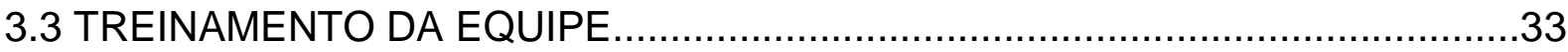

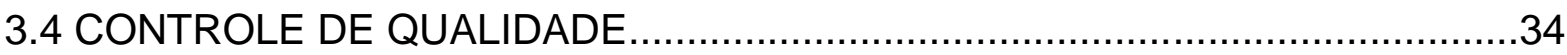

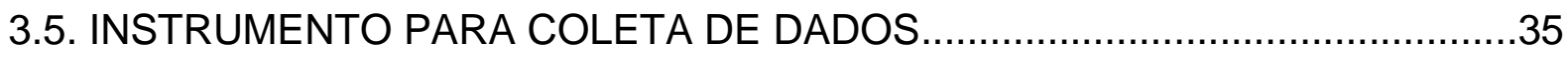




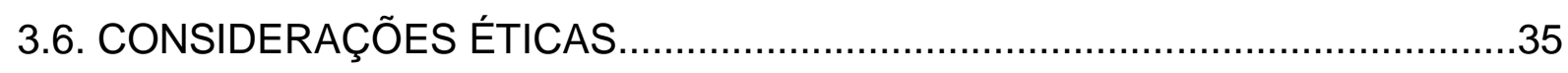

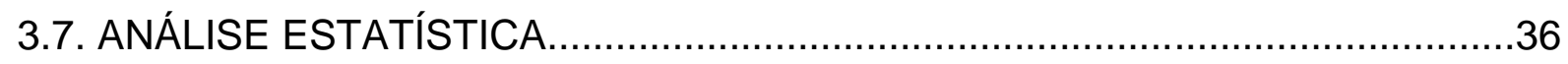

3.7.1 Teste Qui Quadrado para Homogeneidade.................................................36

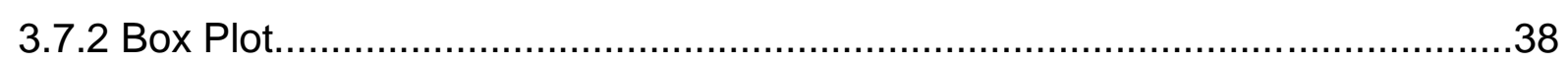

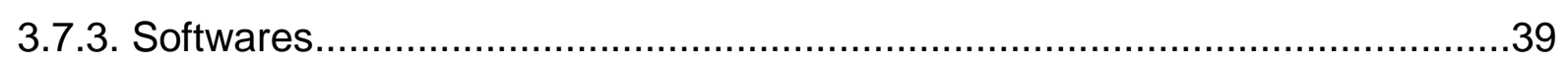

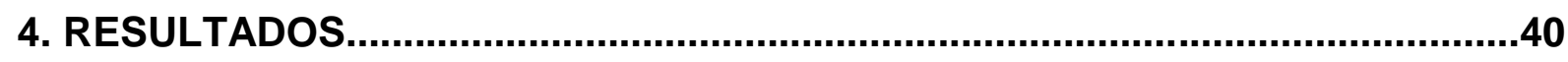

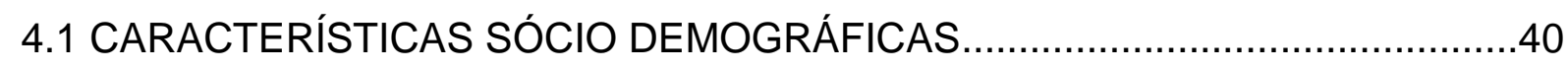

4.2 AUTO AVALIAÇÃO DO ESTADO DE SAÚDE...............................................4

4.3 DESCRIÇÃO DOS SINTOMAS DEPRESSIVOS............................................46

4.4 CLASSIFICAÇÃO DA GRADAÇÃO DOS SINTOMAS DEPRESSIVOS...............54

4.4.1 Prevalência de Depressão por Escola.......................................................56

4.4.2 Prevalência de Depressão por Idade .........................................................58

4.4.3 Prevalência de Depressão por Estado Conjugal dos Pais..............................59

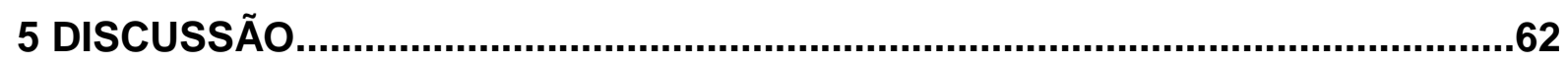

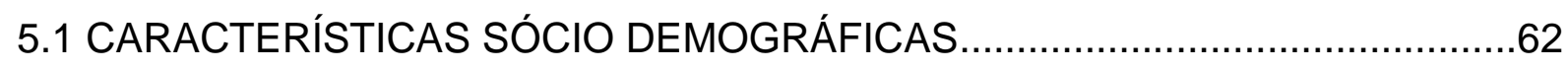

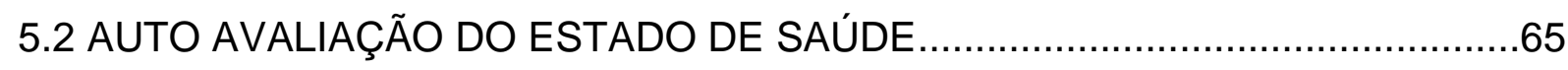

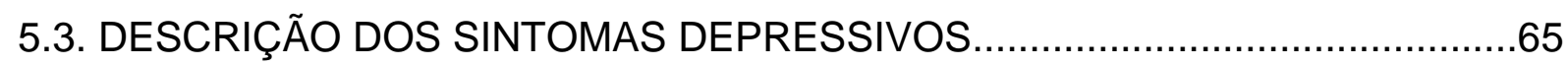

6. CONSIDERAÇÕES FINAIS E RECOMENDAÇÕES........................................70

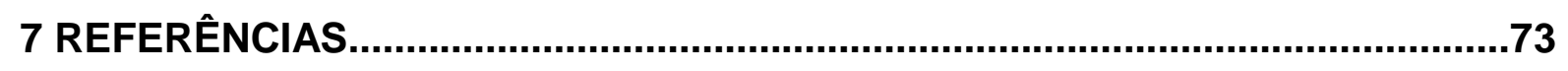




\section{INTRODUÇÃO}

\subsection{A ADOLESCÊNCIA}

A adolescência é o período de transição entre a infância e a vida adulta, caracterizada por desenvolvimento físico, mental, emocional, sexual e social; e pelos esforços do indivíduo em alcançar os objetivos relacionados às expectativas culturais da sociedade em que vive(1) (2)

Os limites cronológicos da adolescência são definidos pela Organização Mundial da Saúde (3) como o período compreendido entre os 10 e 19 anos de idade. No Brasil, o Estatuto da Criança e do Adolescente-ECA (4) classifica como criança pessoas com idade igual ou menor a 12 anos de idade e define a adolescência como a faixa etária compreendida entre os 12 e 18 anos. É importante salientar que devido às assincronias de maturação, ou seja, a diversidade nos parâmetros biológicos e psicossociais, a idade cronológica, embora seja o quesito mais usado, muitas vezes não é o melhor critério descritivo em estudos clínicos, antropológicos e comunitários, ou populacionais (1).

A adolescência também é caracterizada por um período de vulnerabilidade física, psicológica e social, com complexas mudanças no processo de desenvolvimento do ser humano, que origina comportamentos e emoções não antes sentidas pelo próprio indivíduo, por sua família, amigos e profissionais que convivem com ele. Portanto, por se tratar de um período vulnerável, a experiência de adolescer exige esforços e atenção especial por parte dos familiares, dos profissionais da área da saúde e da educação, no sentido de ajudar o futuro adulto a lidar com situações e problemas que possam provocar danos e agravos à saúde (2). 
O funcionamento bio-psico-social e cultural do adolescente sofre-influência de sua cultura, da família e de grupos de amigos aos quais se insere, sendo a pressão dos grupos e de pares fator preditivo para determinar seu comportamento. Dessa forma, estar inserido em determinados grupos significa, para o adolescente, ter um comportamento saudável. Não pertencer a nenhum grupo pode desencadear sintomas relacionados com agravos depressivos. Essa inserção em determinado grupo parece estar relacionada também ao desempenho escolar. Nesse sentido, muitas vezes, a adaptação à escola depende da adaptação ao grupo escolhido. (2). No entanto, a qualidade e o comportamento do grupo podem influenciar aspectos positivos ou negativos tanto no desempenho escolar quanto nas escolhas feitas pelo indivíduo nessa fase.

A adolescência é fase marcada por mudanças psico-afetivas e de conduta, constituindo um dos grupos de pessoas mais sensíveis aos problemas estruturais da sociedade, quais sejam: fome, miséria, desnutrição, analfabetismo, prostituição, violência, abandono, desintegração familiar, dentre outros. Portanto, o adolescente não pode ser tratado de forma padronizada, mas deve ser visto como o produto imbricado ao meio e suas subjetividades, regras, símbolos, valores, idéias, disciplinas, experiências. De igual modo, devem ser levadas em consideração as especificidades de vida do adolescente, que interferem na formação desse jovem (5) (1) (2).

O interesse pela adolescência data do início do século $\mathrm{XV}$, quando surgiram as primeiras tentativas de estudos dessa etapa da vida, embora os estudos científicos referentes à adolescência só tenham sido iniciados a partir de 1904 (5).

\subsection{A ADOLESCÊNCIA E AS TEORIAS DO DESENVOLVIMENTO}


As teorias do desenvolvimento apresentam um papel de destaque na história da psicologia do adolescente. Tais teorias organizaram e deram significado e coerência aos fatos relativos à adolescência, a princípio isolados; e permitiram a dedução e testagem efetiva em trabalhos empíricos subsequentes. Assim sendo, os estudos concernentes à adolescência podem ser divididos em três grandes fases.

\subsubsection{Primeira Fase: A Descrição dos Processos de Desenvolvimento na Adolescência:}

Nesta primeira fase do estudo científico da adolescência, destaca-se a obra de Granville Stanley Hall (6), cujo título era: "Adolescência" e foi publicada no ano de 1904. Esse autor se fundamenta na teoria biológica, baseada no desenvolvimento das espécies e define a adolescência como um período de transição universal e inevitável, considerando-a como um segundo nascimento. Ele reconhece a influência da cultura, ao mesmo tempo em que valoriza as diferenças individuais do adolescente, com suas características de plasticidade (maleabilidade). Foi um precursor das teorias contextualistas contemporâneas.

Ainda dentro da primeira fase, destaca-se o grupo de teorias baseadas nos pressupostos da psicanálise de Sigmund Freud (7), que não identificou a adolescência como fase distinta no desenvolvimento, apesar de considerá-la crucial. Esta perspectiva preconizou que as pessoas são dotadas de um reservatório de impulsos biológicos, identificando a emergência de determinado aspecto da sexualidade humana a cada fase distinta do ciclo vital.

De acordo com Sigmund Frued, a intelectualização passa a ser um mecanismo de defesa adotado pelo adolescente para lidar com a sua revolta emocional, conduzindo-o a mudar seus interesses das questões concretas do corpo 
para questões mais abstratas, isentas de emoção. Sob essa égide, os conflitos da puberdade são considerados normais e até necessários para que ocorra um mecanismo adaptativo dos adolescentes na busca por um novo sentido de personalidade e papel social.

Já Erik Erikson (8), autor da Teoria Psicossocial do Desenvolvimento Humano, destaca a influência dos ambientes e o impacto da socialização dos indivíduos ao longo da vida. A formulação de Erikson fundamenta-se no conceito de epigênese, termo oriundo da Embriologia. $O$ princípio epigenético sustenta que o desenvolvimento ocorre em estágios sequenciais e claramente definidos. A cada um dos oito estágios do desenvolvimento, ocorre o enfrentamento de um conflito central, caracterizado por uma "crise" normal e saudável a ser ultrapassada. De acordo com esse modelo, caso não ocorra uma resolução eficaz de um determinado estágio, todos os outros subsequentes refletirão essa falha, sob a forma de algum tipo de desajuste, seja ele de origem física, cognitiva, social ou emocional. Erikson defende que a energia ativadora do comportamento é de natureza psicossocial, integrando não apenas fatores biológicos e inatos, como também fatores sociais, aprendidos em contextos históricos e culturais específicos.

Portanto, de acordo com o princípio epigenético, o desenvolvimento psicossocial é sinônimo de desenvolvimento da personalidade e ocorre ao longo de oito estágios, que, no seu conjunto, constituem o ciclo da vida. Assim sendo, cada estágio corresponde à formação de um aspecto particular da personalidade e os conflitos ou crises que o indivíduo vive ao longo desses períodos precisam ser resolvidos de forma positiva ou negativa pelos indivíduos. A resolução positiva se transforma em uma virtude que confere ao indivíduo equilíbrio mental e capacidade de um bom relacionamento social. Contudo, se a resolução for negativa, o indivíduo se sente socialmente desajustado e tende a desenvolver sentimentos de ansiedade e de fracasso.

No que se refere especificamente à adolescência, evidenciada no $5^{\circ}$ estágio de Erikson, verifica-se que toda a preocupação do adolescente em encontrar um papel social provoca uma confusão de identidade; afinal, a preocupação com a opinião alheia faz com que o adolescente modifique a todo o tempo as suas atitudes; 
o que o leva, a remodelar, com frequência, a sua personalidade em um período muito curto, segundo o mesmo ritmo das transformações físicas que acontecem com ele.

Erikson refere que o ser humano mantém suas defesas para sobreviver. Ao sinal de qualquer problema, uma delas pode ser ativada. Nesta confusão de identidades, o adolescente pode se sentir vazio, isolado, ansioso e incapaz de se encaixar no mundo adulto, o que pode, muitas vezes, levar a uma regressão e à instalação de sintomas depressivos. Esse autor destaca que todos os indivíduos deveriam construir a sua personalidade ao longo da adolescência, porém essa construção não pode ser feita de um mesmo modo para todos os adolescentes, ou seja, não pode ser realizada de maneira padronizada ou linear.

Durante a adolescência, há sempre a busca por algo mais, com desencadeamento de crises, indecisões e situações conflituosas que são evidenciadas pelo desenvolvimento da identidade, que se encontra em processo de mutação e que depende de experiências e informações adquiridas pelas interações sociais dos adolescentes com as outras pessoas. Desta feita, verifica-se que, segundo este autor, adolescentes que recebem encorajamento e reforço apropriados para sua exploração pessoal tendem a emergir para o início da fase adulta com um sentimento mais consistente acerca de si próprios, e com maiores sentimentos de independência e controle.

Existe, ainda, o conceito de Moratória Social de Erik Erikson, que é caracterizada por um compasso de espera para os compromissos adultos. Trata-se um período de pausa necessária a muitos jovens, de busca de alternativas e de experimentações de papeis, que permitem um trabalho de elaboração interna. As moratórias caracterizam-se pelas necessidades pessoais, mas também por exigências socioculturais e organizacionais. Assim sendo, a moratória psicossocial é essencial para permitir que ocorra no jovem o seu amadurecimento interior, pois muitos adolescentes entram na vida adulta demasiadamente cedo, o que reflete, de forma negativa, no seu processo de evolução futuro. 
Portanto, as contribuições teóricas de Erikson são importantes na medida em que desviam o foco fundamental da sexualidade para as relações sociais. Ele se propõe a ampliar, nesse sentido, a proposta de Freud, pois os estágios psicossociais envolvem outras partes do ciclo vital além da infância. Entretanto, não existe uma negação da importância dos estágios infantis. Para Erikson, a cada etapa, os indivíduos crescem a partir das exigências internas de seu ego, mas também das exigências do meio em que vivem, sendo, portanto, essencial a análise da cultura e da sociedade em que vivem os sujeitos em questão. Não obstante, os contextos sociais podem estimular ou inibir a construção da personalidade ao passo que as inferências educativas (meio psicossocial) vão interferir no processo de desenvolvimento. Essa visão social de Erikson foi fundamental para a compreensão da adolescência e o surgimento das teorias que se seguiram, corroborando para uma compreensão mais estruturalista que a visão reducionista de Freud, que tenta explicar as mudanças da adolescência com um foco predominante na sexualidade

O Terceiro Grupo de Teorias do Desenvolvimento é reconhecido por priorizar aspectos socioculturais da adolescência e preconiza que o comportamento do adolescente é moldado, até certo ponto, pelo ambiente social imediato (pai e pares) e pelo ambiente social amplo (cultura). Nesta fase, destaca-se o trabalho de Margaret Mead (9): "Adolescência, Sexo e Cultura em Samoa". Na obra, ela questiona se os distúrbios que angustiam os adolescentes se devem à natureza própria da adolescência ou à civilização; e conclui que sob diferentes condições, a adolescência apresenta diferentes circunstâncias; e relaciona a rebeldia da puberdade contra a autoridade dos pais ao idealismo do jovem que depende do estilo de vida e da cultura na qual está inserido.

Ainda nesta primeira fase, um quarto grupo de teorias da adolescência, que possui como precursor Jean William Fritz Piaget (10), autor da Teoria Cognitiva, merece destaque ao privilegiar os processos cognitivos do desenvolvimento e afirmar que os comportamentos adolescentes que geram preocupações aos adultos possuem sua origem nas mudanças nas formas de pensar, características do início desta fase. Assim sendo, por meio do desenvolvimento do pensamento formal e por meio da assimilação e da acomodação de novas estruturas, o adolescente revela 
uma maneira própria de compreender a sua realidade e constrói sistemas filosóficos, políticos e éticos como tentativa de se adaptar e mudar o mundo. Portanto, ao perceber que as soluções baseadas apenas no raciocínio lógico não são possíveis, o adolescente inicia a idade adulta por meio de sua inserção na sociedade.

Esses quatro tipos de teorias acima mencionadas tentam descrever as várias mudanças concernentes ao período da adolescência, mas não são suficientes para explicar o desenvolvimento nesta etapa do curso de vida. Isso porque tais teorias são limitadas a apresentar dicotomias entre os aspectos exclusivamente contextuais, tais como herdado versus adquirido; continuidade versus descontinuidade e estabilidade versus mudanças. Isso gerou a necessidade de novos aportes integradores, que levou a uma nova fase dos estudos científicos sobre a adolescência.

\subsubsection{Segunda Fase: A Visão Contextualista do Desenvolvimento do Adolescente:}

A Segunda Fase dos estudos científicos sobre a adolescência inicia-se durante a década de 70 e estes apresentaram uma visão contextualista do desenvolvimento, que enfatizaram o indivíduo e o ambiente de sua dinâmica de relações bidirecionais, bem como o papel do tempo e do espaço no desenvolvimento humano. Nesse sentido, as interações entre as pessoas e os contextos em que elas estão inseridas passam a ser vistas como um fenômeno do desenvolvimento psicológico; e, sob esse aspecto, é importante considerar o indivíduo em constante desenvolvimento, devido ao fluxo de contínuas mudanças nas relações que ele estabelece com o ambiente. Também se torna relevante o desenvolvimento humano caracterizado pelo grande potencial para mudanças sistemáticas em qualquer etapa do curso da vida, sobretudo com relação a situações de plasticidade (flexibilidade) e 
resiliência (superação), além do significado do desenvolvimento humano inserido no contexto social e histórico em que ele acontece (5).

A partir da década de 90, um grupo de estudiosos do desenvolvimento se reuniu com o apoio do Carolina Consortium on Human Development (CCHD) (11), com o objetivo de organizar uma síntese das diferentes teorias sociais, psicológicas e biocomportamentais e que fossem úteis para orientar as pesquisas em diversos níveis da organização humana. Deste modo, foi proposto um modelo abrangente, denominado Ciência do Desenvolvimento, que se refere a um fenômeno multifatorial, composto pelo conjunto de processos de mudanças progressivas, estruturais e organizacionais. Essa Ciência considera que todos esses processos ocorrem por meio de interações entre pessoas e sistemas biológicos, dentro de grupos sociais e ambientes no decorrer do tempo. Para a compreensão do funcionamento deste sistema, é fundamental que sejam investigados os contextos, as propriedades estruturais e funcionais dos indivíduos e do ambiente, suas interações e consequentes mudanças nos processos pessoais de desenvolvimento (12).

Em outras palavras, o desenvolvimento ocorre por meio de forças internas e externas, denominadas de co-ação, que atuam de modo complementar e bidirecional no sentido de adaptar e manter o equilíbrio e a harmonia do sistema diante de situações novas ou adversas. Dessa maneira, o desenvolvimento passou a ser visto como um elemento energético e probabilístico, na medida em que os fatores biológicos e contextuais foram considerados reciprocamente interativos, gerando um grande desafio para a área. A maneira como esses sistemas se integram ao longo do tempo para produzirem saúde ou doença exigiram o entrelaçamento e a integração de disciplinas de diversas áreas, a fim de desvelar os complexos processos que levam os seres humanos a se desenvolverem dentro de uma dinâmica de forças existentes em um mundo em constante transformação (5).

Dentre as orientações teóricas que representam essa perspectiva do desenvolvimento, destacam-se duas grandes teorias: A Teoria do Curso da Vida de ELDER (13) e a Abordagem Bioecológica de BRONFENBRENNER (14). 


\subsubsection{A Teoria do Curso da Vida:}

De acordo com ELDER (13), a Teoria do Curso da Vida é uma orientação teórica que propõe a identificação dos estágios de vida (infância, adolescência, fase adulta e velhice), baseada nos seus aspectos temporais, contextuais e processuais, como uma das formas de compreender as mudanças que ocorrem no desenvolvimento humano. De acordo com essa premissa, os indivíduos adquirem significados próprios do seu contexto histórico e das experiências de outros e, como agentes ativos de mudança, influenciam o seu próprio desenvolvimento por meio de escolhas baseadas nessas experiências (disposições, conhecimentos e crenças) que afetam suas perspectivas, expectativas e adaptações subsequentes.

Neste sentido, a Teoria do Curso da Vida postula a articulação de conceitos do desenvolvimento que ultrapassam os modelos mais tradicionais, que, em sua maioria, apresentam características lineares, unidimensionais, unidirecionais e unifuncionais de crescimento e maturação biológica do indivíduo. Esta visão contemporânea do desenvolvimento contribuiu não somente para a compreensão atual do processo de adolescência, como também para adoção de metodologias mais apropriadas para responder às questões desta fase do curso da vida.

Em consonância com a Teoria do Curso da Vida, Urie Brofenbrenner (15, 16, $17,18,19)$ apresentou um modelo para orientar as pesquisas em desenvolvimento humano denominado Modelo Bioecológico. No livro "A Ecologia do Desenvolvimento Humano", lançado em 1979 e revisado em 1999, o autor sugere que para compreender o desenvolvimento humano, é preciso incorporar, nas diversas análises sobre os indivíduos, não somente as suas características perceptuais, motoras ou cognitivas, mas também as interações e os padrões relacionais que se estabelecem em diferentes contextos, ao longo dos anos. Isto significa que é 
importante analisar as influências múltiplas dos diferentes ambientes, diretos ou indiretos às pessoas.

Com base no Modelo Bioecológico, o desenvolvimento humano pode ser compreendido pela identificação de quatro elementos básicos, que são dinâmicos e inter-relacionados: o processo, a pessoa, o contexto e o tempo. Brofenbrenner $(15,16,17,18,19)$ refere que, ao longo do desenvolvimento, a pessoa se envolve em processos de interações recíprocas, que podem produzir tanto competências como disfunções no desenvolvimento. Neste modelo, o adolescente é visto como um sujeito ativo, produto e produtor do seu desenvolvimento, que ocorre na interação com o contexto que, por sua vez, é definido por uma hierarquia de sistemas interdependentes- micro, meso, exo e macrossistemas - e é composto pelas atividades, papéis e relações interpessoais presentes, por exemplo, nas suas famílias, nos grupos de amigos, na vizinhança, na comunidade, e nas instituições educacionais, de saúde, religiosas, sociais e políticas.

Ainda com base em Brofenbrenner (15,16,17,18,19), verifica-se que durante a adolescência, a família continua a ser considerada como o principal microssistema do desenvolvimento, pois nela ocorrem as interações mais diretas e as experiências mais significativas para o adolescente. Nesse sentido, a família torna-se responsável por conduzir esse grupo de indivíduos à compreensão de conceitos e valores básicos, ao engajamento na realização de tarefas e papéis sociais cada vez mais diversificados e complexos e ao desenvolvimento de competências sociais.

Contudo, à medida que o adolescente passa a participar de outros microssistemas e a formar e ampliar sua rede de relações interpessoais, torna-se evidente a formação de novas relações e influências interdependentes entre a família, o adolescente e os demais contextos de interações proximais (mesosistema). Ademais, mesmo quando o adolescente não possui um papel mais ativo em seus relacionamentos, ele recebe, mesmo que indiretamente, influências provenientes destes ambientes do exosistema, como, por exemplo, o trabalho dos pais, escolas e ou agentes responsáveis pelo lazer e pela cultura, tais como parques, "shoppings", bibliotecas e afins. Como consequência, as influências bidirecionais entre o adolescente e os contextos - sistemas ideológicos de crenças e 
valores, sistemas governamentais e políticas públicas, aspectos étnicos e religiosos, família de origem e disponibilidade de recursos e oportunidades - devem ser considerados ao longo do tempo como fatores intervenientes $(15,16,17,18,19)$.

Portanto, apesar das dificuldades na operacionalização integral deste modelo, sua adoção parcial em estudos sobre a adolescência tem sido especialmente útil, pois auxilia na investigação da forma como os adolescentes estão situados em seus contextos específicos, e como esses contextos influenciam o curso de seu desenvolvimento; ao mesmo tempo em que os adolescentes influenciam esses contextos de forma direta ou indireta.

A chegada do século XXI foi marcada por um contexto de rápidas mudanças que estimularam o interesse conjunto de pesquisadores, políticos e profissionais para a condução de pesquisas voltadas para as questões sociais e para a aplicação e utilização dos resultados em direção ao progresso da sociedade. Nesse sentido, do ponto de vista da adolescência, tem-se buscado ultrapassar a visão negativa e deficitária que predominou no século $X X$, nos campos da ciência do desenvolvimento, da psicologia, da sociologia, da educação, entre outros. Essa nova perspectiva foi oriunda dos modelos dinâmicos do comportamento e desenvolvimento humanos, da compreensão da plasticidade e da importância das relações entre indivíduos e contextos ecológicos do mundo real. Também é possível incluir, nessa nova abordagem, as intervenções feitas nas comunidades, por meio de programas dirigidos aos adolescentes com comportamentos de risco, dentre os quais estão inclusos: a pobreza, o crime, a violência, as drogas, os abusos, o fracasso escolar e o sexo inseguro (20).

Ainda de acordo com Brofenbrenner $(15,16,17,18,19)$, a colaboração mútua entre produtores e consumidores do conhecimento científico e entre a teoria e a prática torna-se essencial para a legitimação da visão otimista do potencial para intervenções no curso de vida e para o fortalecimento da idéia do desenvolvimento positivo. Com base na opinião de cientistas, terapeutas e educadores, a visão positiva preconiza que tanto os adolescentes são fontes de recursos e forças internas a serem desenvolvidas, como as famílias, as escolas e as comunidades 
possuem potencialidades que promovem o amadurecimento saudável desses jovens.

Assim sendo, não se pode negligenciar os recursos provenientes de diferentes ambientes, já que eles exercem influência crescente e decisiva no período da adolescência. Contudo, não são apenas as condições estabelecidas pelos contextos, mas o tempo que o adolescente passa com adultos cuidadores e com pares em atividades que reforçam valores, que asseguram seu sucesso escolar, e garantem o desenvolvimento de comportamentos relativos à consciência social, liderança, solidariedade e valorização da diversidade (5). Por fim, a promoção do desenvolvimento positivo do adolescente vai depender de seus recursos pessoais somados à elaboração de programas específicos de estimulação de seus talentos. Esse resultado irá depender de três fatores distintos: uma relação positiva e sustentável com adultos; a promoção de atividades dirigidas ao desenvolvimento de suas habilidades e a participação do jovem em todas as decisões e vertentes dos programas a eles dirigidos.

Entretanto, nos tempos atuais, o adolescente pode se deparar com mais chances e mais desafios do que nas gerações precedentes. Em muitos casos, diante dos desafios contemporâneos, a adesão a escolhas negativas e destrutivas acaba por comprometer um provável desenvolvimento saudável. Mas a promoção do desenvolvimento positivo não significa, apenas, a prevenção de comportamentos de risco, nem significa que manter o adolescente livre de problemas é certificar-se que ele esteja preparado ou engajado com seu próprio desenvolvimento. Faz-se necessário, portanto, que o adolescente seja acompanhado e estimulado, além de reconhecido nas suas particularidades, estabilidades e mudanças sistemáticas, que ocorrem em paralelo às transições de seus contextos. Sob esta análise, surge uma nova proposta de estudo, denominada ciência aplicada ao desenvolvimento, que visa compartilhar conhecimentos científicos com a comunidade e propõe aprimoramentos nas chances de vida dos adolescentes. Por meio da descrição e explicação dos processos normativos e da ênfase nos aspectos saudáveis, esta ciência norteia intervenções no sentido de prevenir riscos e otimizar sucessos. As ações propostas reforçam as diferenças interindividuais, como raça, etnia, classe 
social e gênero; e intraindividuais, como aquelas esperadas pelas transições da puberdade; além da centralidade do contexto e das relações bidirecionais entre os diferentes níveis ecológicos de desenvolvimento.

Não obstante os avanços na compreensão dos processos oriundos da adolescência, ainda é possível identificar uma tendência a caracterizar este período como apenas um momento do curso da vida, repleto de dificuldades, conflitos, alterações constantes de humor e comportamentos de risco (21). Considerar o adolescente com base em fatores particulares, ou mesmo isolar aspectos genéticos e ambientais, pode impedir um diálogo amplo entre as diferentes áreas da pesquisa, e, por conseguinte, dos pesquisadores com os profissionais e os políticos (22). Além disso, abordar a adolescência como um período de mudança e transitoriedade no desenvolvimento, ou mesmo, um estado de si, não condiz com os avanços nas perspectivas teóricas da ciência e do desenvolvimento humano. Essas concepções distorcem a ideia de processo contínuo do desenvolvimento humano, conforme preconizam os estudos atuais (5).

Dessa forma, buscar os antecedentes geradores das mudanças na adolescência significa tratá-la como um período de intensa exploração e de grandes e múltiplas oportunidades para esses futuros adultos. Além disso, a adolescência não é algo acabado, que tenha um início e um fim bem definido. A delimitação desse período ultrapassa aspectos cronológicos e biológicos, pois esbarra em condições sociais, culturais, históricas e psicológicas específicas.

Outras facetas pouco exploradas na adolescência são determinados agravos à saúde que deixam de ser investigados por serem considerados "condições próprias da idade" como certos sintomas psicológicos ou a própria depressão, em seus vários níveis, nessa fase da vida. Nesse sentido, as pesquisas sobre depressão na adolescência tornam-se relevantes, na medida em que podem propor alternativas de prevenção, detecção precoce, avaliação e intervenções efetivas para o manejo de tal quadro clínico em uma faixa etária que é, de acordo com diversos estudos, vulnerável a ele (23). 


\subsection{DEPRESSÃO:}

De um modo geral, a depressão é caracterizada como um transtorno de humor, que abrange fatores cognitivos, comportamentais, fisiológicos, sociais, econômicos, religiosos e outros mais, estando presente em diversos distúrbios emocionais. Pode aparecer como um sintoma secundário de determinada doença, ou mesmo coexistir junto com outros estados emocionais como causa de certos eventos traumatizantes, ou ainda como agravo isolado (23). Nos dias atuais, a depressão atinge mais de 350 milhões de pessoas em todo o mundo, sendo a principal causa de incapacidade, contribuindo com a carga global de doenças (24). Além disso, é considerada como um problema de saúde pública, uma vez que é a quarta doença mais dispendiosa para o sistema de saúde (25).

A ocorrência de depressão é associada a alguns fatores, tais como: idade, estado civil, classe social e condições sociais. Trata-se de uma condição que afeta todos os indivíduos em alguma fase de suas vidas, seja como humor transitório, ao se sentir abatido ou melancólico; ou como forma mais séria, que pode prejudicar o desempenho físico e psicológico (26). Além disso, esse transtorno é frequentemente associado à incapacitação funcional e ao comprometimento da saúde física (27).

Apesar de não serem registradas em muitos países, as informações diretas sobre prevalência de depressão indicam uma grande variação entre elas. Um estudo transnacional coordenado por KESSLER (28) e conduzido pela OMS, intitulado "Pesquisa Mundial sobre Saúde Mental" verificou as prevalências de depressão mundiais. Os países foram divididos em dois grupos: alta renda (Bélgica, França, Alemanha, Israel, Itália, Japão, Holanda, Nova Zelândia, Espanha e Estados Unidos); e média e baixa renda (Brasil, Colômbia, Índia, China, Líbano, México, África do Sul e Ucrânia). De acordo com o relatório, nos países de alta renda, a 
prevalência média de depressão foi de $14,6 \%$ e nos países de média e baixa renda a prevalência foi de $11,1 \%$; sendo que os maiores índices foram encontrados no Brasil (10,4\%) e, o menor, no Japão (2,2\%). A prevalência em adolescentes foi de $20 \%$. No entanto, não foram classificadas as três formas de depressão nos países avaliados.

O estudo chamado "Global Burden of Diseases"-GBD (29) é uma avaliação abrangente das taxas de mortalidade mundiais. Trata-se do maior esforço já realizado para descrever a distribuição, em âmbito global, de uma grande variedade de doenças, lesões e fatores de risco. Este estudo quantificou os efeitos da saúde de mais de 100 doenças para o mundo como um todo, e ainda estratificando para oito regiões, utilizando, como medida, o "Disability Adjusted Life Year (DALY) (30)". De acordo com este estudo, em 2020, a depressão será a segunda maior causa de mortalidade, superada, apenas, pelas doenças cardiovasculares.

Outro projeto intitulado "Longitudinal Investigation of Depression Outcomes" (LIDO, 2003) (31), foi um estudo de coorte multicêntrico conduzido em seis países para avaliar a relação entre sintomas depressivos, qualidade de vida e utilização de recursos em pacientes que procuram serviços de cuidados primários de saúde. Os países participantes foram: Israel, Brasil, Austrália, Espanha, Rússia e Estados Unidos. Tal pesquisa detectou que os pacientes com uma quantidade maior de sintomas depressivos apresentaram maior comprometimento do funcionamento físico e psicológico, e avaliaram sua qualidade de vida como pior. Além disso, os indivíduos com maior intensidade de sintomas depressivos avaliaram sua saúde como um todo como ruim, e estavam menos satisfeitos com ela do que aqueles com menor intensidade dos sintomas depressivos. Outra informação relevante deste estudo foi a observação de que os pacientes brasileiros com mais sintomas depressivos consultavam os serviços de saúde com maior frequência, permaneciam mais tempo internados e faltavam mais dias ao trabalho dos que os menos deprimidos. Por fim, o projeto LIDO (31) também demonstrou que as mulheres possuem uma sintomatologia depressiva mais intensa do que os homens que procuram os serviços de cuidados primários em saúde.

A alta prevalência de depressão, tanto no Brasil como no mundo, acarreta prejuízos econômicos (32). Este impacto pode ser quantificado por meio de estudos 
como o Disability Adjusted Life Years (DALY) (30)", que é um indicador que procura medir, de forma simultânea, o impacto da mortalidade e dos problemas de saúde que afetam a qualidade de vida dos indivíduos. O DALY (30) mede os anos de vida perdidos, seja por morte prematura (YLL - Years of Life Lost - Anos de vida perdidos por morte prematura) ou incapacidade (YLD - Years Lived with Disability Anos de vida vividos com incapacidade) em relação a uma esperança de vida ideal.

Os dados brasileiros sobre a prevalência de depressão foram coletados pelo estudo "Brazil Megacity Mental Health Survey (33)". Trata-se de um estudo epidemiológico de base populacional que avaliou uma amostra representativa de indivíduos residentes na região metropolitana de São Paulo, com 5.307 avaliados em seus domicílios, sendo o componente brasileiro da "Pesquisa Mundial Sobre Saúde Mental" (28). Nesta pesquisa, a desordem psiquiátrica mais prevalente foi a depressão maior (16,9\%), apresentando maiores índices no sexo feminino $(23,0 \%)$ do que no masculino $(11,0 \%)$. No grupo adolescente, a prevalência desta doença foi de $16,2 \%$.

De acordo com PATEL et al (34), no Brasil, a depressão é duas vezes mais comum entre as mulheres do que entre os homens, e pode começar em qualquer idade, apesar de a média de início ocorrer aos 25 anos. Entre os adolescentes, também foi encontrado um aumento na taxa de depressão na maioria das coortes de nascimento recentes. Entretanto, boa parte da evidência que dá suporte a essa conclusão está baseada em dados recordatórios, por exemplo, um aumento na proporção de adultos em coortes recentes que teve seu primeiro episódio depressivo aos 18 anos (32).

No que diz respeito à associação entre depressão e classe social, os estudos conduzidos no Brasil referem um maior risco de problemas de saúde em classes sociais menos favorecidas tais como as classes socioeconômicas $D$ e $E$, segundo a classificação da Associação Brasileira de Estudos Populacionais (ABEP) (35). Essa população apresenta uma prevalência 2 vezes maior de desenvolver o transtorno quando comparados com as demais classes sociais (36). O autor ressalta também que, em relação à percepção da qualidade vida e intensidade de sintomatologia depressiva existe uma relação inversa entre os dois estados. Nesse sentido, a percepção de um baixo nível de qualidade de vida é expressa por pessoas com altos 
níveis de sintomas depressivos e a melhora ou redução sintomática ofereceria uma melhora direta na qualidade de vida desta população.

De maneira similar, LOPES et al (37) e CASTRO (38) citaram uma forte associação entre o abuso de derivados do tabaco e do álcool com a depressão. Esses achados sugerem que o aglomerado de problemas associados ao uso abusivo de álcool, tais como efeitos adversos à saúde, problemas em relações familiares e profissionais, dentre outros, pode contribuir para a ocorrência de depressão na população adolescente. No entanto os estudos não conseguem esclarecer esclarecer se os jovens se envolvem com drogas porque são deprimidos ou se a depressão é agravada pelo uso da droga.

Portanto, embora a depressão seja objeto de estudo entre vários pesquisadores, é um agravo pouco diagnosticado na população adolescente, e esse aspecto pode ser corroborado pela ambiguidade da temática no âmbito escolar: a sintomatologia da depressão tanto pode ser vista como uma característica típica dessa fase da vida, como também pode ser classificada como doença.

\subsubsection{Depressão em Adolescentes}

De acordo com DAMIÃO et al (23), os adolescentes se deparam, de uma maneira geral, com várias situações novas, o que favorece o surgimento de condições específicas para flutuações de humor e mudanças expressivas de comportamento, e, conforme já mencionado anteriormente, a adolescência é a faixa etária da reorganização emocional, e, portanto, vulnerável aos agravos depressivos.

Esses autores referem ainda que, situações típicas da adolescência, como dificuldades de adaptação social, baixa autoestima e falta de aceitação pessoal, aliada ao sentimento de falta de compreensão dos pais podem se tornar fontes de ansiedade e confusão. Esses conflitos tendem a agravar-se mais se o adolescente estiver inserido numa família que também está em crise. Dessa forma, adolescentes 
deprimidos podem não se apresentar sempre tristes, mas com comportamentos instáveis e irritáveis, que podem propiciar comportamentos destrutivos.

Outras características típicas dos adolescentes com sintomatologia depressiva são as ideias e tentativas de suicídio. Esses aspectos merecem atenção especial, uma vez que costumam apresentar alta letalidade e graves problemas de comportamento.

A depressão em adolescentes começou a ser estudada a partir da década de 60 , porém não se pode afirmar que não existisse antes disso (39). Nos dias atuais, a depressão nesta faixa etária é considerada um grave problema de saúde mundial, já que os estudos epidemiológicos estimam que há uma prevalência de $20 \%$ de transtornos depressivos neste período (28) (33). Além disso, a depressão em adolescentes pode acarretar em um significativo impacto negativo no desempenho escolar, além de prejudicar a autoestima e causar sintomas de instabilidade emocional, irritabilidade, crises de raiva e riscos de suicídio (25).

Em revisão da literatura nacional e internacional, BRAGA E DELL'AGLIO (40) identificaram alguns fatores de risco para o suicídio. Segundo essas autoras, as ações concretas dos adolescentes em relação ao suicídio diferiram por tipo de família e por gênero, sendo que os adolescentes cujos pais eram divorciados apresentaram maiores ideações e tentativas de suicídio; assim como aqueles que já possuíam uma experiência de morte na família. Foi verificado, ainda, que as meninas apresentaram uma maior prevalência de ideações suicidas do que os meninos, embora a consumação do ato seja mais frequente entre meninos, fato esse observado, também, por outros autores e, também, em adultos $(41,42,43)$.

No continente americano, pesquisas indicam que os habitantes de zonas urbanas e os jovens de 15 a 24 anos são os grupos populacionais de maior risco de suicídio (TORO et al, 2009) ${ }^{41}$. No Brasil, estudo conduzido por SOUZA et al (44), avaliou os índices de suicídio entre jovens em nove regiões metropolitanas. Foi evidenciado que a depressão está relacionada ao maior risco de ideação e atos suicidas e que esse tipo de morte ocupa a $6^{\underline{a}}$ posição dentre as principais causas de mortalidade na população adolescente. A incidência variou em função dos diferentes 
espaços sociais, das faixas etárias específicas, do sexo e dos meios utilizados para a execução do ato suicida. Para o conjunto das capitais, observou-se certa elevação das taxas de suicídio nos anos analisados, sendo que Salvador e Rio de Janeiro apresentaram as menores taxas $(0,4 \%$ e $1,0 \%$, respectivamente; em contrapartida, Porto Alegre e Curitiba apresentaram as maiores, de $10,4 \%$ e $8,6 \%$, respectivamente). Uma pesquisa realizada em Terezina- PI, também evidenciou maior prevalência de suicídio entre jovens estudantes (42).

Já um estudo conduzido por WERLANG et al (43), investigou os fatores de risco associados à ideação suicida em adolescentes de Porto Alegre, com idades entre 15 e 19 anos, bem como fatores protetores. Os resultados revelaram que a maioria dos adolescentes com ideação suicida eram mulheres. Esse dado corrobora a literatura sobre suicídio, que indica que as mulheres estão, de um modo geral, mais propensas à ideação suicida e os homens ao suicídio consumado (40).

Outro estudo realizado em duas capitais do Nordeste conduzidos por DAMIÃO et al (23), referiram maior prevalência de depressão em sujeitos do sexo feminino, caracterizada por sentimentos de tristeza, pensamento de suicídio e morte, choro e insônia. Esse estudo corrobora outros dados da literatura acerca da depressão, a qual registra um número duplamente maior de vulnerabilidade à depressão em sujeitos do sexo feminino, tais como o de LOPEZ et al (36), que realizou um estudo em uma cidade da Região Sul do Brasil.

Já no Distrito Federal, um estudo realizado em uma amostra de conveniência, entre adolescentes de $7^{\text {a }}$ e $8^{\text {a }}$ séries de uma escola de ensino fundamental de Ceilândia, mostrou que $20,6 \%$ dos jovens referiram tristeza intensa, 22,9\% irritabilidade fácil e 15,8\% dificuldade de concentração (45). Embora o estudo não fosse destinado à prevalência de depressão, os resultados sugeriram que tais sintomas poderiam estar relacionados a este agravo.

\subsubsection{Sintomatologia da Depressão}


Segundo o DSM-IV-TR ${ }^{1}$ (American Psychiatric Association - APA, 2000) (46), os principais sintomas da depressão em adolescentes são: humor deprimido na maior parte do dia, interesses e prazer acentuadamente diminuídos, perda ou ganho significativo de peso sem estar de dieta, insônia ou hipersônia, agitação ou lentidão psicomotora, fadiga, sentimento de inutilidade e pensamento recorrente de morte. Esses sintomas e manifestações, em conjunto, comprometem o desempenho do indivíduo; entretanto, para ser considerado sintoma depressivo, devem ser afastadas outras condições, tais como luto e uso de drogas.

De acordo com o Código Internacional de Doenças (CID 10) (47), nos episódios típicos de cada um dos três graus de depressão, seja ele leve, moderado ou grave, o paciente apresenta um rebaixamento do humor, redução da energia e diminuição da atividade. Existe alteração da capacidade de experimentar o prazer, perda de interesse, diminuição da capacidade de concentração, associadas em geral à fadiga importante, mesmo após um esforço mínimo. Observam-se, em geral, problemas do sono e diminuição do apetite. Há, quase sempre, uma diminuição da autoestima e da autoconfiança e, frequentemente, idéias de culpabilidade ou de indignidade, mesmo nas formas leves. O humor depressivo varia pouco de dia para dia ou segundo as circunstâncias, e pode se acompanhar de outros sintomas como, por exemplo, perda de interesse ou prazer, despertar matinal precoce, várias horas antes da hora habitual, agravamento matinal da depressão, lentidão psicomotora importante, agitação, perda de apetite, perda de peso e perda da libido.

No episódio depressivo leve, geralmente estão presentes, ao menos, dois ou três dos sintomas citados anteriormente. $O$ paciente usualmente sofre com a presença destes sintomas, mas, em geral é capaz de desempenhar a maior parte das atividades. Já no episódio depressivo moderado, estão presentes quatro ou

\footnotetext{
${ }^{1}$ Os atuais critérios utilizados para o diagnóstico e classificação dos estados depressivos se encontram no Manual Diagnóstico e Estatístico dos Transtornos Mentais, em sua quinta edição (DSM-V), lançado em Maio de 2013. Porém, como a pesquisa foi conduzida no ano de 2008, o questionário foi adaptado aos sintomas descritos na quarta edição (DSM-IV).
} 
mais dos sintomas citados anteriormente e o paciente, aparentemente, tem muita dificuldade para continuar a desempenhar as atividades de rotina. Nos casos de episódios depressivos graves, vários dos sintomas são marcantes e angustiantes, tipicamente a perda da autoestima e as ideias de desvalia ou de culpa. As idéias e os atos suicidas são comuns e observa-se, em geral, uma série dos outros sintomas citados.

Determinar a intensidade dos sintomas depressivos é importante para verificar o estágio da doença e avaliar o seu desfecho, e quanto mais acurada e rápida for esta medida, mais benefícios podem ser alcançados (32). A intensidade dos sintomas depressivos é uma variável que não é completamente mensurável, logo pode ser considerada como um traço latente, que pode ser inferida com base em observações do comportamento dos indivíduos que, neste caso, são observações sobre a presença e intensidade dos diversos sintomas. De modo exemplificativo, tem-se que a dor não pode ser observada diretamente, no entanto, pode ser inferida por meio da observação de comportamentos, tais como caretas, precauções e respostas a itens sobre dor. Para o diagnóstico clinico do agravo depressivo pode-se lançar mão das descrições feitas pelo CID 10 (46) ou DSM IV (47); no entanto, para facilitar o rastreamento e classificação de episódios depressivos, os pesquisadores utilizam as escalas de depressão.

\subsubsection{As Escalas de Classificação da Depressão}

A literatura científica enfatiza a importância e a necessidade das medidas padronizadas para medir a depressão. Na literatura internacional, instrumentos de avaliação de depressão em adultos, adolescentes e crianças são utilizados na pesquisa e na clínica. As escalas de depressão visam auxiliar no diagnóstico da doença e em pesquisas científicas, mas tem sua importância principalmente no 
rastreamento do agravo e na verificação da severidade dos sintomas, que são úteis para o planejamento de intervenções de caráter individual e coletivo (48). Muitos desses instrumentos tem sido adaptados e validados para estudos conduzidos no Brasil.

Dentre as principais escalas utilizadas para a avaliação de depressão nas populações, destacam-se as seguintes:

-Escala de Depressão do Centro de Estudos Epidemiológicos (CES-D Center for Epidemiologic Studies Depression Scale) (49): a CES-D é uma escala autoaplicável composta de 20 itens desenvolvidos para mensurar os sintomas depressivos em uma comunidade. Os entrevistados avaliam os itens com base nos acontecimentos da semana que precede a aplicação do instrumento, utilizando uma escala de respostas de quatro pontos. Esse instrumento foi validado e traduzido para o português brasileiro.

- Escala de Avaliação de Hamilton (HAM-D) (50), foi desenvolvida há mais de 40 anos, e é uma das mais utilizadas no âmbito mundial, tornando-se referência na avaliação da gravidade da depressão, de modo que as escalas desenvolvidas posteriormente são comparadas a ela quanto à confiabilidade e à validade. A Escala de Hamilton enfatiza os sintomas relacionados aos determinantes sociais da saúde, o que a torna particularmente sensível às mudanças vivenciadas por pacientes gravemente deprimidos, além de contribuir para a difusão de seu uso em ensaios clínicos com antidepressivos. Apesar de sua grande popularidade, fácil aplicação, baixo custo e elevados índices de validade e confiabilidade, a Escala de Avaliação de Depressão de Hamilton requer um profissional experiente e capacitado para sua aplicação, o que torna o seu uso restrito e os resultados sujeitos a variações de acordo com diferentes entrevistadores. Ainda assim, a escala de avaliação de Hamilton continua sendo um instrumento valioso e útil na avaliação dos sintomas depressivos para uma população em pesquisa, se aplicada corretamente, seguindo as orientações de seu próprio autor. Preconiza-se a utilização da HAM-D em pacientes previamente diagnosticados como portadores de transtorno depressivo 
maior, após a avaliação clínica baseada nos critérios previstos na $4^{\text {a }}$ edição do DSMIV (46) e do CID 10 (47).

- Escala de depressão de Carroll (CRS - Carroll Rating Scale) (51): instrumento autoaplicável para depressão que apresenta conteúdo informativo e itens específicos bem semelhantes aos da escala de Hamilton.

-Questionário de autoavaliação psíquica (SRQ-20 - Self-Report Questionnaire) (52): o SRQ-20 foi desenvolvido pela Organização Mundial da Saúde (OMS) para a avaliação de transtornos mentais comuns em países em desenvolvimento. O questionário é composto de 20 itens com respostas dicotômicas (sim/não) que avaliam diversos aspectos da saúde mental.

Os questionários são amplamente utilizados para mensurar a intensidade de sintomas depressivos. Tais instrumentos são compostos de itens que contemplam os mais diversos sintomas depressivos observáveis. Dentre os mais conhecidos e frequentemente utilizados, estão o Inventário de Depressão de Beck (Beck Depression inventory - BDI) (53). Este inventário, revisado por Beck e Steel em 1993 é uma das medidas de auto-resposta mais amplamente utilizadas para diagnosticar e avaliar a intensidade de sintomas depressivos e, ainda, para o rastreamento de depressão em populações.

O BDI foi, originalmente, criado por Beck, Ward, Mendensol, Mok e Erbaugh, no ano de 1961. Ele faz parte das chamadas Escalas de Beck, que, ao todo, possuem quatro medidas escalares, quais sejam: o Inventário de Depressão de Beck (BDI), o Inventário de Ansiedade (BAI), a Escala de Desesperança (BHS) e a Escala de Ideação Suicida (BSI). Todas elas foram desenvolvidas por Aaron Temkin Beck e colaboradores no "Center for Cognitive Therapy", da Universidade de Pennsylvania, na Philadelphia, Estados Unidos.

O manual do BDI, no idioma original, é de Beck e Steer (54) e a versão autorizada em português foi publicada em 2001. De acordo com os autores, o BDI é uma escala de auto relato, composta por 21 itens, cada um com quatro alternativas, que subentendem graus crescentes de gravidade da depressão, com escores que 
variam de 0 a 3 . 0 escore total permite a classificação de níveis de intensidade de sintomas depressivos. Ele é obtido pela soma dos escores de cada item, que correspondem às alternativas assinaladas pelos avaliados nos 21 itens. Cada item apresenta quatro alternativas, que podem ter escores de $0,1,2$ ou 3 . Para a versão em Português, os pontos de corte para classificar os respondentes quanto à intensidade dos sintomas depressivos são: ausência ( 0 a 11), leve (12 a 19), moderada (20 a 35) e grave (36 a 63).

Os itens do $\mathrm{BDI}$ foram selecionados com base em observações e relatos de sintomas e atitudes mais frequentes em pacientes psiquiátricos, com transtornos depressivos. Eles se referem a: (1) tristeza; (2) pessimismo; (3) sentimento de fracasso; (4) insatisfação; (5) culpa; (6) punição; (7) auto aversão; (8) auto acusações; (9) ideações suicidas; (10) choro; (11) irritabilidade fácil (12) retraimento social; (13) indecisão; (14) mudanças na auto imagem; (15) dificuldade de trabalhar; (16) insônia; (17) fatigabilidade; (18) perda de apetite; (19) perda ou ganho de peso; (20) preocupações somáticas e (21) perda da libido.

\subsection{A POPULAÇÃO ADOLESCENTE NO CONTEXTO MUNDIAL}

Segundo a Organização das Nações Unidas (ONU) (55), existem 7,2 bilhões de pessoas no mundo. Dessas, 1,8 bilhões estão na faixa de idade compreendida entre os 10 e 24 anos, o que constitui a maior população de jovens (15 a 24 anos) e adolescentes (10 a 19 anos) da história. De acordo com a Organização Mundial da Saúde (OMS) (56), há aproximadamente 1,2 bilhões de adolescentes no mundo, dos quais $87 \%$ encontram-se nos países em desenvolvimento. Segundo o Instituto Brasileiro de Geografia e Estatística (IBGE) (57), a população brasileira já supera os 201 milhões de habitantes, e os adolescentes correspondem à 18\% dessa população; representada por 34.157 .633 de indivíduos. No que se refere ao Distrito Federal, verifica-se que a população é de 2,5 milhões de habitantes; e, de acordo 
com a Pesquisa Distrital de Amostras por Domicílios (PDAD) (58), os adolescentes correspondem a aproximadamente $12 \%$ de indivíduos, representados por cerca de 419.740 habitantes na faixa dos 10 a 19 anos de idade.

Os estudos referentes à adolescência no Brasil são escassos e predominantemente relativos à mortalidade por causas externas, gravidez precoce, violência, infecção por HIV e uso de drogas (45). No entanto, pouco se sabe sobre outros agravos nesse grupo populacional e sobre como os adolescentes percebem o seu estado de saúde. No Distrito Federal, há escassez de estudos referentes à prevalência de depressão na adolescência, o que justificou a realização do presente estudo, a fim de subsidiar os programas de saúde destinados a esse grupo etário. 


\section{OBJETIVOS}

\subsection{OBJETIVO GERAL}

O propósito dessa pesquisa foi investigar a prevalência de depressão leve, moderada e grave em uma amostra representativa de adolescentes estudantes do Distrito Federal e verificar a auto percepção do estado de saúde neste grupo etário.

\subsection{OBJETIVOS ESPECÍFICOS}

- Investigar a prevalência de depressão em adolescentes em uma amostra populacional do Distrito Federal;

- Verificar se existe diferença significativa deste agravo nas diferentes escolas do DF;

- Analisar a diferença desse agravo entre os sexos masculino e feminino. 


\section{MÉTODO}

\subsection{POPULAÇÃO E ÁREA DE ESTUDO}

Foi desenvolvida uma pesquisa quantitativa descritiva por meio de um estudo transversal junto aos adolescentes de escolas públicas e privada de ensino fundamental e médio do Distrito Federal, no período de Fevereiro de 2007 à Março de 2008. O critério utilizado para a classificação de adolescentes foi o da OMS (57), ou seja, a idade entre 10 a 19 anos.

Para a seleção da amostra, foram utilizadas as técnicas de amostragem por múltiplos estágios, iniciando-se com a seleção das Regiões Administrativas, em seguida pelas escolas e, finalmente, pelas classes de adolescentes matriculados, conforme ilustra a Figura 1: 


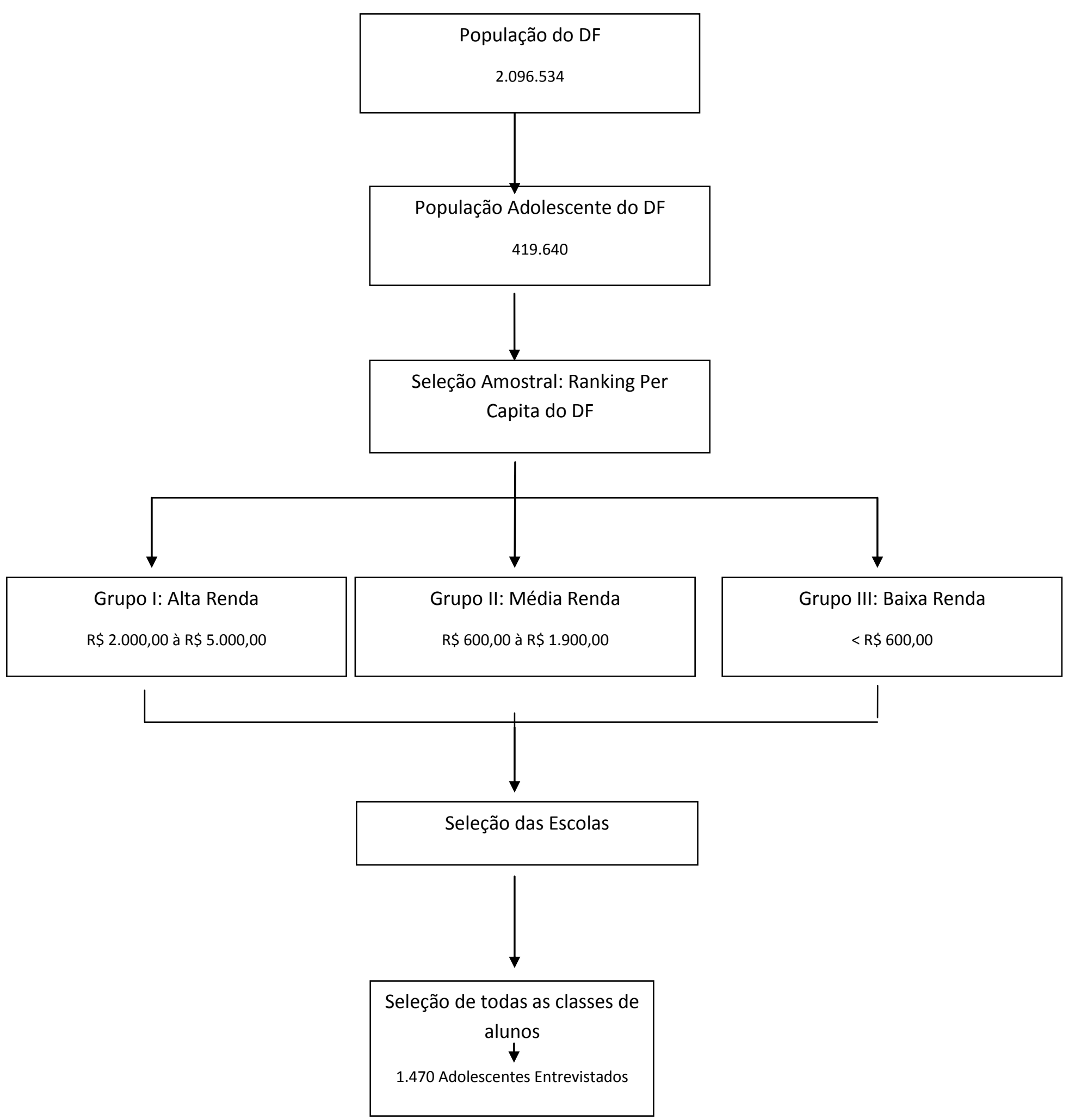

Figura 1: Fluxograma da Coleta de Dados 


\subsection{DELINEAMENTO DA AMOSTRA}

Para o delineamento da amostra, realizou-se, inicialmente, um levantamento junto à base de dados do IBGE (58) com vistas à identificação do quantitativo de adolescentes entre 10 a 19 anos de idade no Distrito Federal. Não foi possível conseguir os números exatos, uma vez que as classificações são realizadas por idades estratificadas entre 10 a 18 anos; e, a partir dos 19 , o quantitativo encontra-se no extrato seguinte, ou seja, de 19 a 23 anos. Portanto, foi considerada a amostragem pertencente no total de adolescentes entre 10 a 18 anos de cada regional selecionada, conforme mostra a Tabela 1.

TABELA 1- População adolescente do Distrito Federal por Regiões Administrativas - 2008*

\begin{tabular}{lcc}
\hline Região Administrativa & População adolescente & Percentual \\
\hline Ceilândia & 67.721 & $19,48 \%$ \\
Samambaia & 39.260 & $11,29 \%$ \\
Planaltina & 32.534 & $9,36 \%$ \\
Taguatinga & 26.930 & $7,75 \%$ \\
Recanto das Emas & 25.678 & $7,38 \%$ \\
Santa Maria & 23.734 & $6,82 \%$ \\
Brasília & 22.184 & $6,38 \%$ \\
Gama & 21.739 & $6,25 \%$ \\
São Sebastião & 16.627 & $4,78 \%$ \\
Sobradinho II & 15.677 & $4,51 \%$ \\
Águas Claras & 14.830 & $4,26 \%$ \\
Guará & 13.550 & $3,89 \%$ \\
Itapoã & 13.497 & $3,88 \%$ \\
Vicente Pires & 9.913 & $2,85 \%$ \\
Brazlândia & 9.732 & $2,80 \%$
\end{tabular}


Conclusão

TABELA 1- População adolescente do distrito federal por regiões administrativas - 2008*

\begin{tabular}{lcc}
\hline Região Administrativa & População Adolescente & Percentual \\
\hline SCIA/Estrutural & 8.708 & $2,50 \%$ \\
Sobradinho & 8.537 & $2,45 \%$ \\
Paranoá & 8.200 & $2,35 \%$ \\
Riacho Fundo II & 7.657 & $2,20 \%$ \\
Riacho Fundo & 5.483 & $1,57 \%$ \\
Sudoeste/Octogonal & 4.596 & $1,32 \%$ \\
Cruzeiro & 3.999 & $1,15 \%$ \\
Jardim Botânico & 3.156 & $0,90 \%$ \\
Núcleo Bandeirante & 3.038 & $0,87 \%$ \\
Lago Norte & 2.769 & $0,79 \%$ \\
Lago Sul & 2.749 & $0,79 \%$ \\
Park Way & 2.585 & $0,74 \%$ \\
Candangolândia & 2.477 & $0,71 \%$ \\
Varjão & 2.071 & $0,59 \%$ \\
Setor de Indústria e Abastecimento (SIA) & 470 & $0,13 \%$ \\
\hline Distrito Federal & $\mathbf{3 4 7 . 5 2 8}$ & $\mathbf{1 0 0 , 0 \%}$ \\
\hline${ }^{*}$ Fonte: Codeplan-DF (2008). & &
\end{tabular}

A maior parcela da população adolescente do Distrito Federal encontra-se na Região Administrativa de Ceilândia, representando $19 \%$ da população nesta faixa etária. Já as menores taxas foram evidenciadas no Varjão e no Setor de Indústria e Abastecimento (SIA), cujos percentuais foram de $0,6 \%$ e $0,1 \%$, respectivamente.

Em seguida, realizou-se um estudo do "ranking" de renda per capita de todas as Regiões Administrativas (RA's) do DF de acordo com os dados da Companhia de Planejamento do Distrito Federal (CODEPLAN - DF) (59), com vistas à obtenção de uma amostra que fosse representativa de adolescentes pertencentes a todos as faixas de renda do Distrito Federal. Para tanto, os adolescentes foram agrupados em 3 categorias, sendo a primeira compreendida pelas Regionais de maior renda do DF; a segunda compreendida pela população de renda média e a terceira agrupou as populações de baixa renda. A Tabela 2, mostra o ranking adotado: 
Tabela 2- Ranking das Regiões Administrativas do DF por renda per capita (2007-2008)*

\begin{tabular}{clc}
\hline GRUPO 1: MAIOR RENDA & RENDA PER CAPITA MENSAL (em R\$) \\
\hline $1^{\circ}$ & Lago Sul & $5.756,38$ \\
$2^{\circ}$ & Lago Norte & $4.864,87$ \\
$3^{\circ}$ & Sudoeste/Octogonal & $4.727,42$ \\
$4^{\circ}$ & Park Way & $3.656,21$ \\
$5^{\circ}$ & Brasília & $3.648,89$ \\
$6^{\circ}$ & Jardim Botânico & $3.449,62$ \\
$7^{\circ}$ & Águas Claras & $2.375,70$ \\
$8^{\circ}$ & Guará & $1.850,35$ \\
$9^{\circ}$ & Cruzeiro & $2.021,16$
\end{tabular}

\begin{tabular}{clc}
\hline GRUPO 2: RENDA MÉDIA & RENDA PER CAPITA MENSAL (em R\$) \\
\hline $10^{\circ}$ & Vicente Pires & $1.707,94$ \\
$11^{\circ}$ & Sobradinho & $1.455,34$ \\
$12^{\circ}$ & Núcleo Bandeirante & $1.388,09$ \\
$13^{\circ}$ & Taguatinga & $1.310,86$ \\
$14^{\circ}$ & Sobradinho II & $1.330,25$ \\
$15^{\circ}$ & Candangolândia & $1.064,08$ \\
$16^{\circ}$ & Gama & $1.015,77$ \\
$17^{\circ}$ & Riacho Fundo & 850,72 \\
$18^{\circ}$ & SIA & 827,94 \\
$19^{\circ}$ & Santa Maria & 658,97 \\
$20^{\circ}$ & Ceilândia & 642,69 \\
$21^{\circ}$ & Brazlândia & 642,21 \\
$22^{\circ}$ & Planaltina & 634,35 \\
\hline GRUPO 3: BAIXA RENDA & 577,67 \\
\hline $23^{\circ}$ & Samambaia & 563,31 \\
$24^{\circ}$ & Riacho Fundo II & 501,47 \\
$25^{\circ}$ & São Sebastião & 491,12 \\
$26^{\circ}$ & Recanto das Emas & 487,55 \\
$27^{\circ}$ & Paranoá & 424,65 \\
$28^{\circ}$ & Varjão & 306,42 \\
$29^{\circ}$ & SCIA (Estrutural) & 343,80 \\
$30^{\circ}$ & Itapoã & \\
\hline
\end{tabular}

*Fonte:CODEPLAN - DF, 2008 População e Renda Per Capita.

Dentre os Grupos citados, foram selecionadas, aleatoriamente, seis escolas: trës pertencentes ao Grupo 1: uma de Brasília e duas do Cruzeiro; uma 
pertencente ao Grupo 2: Sobradinho; e duas do Grupo 3: uma do Recanto das Emas e uma do Riacho Fundo II, conforme mostra a Quadro 1:

Quadro 1: Escolas selecionadas aleatoriamente para o estudo

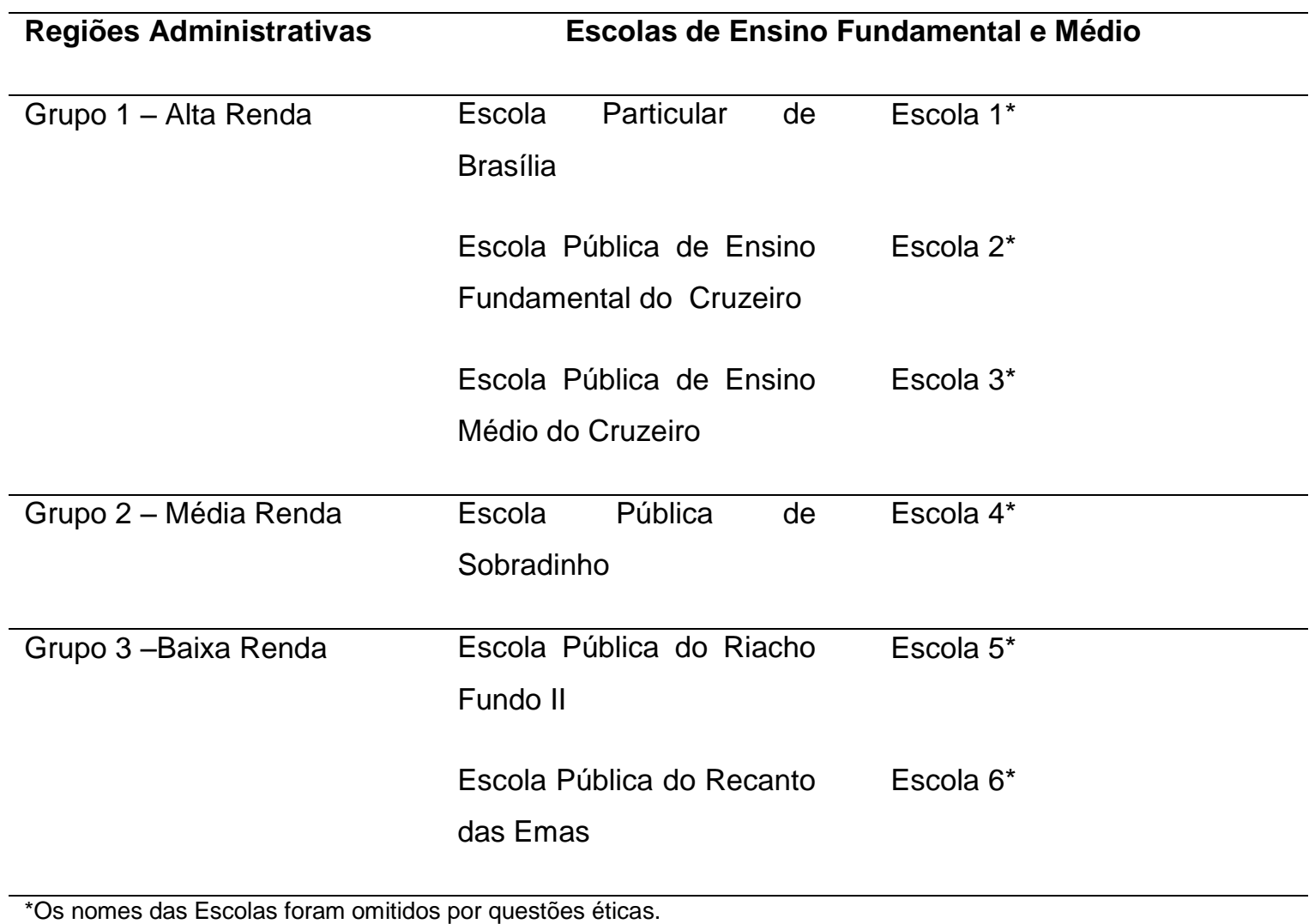

*Os nomes das Escolas foram omitidos por questões éticas.

Após a seleção das regionais, foi obtida uma lista das escolas públicas junto à Secretaria de Estado de Educação do Distrito Federal (SEE-DF). Dessa forma, tornar-se-ia possível obter, em um mesmo ambiente, adolescentes de todas as faixas de idade, de acordo com a definição da OMS. Por intermédio dessa lista, foi observado que, na Regional do Cruzeiro, as escolas selecionadas aleatoriamente não compreendiam alunos dos ciclos fundamental e médio e, isso poderia trazer um viés de seleção, visto que as escolas não abrangiam todas as faixas etárias para o estudo. Portanto, nessa regional foi necessário selecionar duas escolas: uma de ensino fundamental e outra de ensino médio. Em Brasília, foram selecionadas três escolas da rede privada, entretanto apenas uma aceitou 
participar do estudo, o que comprometeu a randomização. Existe uma dificuldade em pesquisa que inclui os extratos de mais alta renda, visto que esses muitas vezes se recusam a participar de estudos epidemiológicos. Considerando que esse aborda uma condição estigmatizante, seria realmente, contar com a anuência da direção de escolas particulares. Por fim, por meio dessa seleção, foi possível a obtenção de 6 escolas para a realização do estudo e um total de 1.470 estudantes de ambos os sexos e na faixa etária pretendida.

Após a seleção das Escolas, todas as turmas de ensino fundamental e médio foram selecionadas. As direções das escolas selecionadas foram previamente contatadas e informadas sobre os objetivos do estudo para que a cooperação e o desenvolvimento da pesquisa fossem assegurados. Não houve objeção de nenhuma direção das escolas públicas selecionadas.

\subsection{TREINAMENTO DA EQUIPE}

A Equipe foi composta por um coordenador de pesquisa e sete entrevistadores, estudantes do Curso de Medicina dos Programas de Iniciação Científica (PIC) e Programa Institucional de Bolsas de Iniciação Científica (PIBIC) da Escola Superior em Ciências da Saúde (ESCS). Esses alunos foram os responsáveis pela adaptação do instrumento de coleta de dados e posterior entrada dos dados no "Statistical Package for the Social Sciences (SPSS)". Antes do trabalho de campo, toda a equipe participou de um treinamento, ministrado pela coordenadora, a fim de que houvesse padronização nas atividades propostas e diminuição de possíveis dúvidas ou entraves pertinentes ao objeto da pesquisa. Por fim, foi realizado um estudo piloto junto a sujeitos com características semelhantes aos da pesquisa, porém de uma escola não selecionada para o estudo, para testar e refinar o instrumento de coleta de dados. 


\subsection{CONTROLE DE QUALIDADE}

Os alunos participantes da pesquisa responderam a questionários autoaplicáveis nas escolas em análise. Os entrevistadores estiveram presentes no momento da atividade, para que todas as informações fossem repassadas aos alunos com clareza e para que as dúvidas fossem sanadas de imediato. Após o término do questionário, os entrevistadores os revisaram imediatamente. Em caso de detecção de falhas nas respostas, o respondente era imediatamente contatado para as devidas correções.

\subsection{INSTRUMENTO PARA A COLETA DE DADOS}

Nesta pesquisa, foi escolhido Inventário de Depressão de Beck por se tratar de uma das medidas de auto-resposta mais amplamente utilizadas para avaliar a gradação dos sintomas depressivos. As alternativas de resposta a cada item pressupõem níveis de gravidade crescente de depressão. De acordo com SALLE et al (2012), o BDI foi aplicado em adolescentes, bem como em um contexto de cuidados primários. Para este autor, essa medida correlacionou-se positivamente com a prevalência de depressão determinada por meio de entrevistas clínicas. Diante do exposto, a avaliação específica da utilidade do BDI, na sua versão brasileira, para a adolescência, parece extremamente importante (25).

O questionário aplicado continha as variáveis sóciodemográficas e uma escala de depressão baseada no Código Internacional de Doenças CID 10 e na Escala do Inventário de Depressão de Beck, além das questões relativas à autopercepção do estado de saúde (Anexo I). 
De acordo com o Inventário de Depressão de Beck, cada uma das três respostas pertencentes às questões de 16 a 34 do questionário recebeu uma pontuação específica. Foram aplicados os seguintes pontos de corte, propostos pelo $\mathrm{BDI}$, de acordo com o somatório dos pontos das questões, para cada adolescente avaliado:

-Pontuação menor ou igual a 11: ausência de depressão;

- Pontuação entre 12 e 19: depressão leve;

- Pontuação entre 20 a 35: depressão moderada;

- Pontuação maior que 36 a 63: depressão grave.

\subsection{CONSIDERAÇÕES ÉTICAS}

O projeto foi submetido e avaliado pelo comitê de Ética da Fundação de Ensino e Pesquisa em Ciências da Saúde da Secretaria de Estado de Saúde (FEPECS/SES-DF), e aprovado em 15 de Junho de 2007, com número de registro CEP/FEPECS-062/07. Foi, solicitado, ainda, a assinatura do consentimento livre e esclarecido por escrito dos adolescentes e dos seus responsáveis. Este projeto não apresenta quaisquer conflitos de interesse e está dentro da categoria 1 da regulamentação da pesquisa em seres humanos no Brasil (pesquisa sem risco), porque envolve apenas questionários. 


\subsection{ANÁLISE ESTATÍSTICA}

Foram feitas análises descritivas de frequência das variáveis estudadas bem como a análise bivariada, utilizando-se o teste de Qui-Quadrado $\left(X^{2}\right)$, a fim de verificar se as distribuições de duas ou mais amostras não relacionadas diferiam significativamente.

\subsubsection{Teste Qui-Quadrado ( $\left.X^{2}\right)$ para homegeneidade}

O teste de Qui-Quadrado $\left(\mathrm{X}^{2}\right)$ de homogeneidade é utilizado exclusivamente para variáveis nominais e ordinais, a fim de testar se diferentes populações possuem uma mesma proporção de indivíduos com alguma característica estudada. De modo geral, os dados referem-se a mensurações de duas características (A e B) feitas em $n$ unidades experimentais.

Se $A$ e $B$ forem independentes, temos que, para todos os possíveis $\left(A_{i}\right.$ e $\left.B_{j}\right)$ :

$$
P\left(A_{i} \cap B_{j}\right)=P\left(A_{i}\right) \times P\left(B_{j}\right) \quad i=1,2, \ldots, \text { r e } j=1,2, \ldots, s .
$$

Logo, o número esperado de observações com as características $\left(A_{i}\right.$ e $\left.B_{j}\right)$ entre as $n$ observações sob a hipótese de independência, é dado por:

$$
E_{i j}=\frac{n_{i-} \times n_{\cdot j}}{n_{m}}
$$


O processo deve ser repetido para todas as células (ij). A distância entre os valores observados e os valores esperados, sob a suposição de independência, consiste na estatística qui-quadrado para a inferência desta propriedade:

$$
\chi^{2}=\sum_{i=1}^{r} \sum_{j=1}^{s} \frac{\left(O_{i j}-E_{i j}\right)^{2}}{E_{i j}}
$$

em que $O_{i j}=n_{i j}$ representa o total de observações na célula (ij).

Supondo que as variáveis sejam estatisticamente independentes, vem:

$$
\chi^{2}=\sum_{i=1}^{r} \sum_{j=1}^{s} \frac{\left(O_{i j}-E_{i j}\right)^{2}}{E_{i j}} \sim \chi_{q}^{2}
$$

sendo $q=(r-1) \times(s-1)$ graus de liberdade.

A regra de decisão baseia-se no nível descritivo $P$, neste caso, entendido como sendo:

$$
P=P\left(\chi_{q}^{2} \geq \chi_{o b s}^{2}\right)
$$

em que $X^{2}$ obs é o valor calculado, a partir dos dados, para a estatística do teste em apreço.

Em formato gráfico, a descrição teórica acima pode ser sintetizada pela Figura 2: 


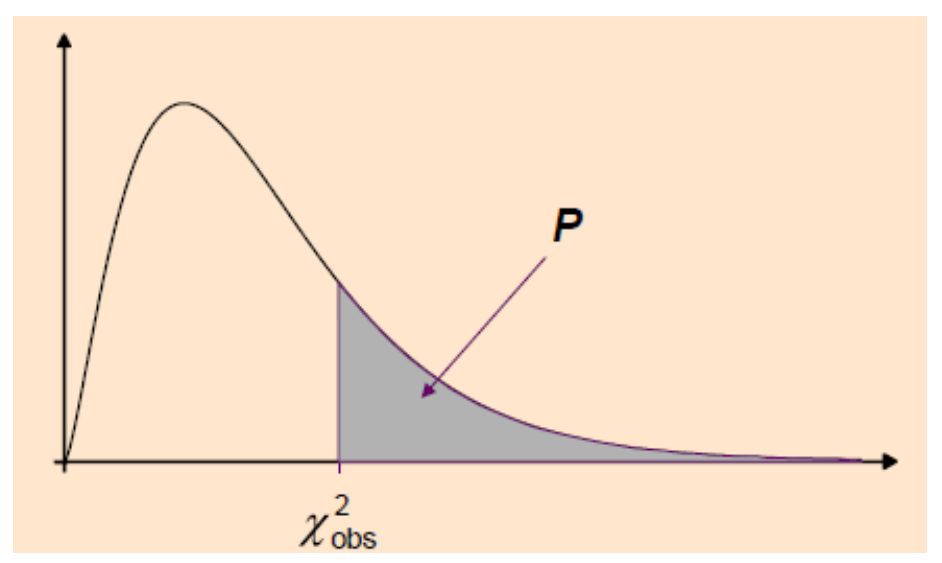

Figura 2 - Ilustração do teste Qui-Quadrado

Se, para fixado valor obtermos $\mathrm{P} \leq \alpha$, rejeita-se a hipótese de independência. Com efeito, o teste de Qui-Quadrado $\left(X^{2}\right)$ de independência é utilizado para inferir se duas variáveis de interesse, medidas nas mesmas unidades experimentais, apresentam independência entre si. Para esse teste, formulam-se as seguintes hipóteses:

- $H_{0:}$ Os grupos em análise são independentes

- $H_{1}$ : Os grupos em análise não são independentes

Considerando um nível de significância ( $\alpha$ ) de $5 \%$, ou seja, estabelecendo em $5 \%$ a probabilidade de se rejeitar a hipótese nula $\left(\mathrm{H}_{0}\right)$, sendo ela verdadeira, rejeitase a hipótese de proporções iguais entre as variáveis se o $p$-valor for inferior a 0,05.

\subsubsection{Box-Plot}

O boxplot (gráfico de caixa) é um gráfico utilizado para avaliar a distribuição empírica dos dados, facilitando a visualização do comportamento das observações. O boxplot é formado pelo primeiro quartil, terceiro quartil e mediana. As hastes 
inferiores e superiores se estendem, respectivamente, do quartil inferior até o menor valor não inferior ao limite inferior e do quartil superior até o maior valor não superior ao limite superior.

Os limites são calculados através das fórmulas a seguir:

Limite inferior: $Q_{1}-1,5\left(Q_{3}-Q_{1}\right)$.

Limite superior: $Q_{3}+1,5\left(Q_{3}-Q_{1}\right)$.

Os pontos fora dos limites superior e inferior são considerados valores discrepantes (outliers).

\subsubsection{Softwares}

O software utilizado para as análises do banco de dados foi o Statistical Package for The Social Sciences (SPSS) versão 18.0. Já para as análises estatísticas foi utilizado o software "free $R$ ", que é um programa gratuito de análises estatísticas. 


\section{RESULTADOS}

\subsection{CARACTERÍSTICAS SÓCIO-DEMOGRÁFICAS}

Foram analisados 1.470 questionários de adolescentes, entre 10 e 19 anos de idade, com média de idade de $14 \pm 2,06$ anos; sendo 720 (48,9\%) do sexo masculino e $750(51,1 \%)$ do sexo feminino conforme mostrado na Figura 3. As diferenças entre os sexos não foram estatisticamente significativas $(p>0,05)$. A distribuição entre os gêneros dos adolescentes apresentou semelhança com a distribuição do Distrito Federal no ano da pesquisa, que foi de $52,53 \%$ para o sexo feminino e $47,47 \%$ para o sexo masculino. Já a tabela 3 mostra a distribuição dos adolescentes por sexo, de acordo com a Escola participante.

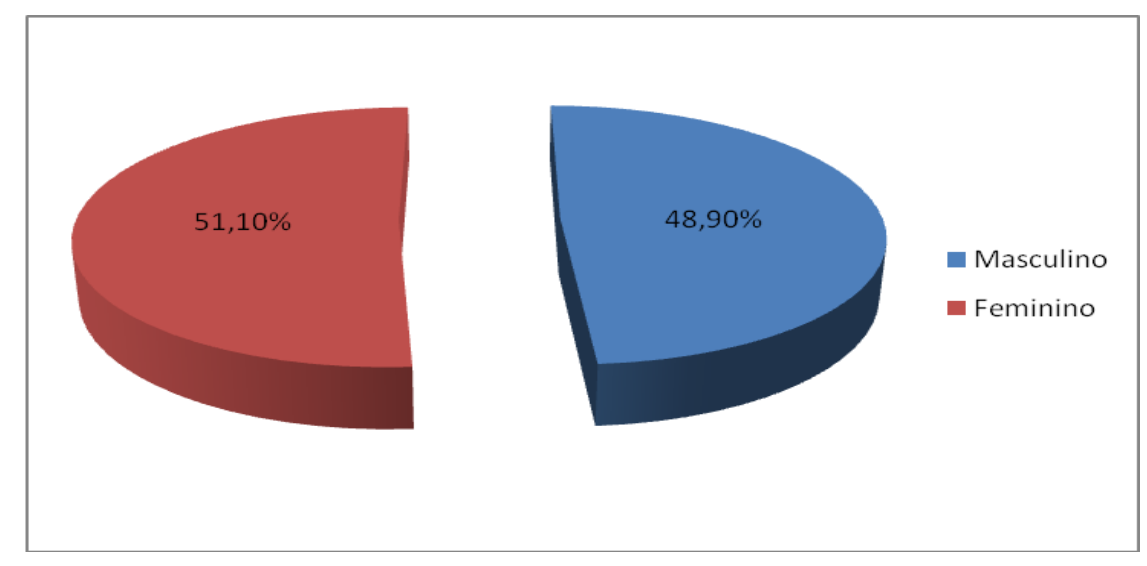

Figura 3: Distribuição dos Adolescentes por sexo ( $p$-valor $=0,2685)$ 
Tabela 3- Total de adolescentes entrevistados por escola segundo o sexo.

\begin{tabular}{lcccccc}
\hline Escolas & \multicolumn{2}{c}{ Masculino } & \multicolumn{2}{c}{ Feminino } & \multicolumn{2}{c}{ Total } \\
\cline { 2 - 7 } & $\mathrm{N}$ & $\%$ & $\mathrm{~N}$ & $\%$ & $\mathrm{~N}$ & $\%$ \\
Escola 1 & 120 & 8,00 & 129 & 9,00 & 249 & 17,00 \\
Escola 2 & 85 & 5,78 & 92 & 6,26 & 177 & 12,04 \\
Escola 3 & 92 & 6,26 & 78 & 5,31 & 170 & 11,57 \\
Escola 4 & 138 & 9,39 & 158 & 10,75 & 297 & 20,14 \\
Escola 5 & 133 & 9,05 & 150 & 10,20 & 283 & 19,25 \\
Escola 6 & 151 & 10,27 & 143 & 9,73 & 294 & 20,00 \\
\hline Total & 719 & 48,90 & 750 & 51,10 & 1470 & 100 \\
\hline
\end{tabular}

As tabelas 4 e 5 resumem os resultados das variáveis sócio-demográficas. De acordo com a distribuição geográfica, foi evidenciado que a região administrativa do cruzeiro apresentava, na ocasião da pesquisa, a maior proporção de adolescentes $(23,6 \%)$ enquanto a menor proporção foi encontrada na Região Administrativa do Plano Piloto (17\%). Essas diferenças foram estatisticamente significativas $(p<0,05)$. Verificou-se, ainda, que a maioria dos adolescentes entrevistados (80,7\%) exercia exclusivamente a ocupação de estudantes, ao passo que $18,2 \%$ referiram trabalhar e estudar. Tais diferenças também foram estatisticamente significativas $(p<0,05)$.

Em relação ao arranjo familiar verifica-se que, embora a maioria dos adolescentes $(58,2 \%)$ tenha referido viver com pai e a mãe, uma proporção de $20,3 \%$ referiu morar só com a mãe. Essas diferenças foram estatisticamente significativas $(p<0,05)$.

No que diz respeito ao estado conjugal dos pais (tabela 5), evidenciou-se que $64,9 \%$ dos pais dos adolescentes eram casados ou unidos consensualmente. Com relação à escolaridade dos pais, verificou-se que a maioria tinha apenas o ensino fundamental ou médio $(63,5 \%)$ e $21,2 \%$ possuíam ensino superior. Com relação à escolaridade das mães dos estudantes, foram encontradas proporções semelhantes 
às encontradas para os pais, que foi de $61,1 \%$ para o ensino fundamental ou médio e $21,0 \%$ ensino superior.

Tabela 4-Distribuição das características sóciodemográficas dos adolescentes relativas ao sexo, idade, local de residência e arranjo familiar.

\begin{tabular}{|c|c|c|c|}
\hline Característica & $\mathbf{N}$ & (\%) & (p-valor) \\
\hline Sexo & & & 0,2685 \\
\hline Masculino & 720 & 48,9 & \\
\hline Feminino & 750 & 51,1 & \\
\hline NS/NR & 0 & 0 & \\
\hline Faixa Etária* & & & $<0,001$ \\
\hline $10|--| 12$ & 363 & 24,7 & \\
\hline $13|--| 15$ & 704 & 47,9 & \\
\hline $16|--| 19$ & 396 & 26,9 & \\
\hline 20 ou + & 3 & 0,2 & \\
\hline NS/NR & 4 & 0,3 & \\
\hline Cidade em que reside & & & 0,000362 \\
\hline Cruzeiro & 347 & 23,6 & \\
\hline Plano Piloto & 250 & 17,0 & \\
\hline Recanto das Emas & 294 & 20,0 & \\
\hline Riacho Fundo II & 283 & 19,3 & \\
\hline Sobradinho & 296 & 20,1 & \\
\hline Está trabalhando & & & $<0,001$ \\
\hline Sim & 267 & 18,2 & \\
\hline Não & 1187 & 80,7 & \\
\hline NS/NR & 16 & 1,1 & \\
\hline Com quem vive & & & $<0,001$ \\
\hline Pai e Mãe & 856 & 58,2 & \\
\hline Só com a Mãe & 298 & 20,3 & \\
\hline Só com o Pai & 32 & 2,2 & \\
\hline Com a Mãe e o Padrasto & 145 & 9,9 & \\
\hline Com o Pai e a Madrasta & 26 & 1,8 & \\
\hline Com Avós & 25 & 1,7 & \\
\hline Outros & 87 & 5,9 & \\
\hline NS/NR & 1 & 0,1 & \\
\hline
\end{tabular}


Tabela 5- Distribuição das características sóciodemográficas dos pais dos adolescentes segundo o estado conjugal e a escolaridade

\begin{tabular}{|c|c|c|c|}
\hline Característica & $\mathbf{N}$ & $\%$ & (p-valor) \\
\hline $\begin{array}{l}\text { Estado conjugal dos } \\
\text { pais }\end{array}$ & & & $<0,001$ \\
\hline Solteiros & 108 & 7,3 & \\
\hline $\begin{array}{l}\text { Casados ou unidos } \\
\text { consensualmente }\end{array}$ & 955 & 64,9 & \\
\hline $\begin{array}{ll}\text { Separados } & \text { ou } \\
\text { divorciados } & \end{array}$ & 342 & 23,3 & \\
\hline Viúvo (a) & 47 & 3,2 & \\
\hline Ambos falecidos & 7 & 0,5 & \\
\hline Outros & 10 & 0,7 & \\
\hline NS/NR & 1 & 0,1 & \\
\hline Escolaridade do Pai & & & $<0,001$ \\
\hline Ensino Superior & 311 & 21,2 & \\
\hline Ensino Médio & 315 & 21,4 & \\
\hline Ensino Fundamental & 427 & 39,0 & \\
\hline $\begin{array}{l}\text { Sabe ler e escrever, } \\
\text { mas não frequentou } \\
\text { escola }\end{array}$ & 72 & 4,9 & \\
\hline Nenhuma & 91 & 6,2 & \\
\hline NS/NR & 326 & 22,2 & \\
\hline $\begin{array}{l}\text { Escolaridade da } \\
\text { Mãe }\end{array}$ & & & $<0,001$ \\
\hline Ensino Superior & 309 & 21,0 & \\
\hline
\end{tabular}


Conclusão:

Tabela 5- Distribuição das características sóciodemográficas dos pais dos adolescentes segundo o estado conjugal e a escolaridade

\begin{tabular}{lccc}
\hline Característica & N & $\%$ & (p-valor) \\
\hline Ensino Médio & 405 & 27,6 & 29,9 \\
Ensino Fundamental & 439 & 3,6 & \\
Sabe ler e escrever, & 53 & \\
mas não frequentou & & 3,2 \\
escola & 46 & 14,8 \\
Nenhuma & 218 & \\
NS/NR &
\end{tabular}

\subsection{AUTO AVALIAÇÃO DO ESTADO DE SAÚDE}

No que se refere à avaliação do adolescente sobre o seu estado de saúde (tabela 6), verificou-se que $88,8 \%$ dos entrevistados, representado por 1.306 alunos, responderam ter boas condições de saúde. As diferenças entre os sexos, foram estatisticamente significativas $(p<0,05)$. Verificou-se, também, que, embora $97 \%$ dos entrevistados tenha referido que se considerava uma pessoa digna de respeito, $81,4 \%$ da amostra referiu que gostaria de se valorizar mais. Em ambos os casos, as diferenças entre os sexos também foram estatisticamente significativas $(p<0,05)$. Outro aspecto avaliado na pesquisa foi a satisfação pessoal. Sobre este item, verificou-se que $84,3 \%$ dos estudantes afirmaram que estavam satisfeitos consigo e $91,6 \%$ afirmaram que se sentem orgulhosos acerca de si próprios. Nestes dois casos, as diferenças entre os sexos não foram estatisticamente significativas; e Nestas duas questões, o sexo masculino apresentaram-se mais satisfeitos e 
orgulhosos dos que as meninas as maiores proporções de satisfação e orgulho de si próprio ( $90 \%$ e $79 \%$, respectivamente; e $93 \%$ e $90 \%$, respectivamente).

Tabela 6- Distribuição dos aspectos avaliados para a classificação da auto avaliação dos adolescentes sobre seus estados de saúde

\begin{tabular}{|c|c|c|c|c|c|c|c|}
\hline Variável & $\mathbf{N}$ & $(\%)$ & Masculino & $\%$ & Feminino & $\%$ & p-valor \\
\hline \multicolumn{8}{|c|}{ Como está sua saúde nesse momento } \\
\hline Bom/muito bom & 1306 & 88,8 & 661 & 92 & 644 & 86 & 0,0002851 \\
\hline Ruim/muito ruim & 51 & 3,5 & 16 & 2 & 35 & 5 & 0,01047 \\
\hline NS/NR & 113 & 7,7 & 42 & 6 & 70 & 9 & 0,01146 \\
\hline \multicolumn{8}{|c|}{ Sinto que sou uma pessoa digna de respeito } \\
\hline Concordo/Concordo & 1429 & 97,2 & 691 & 96 & 737 & 98 & 0,0007005 \\
\hline \multicolumn{8}{|l|}{ Totalmente } \\
\hline Discordo/Discordo & 41 & 2,8 & 28 & 4 & 13 & 2 & 0,00121 \\
\hline \multicolumn{8}{|l|}{ Totalmente } \\
\hline NS/NR & 0 & 0 & 0 & 0 & 0 & 0 & 0 \\
\hline \multicolumn{8}{|c|}{ Creio que tenho várias qualidades boas } \\
\hline Concordo/Concordo & 1420 & 96,6 & 704 & 98 & 715 & 95 & 0,6797 \\
\hline \multicolumn{8}{|l|}{ Totalmente } \\
\hline Discordo/Discordo & 50 & 3,4 & 15 & 2 & 35 & 5 & $<0,0001$ \\
\hline \multicolumn{8}{|l|}{ Totalmente } \\
\hline NS/NR & 0 & 0 & 0 & 0 & 0 & 0 & 0 \\
\hline \multicolumn{8}{|c|}{$\begin{array}{l}\text { Tenho atitudes em busca de meu } \\
\text { crescimento profissional }\end{array}$} \\
\hline Concordo/Concordo & 1387 & 94,4 & 686 & 95 & 700 & 93 & 0,008902 \\
\hline \multicolumn{8}{|l|}{ Totalmente } \\
\hline Discordo/Discordo & 82 & 5,6 & 32 & 4 & 50 & 7 & 0,006307 \\
\hline \multicolumn{8}{|l|}{ Totalmente } \\
\hline NS/NR & 1 & 0,1 & 0 & 0 & 0 & 0 & 0 \\
\hline
\end{tabular}

Em geral, sou satisfeito comigo mesmo

\begin{tabular}{lccccccc}
\hline $\begin{array}{l}\text { Concordo/Concordo } \\
\text { Totalmente }\end{array}$ & 1239 & 84,3 & 645 & 90 & 593 & 79 & 0,1035 \\
$\begin{array}{l}\text { Discordo/Discordo } \\
\text { Totalmente }\end{array}$ & 230 & 15,6 & 74 & 10 & 156 & 21 & 0,0635 \\
NS/NR & 1 & 0,1 & 0 & 0 & 0 & 0 & 0
\end{tabular}


Conclusão

Tabela 6-Distribuição dos aspectos avaliados para a classificação da auto-avaliação dos adolescentes sobre seus estados de saúde

\begin{tabular}{|c|c|c|c|c|c|c|c|}
\hline Variável & $\mathbf{N}$ & $(\%)$ & Masculino & $\%$ & Feminino & $\%$ & p-valor \\
\hline \multicolumn{8}{|c|}{ Gostaria de me valorizar mais } \\
\hline Concordo/Concordo & 1196 & 81,4 & 586 & 82 & 609 & 81 & 0,000028 \\
\hline \multicolumn{8}{|l|}{ Totalmente } \\
\hline Discordo/Discordo & 271 & 18,4 & 131 & 18 & 140 & 19 & 0,0000283 \\
\hline \multicolumn{8}{|l|}{ Totalmente } \\
\hline NS/NR & 3 & 0,2 & 0 & 0 & 0 & 0 & 0 \\
\hline \multicolumn{8}{|c|}{ Creio que tenho motivos para sentir orgulho de quem sou } \\
\hline $\begin{array}{l}\text { Concordo/Concordo } \\
\text { totalmente }\end{array}$ & 1347 & 91,6 & 670 & 93 & 676 & 90 & 0,924 \\
\hline $\begin{array}{l}\text { Discordo/discordo } \\
\text { totalmente }\end{array}$ & 122 & 8,4 & 48 & 74 & 74 & 10 & 0,8158 \\
\hline $\mathrm{NS} / \mathrm{NR}$ & 1 & 0 & 0 & 0 & 0 & 0 & 0 \\
\hline
\end{tabular}

\subsection{DESCRIÇÃO DOS SINTOMAS DEPRESSIVOS}

Os itens do questionário do BDI (Apêndice 1) foram correlacionados com as perguntas de números 16 a 34 do questionário aplicado aos estudantes, que as responderam com base em observações e relatos de sintomas mais frequentes nas duas semanas anteriores à realização da pesquisa. O Anexo 1 mostra a correlação entre $\circ$ (BDI) e as perguntas do questionário aplicado aos adolescentes. Cabe ressaltar que as perguntas referentes à quantificação da perda ponderal e a perda de libido, originalmente presentes no BDI, não foram utilizadas por entender-se que, na depressão, tanto pode haver perda ou aumento de peso; e a questão referente à libido é mais utilizada para enquetes em adultos, o que poderia causar um viés na coleta de dados. A Tabela 7 mostra a distribuição dos sintomas depressivos nos estudantes avaliados: 
Tabela 7- Distribuição dos sintomas de depressão referidos pelos estudantes por sexo

\begin{tabular}{|c|c|c|c|c|c|c|c|}
\hline Variáveis & $\mathbf{N}$ & (\%) & Masculino & $\%$ & Feminino & $\%$ & p-valor \\
\hline \multicolumn{8}{|c|}{ Sentimentos de tristeza } \\
\hline $\begin{array}{l}\text { Eu fico triste de } \\
\text { vez em quando }\end{array}$ & 1137 & 77,3 & 623 & $87 \%$ & 513 & $68 \%$ & $<0,001$ \\
\hline $\begin{array}{l}\text { Eu fico triste } \\
\text { muitas vezes }\end{array}$ & 296 & 20,1 & 85 & $12 \%$ & 211 & $28 \%$ & $<0,001$ \\
\hline $\begin{array}{l}\text { Eu fico triste o } \\
\text { tempo todo }\end{array}$ & 34 & 2,3 & 8 & $1 \%$ & 26 & $4 \%$ & 0,00267 \\
\hline NS/NR & 3 & 0,2 & 3 & 0 & 0 & $0 \%$ & \\
\hline \multicolumn{8}{|c|}{ Sentimentos de Pessimismo } \\
\hline $\begin{array}{l}\text { Nada nunca vai } \\
\text { dar certo pra } \\
\text { mim }\end{array}$ & 54 & 3,7 & 21 & $3 \%$ & 33 & $4 \%$ & 0,1307 \\
\hline $\begin{array}{l}\text { Não tenho } \\
\text { certeza se as } \\
\text { coisas darão } \\
\text { certo pra mim }\end{array}$ & 765 & 52,0 & 332 & $46 \%$ & 432 & $58 \%$ & 0,01036 \\
\hline $\begin{array}{l}\text { Vai dar tudo } \\
\text { certo pra mim }\end{array}$ & 650 & 44,2 & 365 & $51 \%$ & 285 & $38 \%$ & 0,00094 \\
\hline NS/NR & 1 & 0,1 & 1 & 0 & 0 & $0 \%$ & \\
\hline \multicolumn{8}{|c|}{ Sentimentos de Fracasso } \\
\hline $\begin{array}{l}\text { Eu faço quase } \\
\text { tudo certo }\end{array}$ & 766 & 52,1 & 432 & $60 \%$ & 334 & $45 \%$ & $<0,001$ \\
\hline $\begin{array}{l}\text { Muitas coisas eu } \\
\text { faço errado }\end{array}$ & 647 & 44,0 & 269 & $37 \%$ & 377 & $50 \%$ & $<0,001$ \\
\hline $\begin{array}{l}\text { Eu faço tudo } \\
\text { errado }\end{array}$ & 54 & 3,7 & 16 & $2 \%$ & 38 & $5 \%$ & 0,00375 \\
\hline NS/NR & 3 & 0,2 & 2 & 0 & 1 & 0 & \\
\hline \multicolumn{8}{|c|}{ Sentimentos de Insatisfação Pessoal } \\
\hline $\begin{array}{ll}\text { Eu me } & \text { divirto } \\
\text { com } & \text { muitas } \\
\text { coisas } & \end{array}$ & 957 & 65,1 & 500 & $70 \%$ & 456 & $61 \%$ & $<0,0001$ \\
\hline $\begin{array}{l}\text { Eu me divirto } \\
\text { com algumas } \\
\text { coisas }\end{array}$ & 481 & 32,7 & 209 & $29 \%$ & 272 & $36 \%$ & 0,00310 \\
\hline
\end{tabular}


Continuação

Tabela 7- Distribuição dos sintomas de depressão referidos pelos estudantes por sexo

\begin{tabular}{lccccccc}
\hline Variáveis & $\mathbf{N}$ & $(\%)$ & Masculino & $\%$ & Feminino & $\%$ & p-valor \\
\hline $\begin{array}{l}\text { Não me divirto } \\
\text { com nada }\end{array}$ & 29 & 2,0 & 9 & $1 \%$ & 20 & $3 \%$ & 0,05089 \\
NS/NR & 3 & 0,2 & 1 & 0 & 2 & 0 & \\
Continua & & & & & & & \\
\hline
\end{tabular}

Sentimentos de

Culpa

\begin{tabular}{lccccccc}
\hline $\begin{array}{l}\text { Eu sou ruim o } \\
\text { tempo todo }\end{array}$ & 27 & 1,8 & 17 & $2 \%$ & 10 & $1 \%$ & 0,05676 \\
$\begin{array}{l}\text { Muitas vezes eu } \\
\text { sou ruim }\end{array}$ & 263 & 17,9 & 117 & $16 \%$ & 146 & $19 \%$ & 0,01144 \\
$\begin{array}{l}\text { Eu sou ruim } \\
\text { uma vez ou }\end{array}$ & & & & & & & \\
outra
\end{tabular}

\begin{tabular}{lllllll} 
NS/NR & 5 & 0,3 & 4 & $1 \%$ & 1 & 0 \\
\hline
\end{tabular}

Sentimentos de auto acusação

\begin{tabular}{lccccccc}
\hline $\begin{array}{l}\text { Todas as coisas } \\
\text { ruins acontecem }\end{array}$ & 66 & 4,5 & 33 & $5 \%$ & 33 & $4 \%$ & 0,8651 \\
$\begin{array}{l}\text { por minha culpa } \\
\text { Muitas coisas }\end{array}$ & 384 & 26,1 & 163 & $23 \%$ & 221 & $29 \%$ & 0,00289 \\
ruins acontecem \\
por minha culpa
\end{tabular}


Continua

Tabela 7-Distribuição dos sintomas de depressão referidos pelos estudantes por sexo

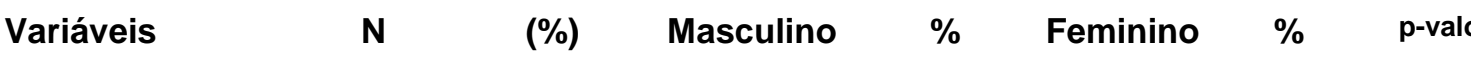

Sentimentos de Punição

$\begin{array}{llllllll}\text { Eu penso que } & 599 & 40,7 & 332 & 46 \% & 267 & 36 \% & 0,04082\end{array}$

coisas ruins

podem

acontecer

comigo uma vez

ou outra

Eu fico

806

54,8

362

$50 \%$

$443 \quad 59 \% \quad 0,00070$

preocupado que

coisas ruins

aconteçam

comigo

$\mathrm{Eu}$

tenho

61

4,1

22

$3 \%$

39

$5 \% \quad 0,03933$

certeza que

coisas horríveis

vão acontecer

comigo

$\mathrm{NS} / \mathrm{NR}$

4

0,3

3

0

1

$0 \quad 0$

Ideações Suicidas

\begin{tabular}{lccccccc}
\hline $\begin{array}{l}\text { Eu não penso } \\
\text { em me matar }\end{array}$ & 1001 & 68,1 & 551 & $77 \%$ & 449 & $60 \%$ & $<0,0001$ \\
$\begin{array}{l}\text { Eu penso em } \\
\text { me matar, mas }\end{array}$ & 446 & 30,3 & 161 & $22 \%$ & 285 & $38 \%$ & $<0,0001$ \\
não faria isso & & & & & & \\
$\begin{array}{l}\text { Eu quero me } \\
\text { matar }\end{array}$ & 19 & 1,3 & 5 & $1 \%$ & 14 & $2 \%$ & 0,0467 \\
NS/NR & 4 & 0,3 & 2 & 0 & 2 & 0 & 0 \\
\hline $\begin{array}{l}\text { Choro } \\
\begin{array}{l}\text { Tenho vontade } \\
\text { de chorar todos }\end{array} \\
\text { os dias }\end{array}$ & 122 & 8,3 & 21 & $3 \%$ & 101 & $13 \%$ & $<0,0001$ \\
\end{tabular}


Continua

Tabela 7- Distribuição dos sintomas de depressão referidos pelos estudantes por sexo

\begin{tabular}{|c|c|c|c|c|c|c|c|}
\hline Variáveis & $\mathbf{N}$ & (\%) & Masculino & $\%$ & Feminino & $\%$ & p-valor \\
\hline $\begin{array}{l}\text { Tenho vontade } \\
\text { de chorar quase } \\
\text { todos os dias }\end{array}$ & 224 & 15,2 & 43 & $6 \%$ & 181 & $24 \%$ & $<0,0001$ \\
\hline $\begin{array}{l}\text { Tenho vontade } \\
\text { de chorar uma } \\
\text { vez ou outra }\end{array}$ & 1102 & 75,0 & 637 & $89 \%$ & 465 & $62 \%$ & $<0,0001$ \\
\hline NS/NR & 22 & 1,5 & 19 & $2 \%$ & 3 & 0 & 0,00040 \\
\hline \multicolumn{8}{|l|}{$\begin{array}{l}\text { Sentimentos de } \\
\text { Irritabilidade }\end{array}$} \\
\hline $\begin{array}{lr}\text { Tem } & \text { sempre } \\
\text { alguma } & \text { coisa } \\
\text { me aborrecendo }\end{array}$ & 300 & 20,4 & 119 & $17 \%$ & 181 & $24 \%$ & 0,00029 \\
\hline $\begin{array}{l}\text { Quase sempre } \\
\text { tem uma coisa } \\
\text { me aborrecendo }\end{array}$ & 413 & 28,1 & 157 & $22 \%$ & 256 & $34 \%$ & 0,00014 \\
\hline $\begin{array}{l}\text { Uma vez ou } \\
\text { outra tenho } \\
\text { aborrecimento }\end{array}$ & 753 & 51,2 & 440 & $61 \%$ & 312 & $42 \%$ & $<0,0001$ \\
\hline NS/NR & 4 & 0,3 & 3 & 0 & 1 & 0 & \\
\hline
\end{tabular}

Retraimento

Social

\begin{tabular}{lccccccc}
\hline $\begin{array}{l}\text { Eu gosto de } \\
\text { estar com outras }\end{array}$ & 1189 & 80,9 & 606 & $84 \%$ & 582 & $78 \%$ & 0,01337 \\
$\begin{array}{l}\text { pessoas } \\
\begin{array}{l}\text { Muitas vezes eu } \\
\text { não gosto de }\end{array}\end{array}$ & 240 & 16,3 & 94 & $13 \%$ & 146 & $19 \%$ & 0,00088 \\
$\begin{array}{l}\text { estar com outras } \\
\text { pessoas }\end{array}$ & & & & & & & \\
$\begin{array}{l}\text { Eu não tenho } \\
\text { vontade de estar }\end{array}$ & 40 & 2,7 & 19 & $3 \%$ & 21 & $3 \%$ & 0,8496 \\
com ninguém & & & & & & & \\
NS/NR & 1 & 0,1 & 0 & 0 & 1 & 0 & 0 \\
\hline
\end{tabular}

Dificuldades

em Tomar

Decisões

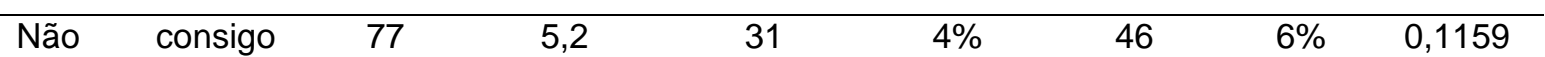

tomar decisões 
Continua

Tabela 7- Distribuição dos sintomas de depressão referidos pelos estudantes por sexo

\begin{tabular}{|c|c|c|c|c|c|c|c|}
\hline Variáveis & $\mathbf{N}$ & (\%) & Masculino & $\%$ & Feminino & $\%$ & p-valor \\
\hline $\begin{array}{l}\text { É difícil tomar } \\
\text { decisões }\end{array}$ & 858 & 58,4 & 386 & $54 \%$ & 471 & $63 \%$ & 0,00035 \\
\hline $\begin{array}{l}\text { Eu me decido } \\
\text { sobre as coisas } \\
\text { facilmente }\end{array}$ & 532 & 36,2 & 300 & $42 \%$ & 232 & $31 \%$ & 0,01841 \\
\hline NS/NR & 3 & 0,2 & 2 & 0 & 1 & 0 & 0 \\
\hline \multicolumn{8}{|l|}{ Auto Estima } \\
\hline $\begin{array}{l}\text { Minha aparência } \\
\text { é legal }\end{array}$ & 693 & 47,1 & 408 & $57 \%$ & 372 & $38 \%$ & $<0,0001$ \\
\hline $\begin{array}{l}\text { Tem umas } \\
\text { coisas que eu } \\
\text { não gosto na } \\
\text { minha aparência }\end{array}$ & 644 & 43,8 & 271 & $38 \%$ & 92 & $50 \%$ & $<0,0001$ \\
\hline Eu me sinto feio & 132 & 9,0 & 40 & $6 \%$ & 1 & $12 \%$ & $<0,0001$ \\
\hline NS/NR & 1 & 0,1 & 0 & 0 & 0 & 0 & \\
\hline \multicolumn{8}{|l|}{$\begin{array}{l}\text { Dificuldade de } \\
\text { Concentração }\end{array}$} \\
\hline $\begin{array}{l}\text { Eu tenho } \\
\text { sempre que me } \\
\text { forçar a fazer } \\
\text { minhas tarefas } \\
\text { escolares }\end{array}$ & 362 & 24,6 & 203 & $28 \%$ & 159 & $21 \%$ & 0,001853 \\
\hline $\begin{array}{l}\text { Muitas vezes eu } \\
\text { tenho que me } \\
\text { forçar a fazer } \\
\text { minhas tarefas } \\
\text { escolares }\end{array}$ & 509 & 34,6 & 250 & $35 \%$ & 258 & $34 \%$ & 0,896 \\
\hline $\begin{array}{l}\text { Não tenho } \\
\text { problemas para } \\
\text { fazer as tarefas } \\
\text { escolares }\end{array}$ & 597 & 40,6 & 265 & $37 \%$ & 332 & $44 \%$ & 0,00358 \\
\hline NS/NR & 2 & 0,1 & 1 & 0 & 1 & 0 & 0 \\
\hline
\end{tabular}


Continua

Tabela 7-Distribuição dos sintomas de depressão referidos pelos estudantes por sexo

\begin{tabular}{|c|c|c|c|c|c|c|c|}
\hline Variáveis & $\mathbf{N}$ & (\%) & Masculino & $\%$ & Feminino & $\%$ & p-valor \\
\hline \multicolumn{8}{|l|}{ Insônia } \\
\hline $\begin{array}{l}\text { Tenho problema } \\
\text { para dormir } \\
\text { todas as noites }\end{array}$ & 92 & 6,3 & 49 & $7 \%$ & 43 & $6 \%$ & 0,3960 \\
\hline $\begin{array}{l}\text { Muitas vezes } \\
\text { tenho problema } \\
\text { para dormir }\end{array}$ & 295 & 20,1 & 102 & $14 \%$ & 192 & $26 \%$ & $<0,0001$ \\
\hline Eu durmo bem & 1078 & 73,3 & 565 & $79 \%$ & 513 & $68 \%$ & $<0,0001$ \\
\hline NS/NR & 5 & 0,3 & 3 & 0 & 2 & 0 & 0 \\
\hline \multicolumn{8}{|l|}{$\begin{array}{ll}\text { Perda } & \text { de } \\
\text { Apetite } & \end{array}$} \\
\hline $\begin{array}{l}\text { Na maioria dos } \\
\text { dias eu não } \\
\text { estou a fim de } \\
\text { comer }\end{array}$ & 167 & 11,4 & 61 & $8 \%$ & 106 & $14 \%$ & 0,0006 \\
\hline $\begin{array}{l}\text { Muitos dias eu } \\
\text { não estou a fim } \\
\text { de comer }\end{array}$ & 195 & 13,3 & 62 & $9 \%$ & 133 & $18 \%$ & $<0,0001$ \\
\hline Eu como bem & 1107 & 75,3 & 595 & $83 \%$ & 511 & $68 \%$ & $<0,0001$ \\
\hline NS/NR & 1 & 0,1 & 1 & 0 & 0 & 0 & \\
\hline \multicolumn{8}{|l|}{ Hipocondria } \\
\hline $\begin{array}{l}\text { Dores não me } \\
\text { preocupam }\end{array}$ & 672 & 45,7 & 383 & $53 \%$ & 289 & $39 \%$ & $<0,0001$ \\
\hline $\begin{array}{l}\text { Muitas vezes eu } \\
\text { me preocupo } \\
\text { com dores }\end{array}$ & 496 & 33,7 & 215 & $30 \%$ & 280 & $37 \%$ & 0,00244 \\
\hline $\begin{array}{l}\text { Eu sempre me } \\
\text { preocupo com } \\
\text { dores }\end{array}$ & 301 & 20,5 & 120 & $17 \%$ & 181 & $24 \%$ & 0,00039 \\
\hline NS/NR & 1 & 0,1 & 0 & 0 & 0 & 0 & \\
\hline Fadiga & & & & & & & \\
\hline $\begin{array}{l}\text { Eu fico cansado } \\
\text { uma vez ou } \\
\text { outra }\end{array}$ & 990 & 67,3 & 538 & $75 \%$ & 451 & $60 \%$ & $<0,0001$ \\
\hline
\end{tabular}


Conclusão

Tabela 7-Distribuição dos sintomas de depressão referidos pelos estudantes por sexo

\begin{tabular}{lccccccc}
\hline Variáveis & $\mathbf{N}$ & $(\%)$ & Masculino & $\%$ & Feminino & $\%$ & p-valor \\
\hline $\begin{array}{l}\text { Eu fico cansado } \\
\text { a maioria dos }\end{array}$ & 359 & 24,4 & 141 & $20 \%$ & 218 & $29 \%$ & $<0,0001$ \\
dias & & & & & & & \\
$\begin{array}{l}\text { Estou sempre } \\
\text { cansado }\end{array}$ & 121 & 8,2 & 40 & $6 \%$ & 81 & $11 \%$ & 0,00025 \\
NS/NR & 0 & 0 & 0 & 0 & 0 & 0 & \\
\hline
\end{tabular}

Dentre os sintomas avaliados, verificou-se que as maiores prevalências de sintomas depressivos ocorreram, em sua maioria, na população feminina, com destaque para: sentimentos de tristeza ("eu fico triste muitas vezes":28\% para as meninas e $12 \%$ para os meninos); sentimentos de fracasso ("muitas coisas eu faço errado": $50 \%$ para as meninas e $37 \%$ para os meninos); sentimentos de autoaversão ("eu não gosto de mim": $12 \%$ para as meninas e $4 \%$ para os meninos); ideações suicidas ("eu penso em me matar, mas eu não faria isso": $38 \%$ para as meninas e $22 \%$ para os meninos); choro ("tenho vontade de chorar todos os dias": $13 \%$ para as meninas e $3 \%$ para os meninos) e auto-estima ("eu me sinto feio": $12 \%$ para as meninas e $6 \%$ para os meninos). Em todas essas questões, as diferenças entre os sexos foram estatisticamente significativas.

Já os sintomas de depressão mais prevalentes na população masculina se referiram aos sentimentos de culpa ("eu sou ruim o tempo todo": $2 \%$ para os meninos e $1 \%$ para as meninas); de auto-acusação ("todas as coisas ruins acontecem por minha culpa":5\% para os meninos e $4 \%$ para as meninas); dificuldade de concentração ("eu tenho sempre que me forçar a fazer minhas tarefas escolares": $28 \%$ para as meninas e $21 \%$ para os meninos) e insônia ("tenho problemas para dormir todas as noites": $7 \%$ para as meninas e $6 \%$ para os meninos). Em todas essas questões, as diferenças entre os sexos não foram estatisticamente significativas, exceto no sintoma relacionado à dificuldade de concentração ("eu tenho que me forçar a fazer minhas tarefas escolares": $p=$ $0,001853)$. 


\subsection{CLASSIFICAÇÃO DA GRADAÇÃO DOS SINTOMAS DEPRESSIVOS}

De acordo com a escala utilizada, cada uma das três respostas pertencentes às questões de 16 a 34 do questionário recebeu uma pontuação específica. Foram aplicados os pontos de corte, propostos pelo BDI, de acordo com o somatório dos pontos das questões, para cada adolescente avaliado, conforme descrito no método (item 3).

Com relação à classificação da gradação da depressão, foi possível verificar que $32 \%$ dos adolescentes avaliados não tinham depressão; $45 \%$ foram classificados como portadores de depressão leve; $19 \%$ de depressão moderada e $4 \%$ de depressão grave. Com relação à comparação entre os sexos, verificou-se que, para a depressão leve, as prevalências foram muito semelhantes entre os sexos, $45 \%$ para meninos e $46 \%$ para as meninas. Já para as classificações de depressão moderada e grave, a prevalência foi maior entre as meninas (25\% e $6 \%$ e $13 \%$ e $1 \%$, respectivamente), sendo a diferença entre os gêneros estatisticamente significativa

Tabela 8- Gradação da depressão segundo o sexo

\begin{tabular}{|c|c|c|c|c|c|c|c|c|}
\hline Gradação & $\mathbf{N}$ & $\%$ & Masculino & $\%$ & Feminino & $\%$ & $\begin{array}{l}\text { Desvio de } \\
\text { resíduo }\end{array}$ & p-valor \\
\hline Ausência & 470 & $32 \%$ & 295 & $41 \%$ & 177 & $23 \%$ & 7,13 & $<0,0001$ \\
\hline Depressão Leve & 662 & $45 \%$ & 321 & $45 \%$ & 343 & $46 \%$ & 0,44 & $>0,05$ \\
\hline Depressão & 279 & $19 \%$ & 95 & $13 \%$ & 185 & $25 \%$ & 5,59 & $<0,0001$ \\
\hline \multicolumn{9}{|l|}{ Moderada } \\
\hline Depressão Grave & 59 & $4 \%$ & 9 & $1 \%$ & 45 & $6 \%$ & 4,83 & $<0,0001$ \\
\hline
\end{tabular}




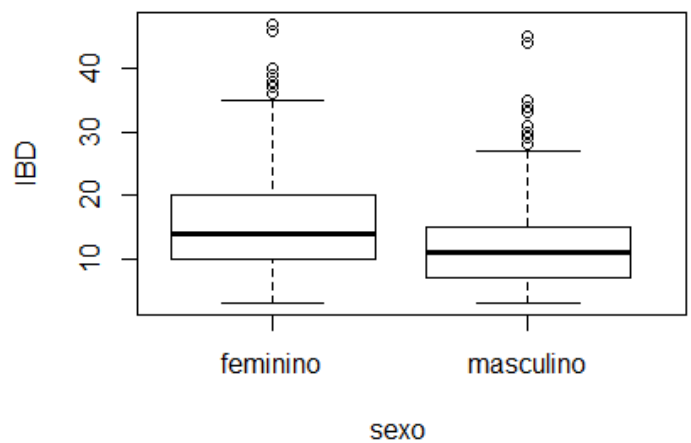

Figura 4: Gradação nos níveis de depressão por sexo.

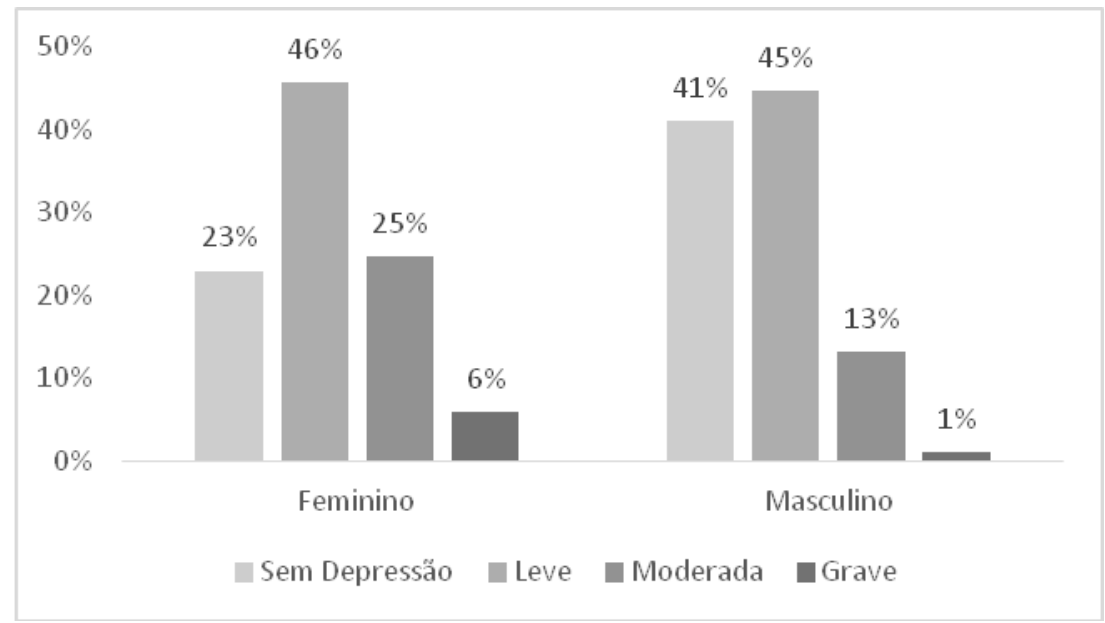

Figura 5: Distribuição da gradação dos estados depressivos por sexo. 


\subsubsection{Prevalência de Depressão por Escola}

No que se refere à análise da gradação de depressão por Escola, verifica-se que a maior prevalência foi verificada na categoria de depressão leve, e essa foi encontrada na Escola 1, única escola particular da pesquisa (52\%). As menores prevalências foram evidenciadas na classificação de depressão grave e apresentaram valores semelhantes em todas as escolas avaliadas. Essas diferenças não foram estatisticamente significativas. (Tabela 9 e Figuras 6 e 7).

\begin{tabular}{|c|c|c|c|c|c|c|c|c|}
\hline & Ausência & $\%$ & Leve & $\%$ & Moderada & $\%$ & Grave & $\%$ \\
\hline $\begin{array}{l}\text { Escola } \\
1\end{array}$ & 75 & 30 & 129 & 52 & 40 & 16 & 6 & 2 \\
\hline $\begin{array}{l}\text { Escola } \\
2\end{array}$ & 65 & 37 & 81 & 46 & 25 & 14 & 6 & 3 \\
\hline $\begin{array}{l}\text { Escola } \\
3\end{array}$ & 57 & 33 & 81 & 48 & 29 & 17 & 3 & 2 \\
\hline $\begin{array}{l}\text { Escola } \\
4\end{array}$ & 85 & 29 & 144 & 48 & 55 & 19 & 12 & 4 \\
\hline $\begin{array}{l}\text { Escola } \\
5\end{array}$ & 97 & 35 & 107 & 38 & 66 & 23 & 12 & 4 \\
\hline $\begin{array}{l}\text { Escola } \\
6\end{array}$ & 93 & 32 & 122 & 41 & 65 & 22 & 14 & 5 \\
\hline$p$-valor & 0,4581 & & 0,01827 & & 0,07471 & & 0,4976 & \\
\hline
\end{tabular}




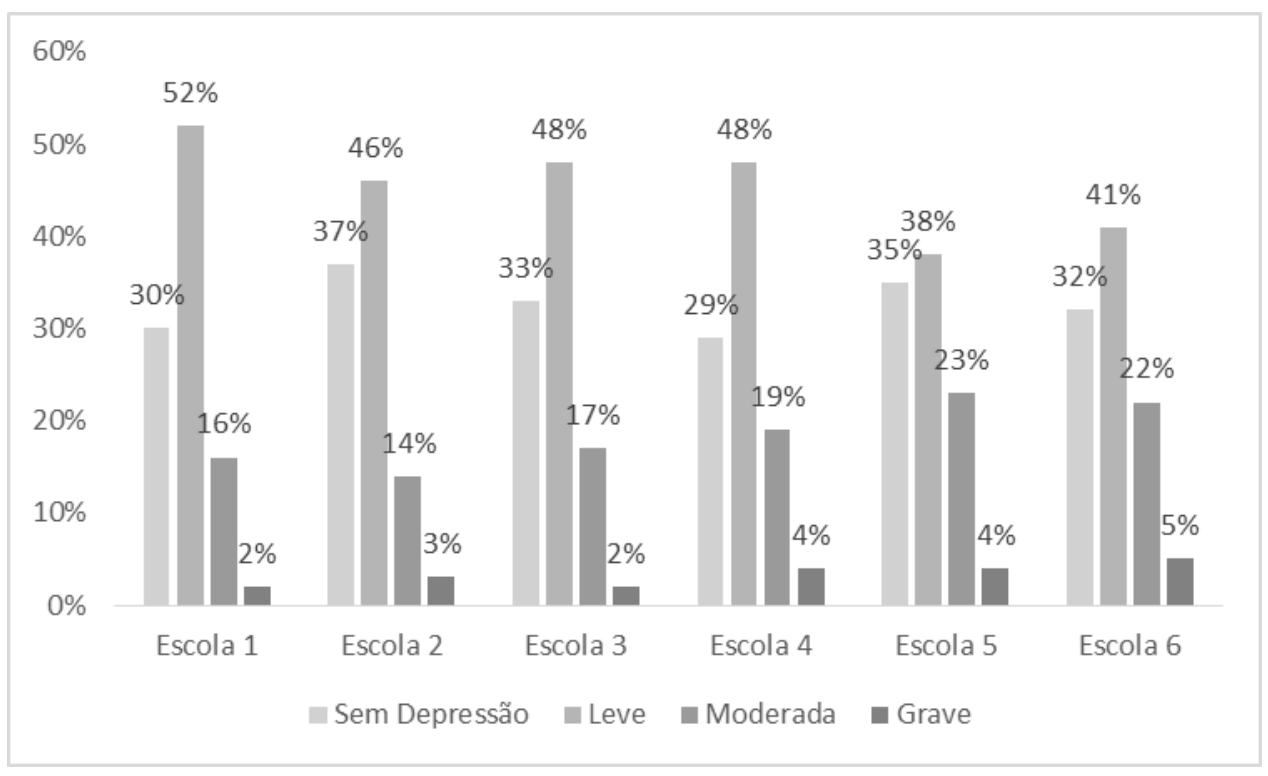

Figura 6: Prevalência de depressão por escola

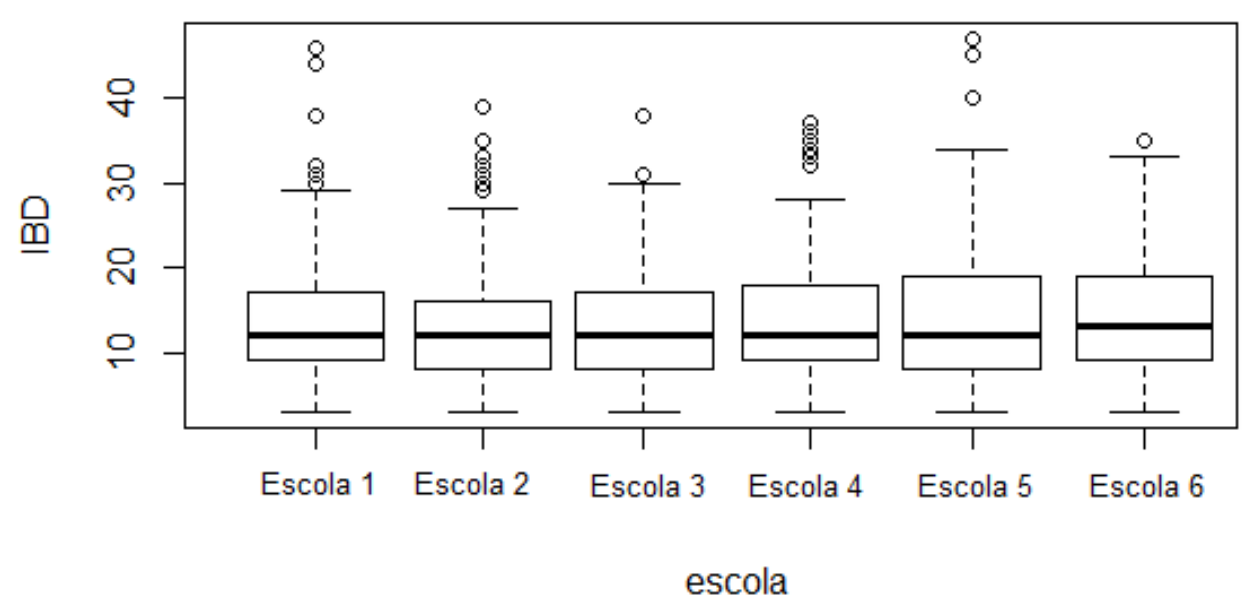

Figura 7: Gradação dos níveis de depressão por escola 


\subsubsection{Prevalência de Depressão por Idade}

Em relação à análise de gradação de depressão por idade (Tabela 10), foi verificada a predominância da forma leve em todas as faixas etárias e estas foram semelhantes entre os sexos, com maior prevalência nas meninas; exceto na faixa etária de 10 a 12 anos. Essas diferenças não foram estatisticamente significativas $(p>0,05)$. Já para as formas de depressão moderada e grave, foram verificadas prevalências superiores no sexo feminino, com destaque para a depressão grave na faixa etária de 16 a 19 anos, que foi 10,48 vezes superior ao resultado encontrado nos meninos $(p<0,05)$.

Tabela 10 - Classificação dos níveis de depressão por idade

\begin{tabular}{|c|c|c|c|c|c|c|c|c|}
\hline \multirow{2}{*}{$\begin{array}{l}\text { Faixa } \\
\text { Etária }\end{array}$} & \multicolumn{8}{|c|}{10 a 12 anos } \\
\hline & Ausência & $\%$ & Leve & $\%$ & Moderada & $\%$ & Grave & $\%$ \\
\hline Masculino & 75 & 42,13 & 82 & 46,07 & 20 & 11,24 & 1 & 0,56 \\
\hline Feminino & 57 & 30,81 & 85 & 45,95 & 38 & 20,54 & 5 & 2,70 \\
\hline p-valor & \multicolumn{2}{|c|}{0,02} & \multicolumn{2}{|c|}{$>0,05$} & \multicolumn{2}{|c|}{0,01} & \multicolumn{2}{|c|}{$>0,05$} \\
\hline Faixa & \multirow{2}{*}{\multicolumn{8}{|c|}{13 a 15 anos }} \\
\hline Etária & & & & & & & & \\
\hline & Ausência & $\%$ & Leve & $\%$ & Moderada & $\%$ & Grave & $\%$ \\
\hline Masculino & 137 & 39,94 & 155 & 45,19 & 45 & 13,12 & 6 & 1,75 \\
\hline Feminino & 74 & 20,50 & 167 & 46,26 & 91 & 25,21 & 29 & 8,03 \\
\hline
\end{tabular}


Conclusão

Tabela 10-Classificação dos níveis de depressão por idade

Faixa

13 a 15 anos

Etária

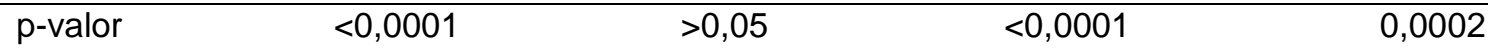

Faixa

16 a 19 anos

Etária

\begin{tabular}{|c|c|c|c|c|c|c|c|c|}
\hline & Ausência & $\%$ & Leve & $\%$ & Moderada & $\%$ & Grave & $\%$ \\
\hline Masculino & 80 & 41,24 & 83 & 42,78 & 30 & 15,46 & 1 & 0,52 \\
\hline Feminino & 44 & 21,78 & 91 & 45,05 & 56 & 27,72 & 11 & 5,45 \\
\hline p-valor & $<0,05$ & & & & 0,00 & & & \\
\hline
\end{tabular}

\subsubsection{Prevalência de Depressão por Estado Conjugal dos Pais}

Quanto às análises de gradação de depressão de acordo com o estado conjugal dos pais (Tabela 11 e Figuras 8 e 9), verifica-se que as maiores prevalências de depressão ocorreram na forma leve e no grupo de adolescentes que possuíam pais falecidos $(71 \%)$ ou pais solteiros (que nunca viveram juntos $(55 \%)$. Prevalências elevadas para depressão leve e moderada também foram observadas nos adolescentes que referiram ter pais separados ou divorciados $(43 \%$ e $25 \%$, respectivamente). Já as menores prevalências ocorreram entre os adolescentes que referiram ter pais casados/unidos consensualmente $(<1 \%)$. Todas essas proporções apresentaram diferenças estatisticamente significativas $(p<0,05)$. 
TABELA 11- Classificação dos níveis de depressão segundo o estado conjugal dos pais

\begin{tabular}{|c|c|c|c|c|c|c|c|c|c|c|c|c|c|}
\hline & Ausência & $\%$ & $\begin{array}{l}\begin{array}{c}\text { Desvio do } \\
\text { resíduo }\end{array} \\
\end{array}$ & Leve & $\%$ & $\begin{array}{l}\text { Desvio do } \\
\text { resíduo }\end{array}$ & Moderada & $\%$ & $\begin{array}{l}\text { Desvio do } \\
\text { resíduo }\end{array}$ & Grave & $\%$ & $\begin{array}{l}\text { Desvio do } \\
\text { resíduo }\end{array}$ & $\mathrm{P}-$ valor \\
\hline Falecidos & 0 & 0 & $-1,82$ & 5 & 71 & 1,39 & 2 & 29 & 0,64 & 0 & 0 & $-0,52$ & 0,00044 \\
\hline $\begin{array}{l}\text { Casados e Unidos } \\
\text { Consensualmente }\end{array}$ & 340 & 0,36 & 3,98 & 426 & 0,45 & $-0,59$ & 158 & 0,17 & $-3,32$ & 31 & 0,03 & $-1,36$ & 0,0004 \\
\hline Divorciados/Separados & 95 & 28 & $-1,9$ & 146 & 43 & $-1,02$ & 85 & 25 & 3,13 & 15 & 4 & 0,72 & 0,00044 \\
\hline $\begin{array}{l}\text { Solteiros, nunca } \\
\text { viveram juntos }\end{array}$ & 20 & 18 & 3,13 & 59 & 55 & 2,03 & 25 & 23 & 1,11 & 4 & 4 & $-0,02$ & 0,00044 \\
\hline Viúvo & 16 & 34 & 0,29 & 23 & 49 & 0,51 & 6 & 13 & $-1,11$ & 2 & 4 & 1,65 & 0,00044 \\
\hline Outros & 0 & 0 & $-2,18$ & 5 & 50 & 0,3 & 4 & 40 & 1,69 & 1 & 10 & 1,04 & 0,0004 \\
\hline
\end{tabular}




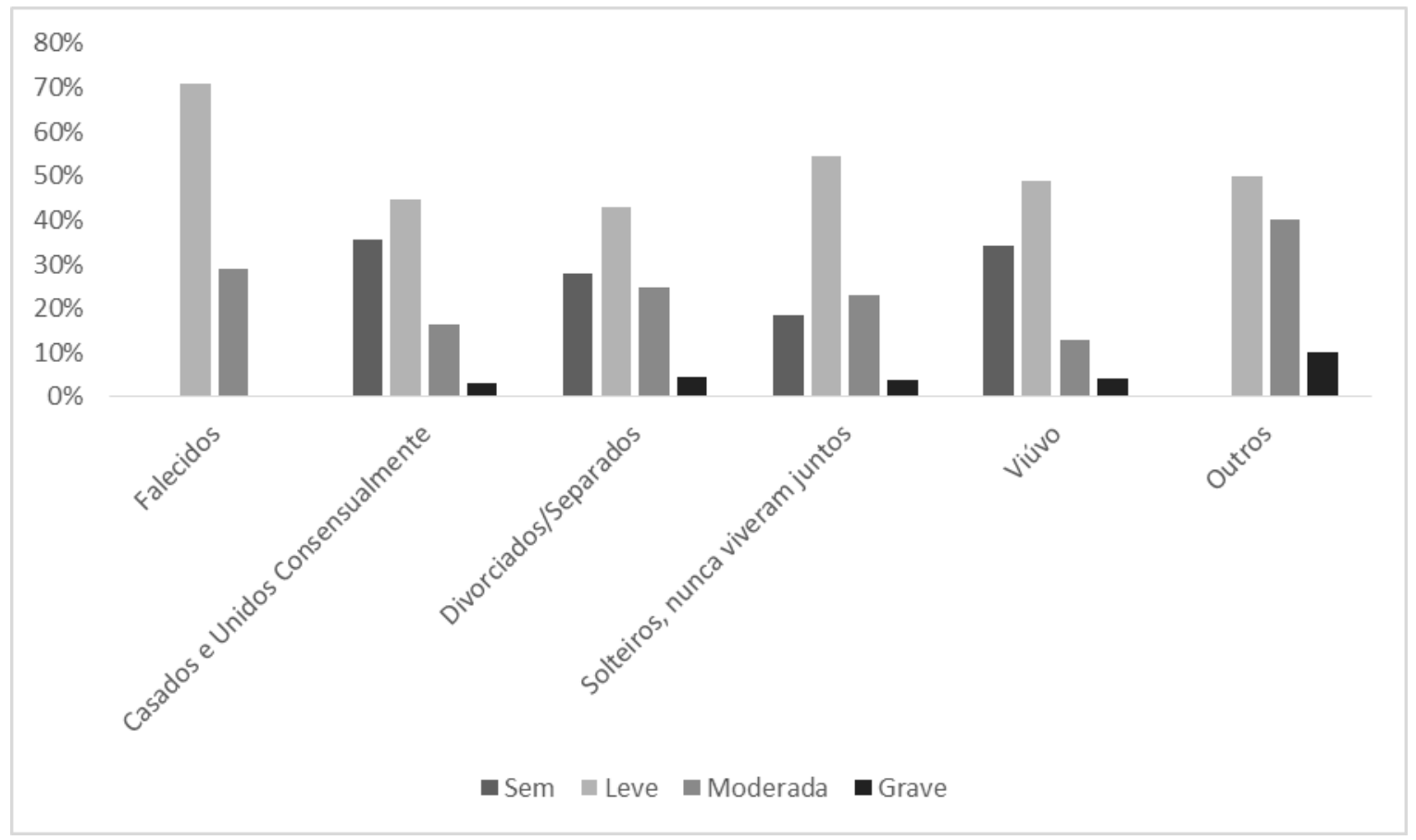

Figura 8: Prevalência de depressão segundo o estado conjugal dos pais

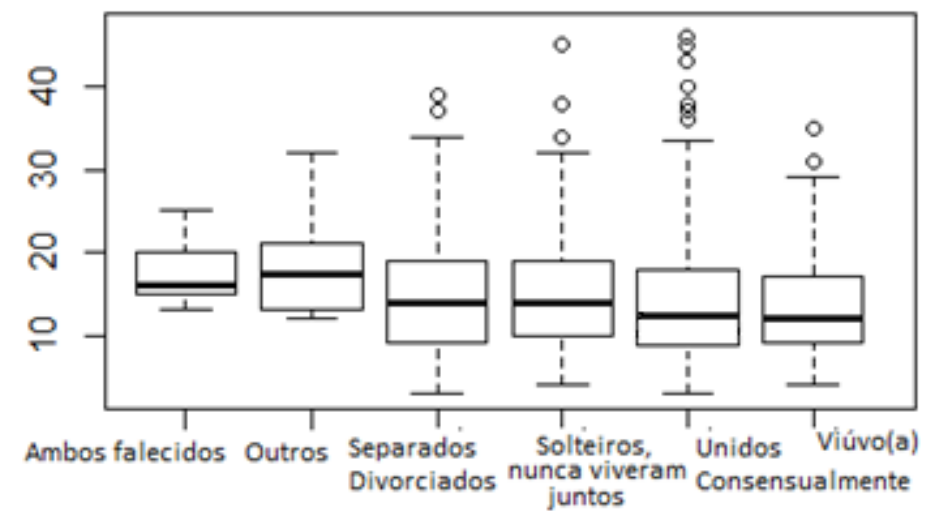

Figura 9: Gradação dos níveis de depressão segundo o estado conjugal dos pais. 


\section{DISCUSSÃO:}

O presente estudo foi desenvolvido seguindo-se critérios metodológicos rigorosos; no entanto, apresenta algumas limitações que merecem ser mencionadas para a interpretação dos resultados. Em relação à estas, verifica-se que os dados foram coletados apenas na população de adolescentes em ambiente escolar, desconsiderando aqueles que não frequentavam a escola no período da pesquisa. Outro aspecto que comprometeu a randomização foi o fato de duas escolas privadas terem recusado à participação na pesquisa, restando, apenas, uma dentre as três selecionadas de início . O estudo não previu a reposição em caso de recusa. Tal situação reduz a amostra dos estudantes de renda mais alta.

\subsection{CARACTERÍSTICAS SÓCIODEMOGRÁFICAS}

No que se refere às principais características sóciodemográficas, verifica-se que houve uma pequena diferença de proporção entre os sexos masculino e feminino, mas essa diferença não foi estatisticamente significativa. Verificou-se, ainda, que estes dados estão em consonância com a distribuição entre os sexos no Brasil e no Distrito Federal, de acordo com as pesquisas nacionais e regionais da época, que apresentaram os resultados de $48,5 \%$ para a população masculina e $51,5 \%$ para a população feminina; (PNAD-IBGE, 2009)(57) e $47,47 \%$ para a população masculina e $52,33 \%$ para a população feminina (PDAD - CODEPLANDF, 2009) (58) respectivamente. Esse achado foi importante, porque evidencia o caráter representativo da amostra para adolescentes escolares do DF, o que sugere 
que os resultados possivelmente seriam semelhantes se o estudo tivesse incluído, também, adolescentes não matriculados em escolas do DF.

Quanto à análise de depressão por faixa etária, verificou-se que as maiores prevalências foram encontradas na população feminina, exceto para a depressão leve nas faixas etárias de 10 a 12 anos. O destaque ocorreu para a classificação da depressão grave, que foi 10 vezes maior nas meninas, na faixa etária de 10 a 19 anos. Já com relação à distribuição dos adolescentes por Região Administrativa, evidenciou-se que, a maior prevalência de depressão leve $(52 \%)$ foi verificada no Plano Piloto, evidenciada na única escola particular que participou da pesquisa. Uma possível explicação para este achado é que algumas características disciplinares desta escola possa estar relacionada com a o surgimento de alguns sintomas depressivos, já que ela é essencialmente voltada para o treinamento e capacitação de alunos para o enfrentamento de vestibulares dos cursos mais concorridos das universidades federais. Esses fatores podem atuar como agentes estressores para os jovens.

Já as maiores prevalências para os níveis de depressão moderada (23\%) e grave $(5 \%)$ foram encontradas no Riacho Fundo II e no Recanto das Emas, que ocuparam o Grupo III (Baixa Renda), no ranking de renda per capita. Entretanto, foi possível verificar que as proporções de depressão grave foram mais representativas no Recanto das Emas, cuja renda era a mais baixa dentre as regiões administrativas avaliadas. Este resultado corrobora os achados de LOPES et al (37) e CASTRO et al (38) , que verificaram que as baixas condições econômicas e de escolaridade dos pais, além de conflitos familiares e conjugais, estavam associados a problemas de comportamento na adolescência. Além disso, de acordo com esses autores, o capital econômico apresenta um profundo impacto na saúde e está frequentemente associado a outros fatores, tais como o baixo nível de educação dos pais. Portanto, uma educação parental baixa ou inconsistente, aliada a uma exposição constante a eventos estressores, pode apresentar efeitos relevantes no desempenho escolar e no funcionamento sócio emocional do adolescente. Neste estudo, verificou-se que $65,3 \%$ dos pais e $61,1 \%$ das mães dos adolescentes não possuíam ensino superior. 
A renda das famílias, entretanto, não foi diretamente avaliada nesta pesquisa, considerando-se apenas o ranking das regiões adminstrativas do DF.

Apesar da maior quantidade de adolescentes ter afirmado que possuíam pai e mãe vivendo juntos $(58,2 \%)$, a avaliação comparativa entre o estado conjugal dos pais dos adolescentes e a prevalência de depressão evidenciou que os índices mais elevados deste agravo, nas classificações moderada e grave, ocorreram entre os jovens que possuíam um ou ambos os pais ausentes. Esse achado sugere que a ausência de um, ou de ambos, parece estar relacionada com a maior prevalência de depressão. Esse achado está de acordo com o estudo conduzido por DAMIÃO et al (23), que referiu que esta condição pode favorecer flutuações de humor e mudanças expressivas no comportamento que, por conseguinte, colaboram para a instalação da sintomatologia depressiva.

Os adolescentes que possuíam pais casados ou unidos consensualmente apresentaram as menores prevalências de depressão para os três níveis avaliados (Tabela 14). Esses resultados estão em consonância com o estudos conduzidos por BRAGA E DELL'AGLIO (40) e WERLANG (43),que referem que o adolescente que tem relacionamentos familiares afetuosos e próximos possuem mais condições de enfrentar experiências estressantes do que aqueles sem tal apoio. Para estes autores, o apoio familiar se constitui em um importante fator de proteção na adolescência contra a depressão.

Portanto, as características da família, da educação e do funcionamento familiar parecem influenciar o bem-estar emocional do adolescente, sobretudo no que se refere à sensibilidade $e$ à resposta às necessidades dele. BROFENBRENNER $(14,15,16,17,18,19)$ refere que, durante a adolescência, a família continua a ser considerada como o principal microssistema do desenvolvimento, pois nela ocorrem as interações mais diretas e as experiências mais significativas para o adolescente. Nesse sentido, a percepção de competência parental, por parte dos pais, apresenta-se como um papel protetor aos distúrbios do humor, em que são evitados os comportamentos marcados por agressividade, hostilidade, comprometimentos punitivos e manipulativos (44). 


\subsection{AUTO AVALIAÇÃO DO ESTADO DE SAÚDE}

De modo geral, os adolescentes apresentaram resultados satisfatórios quanto à auto- avaliação de seus estados de saúde $(88,8 \%)$, além de afirmarem, em sua maioria, que possuem várias qualidades boas $(96,6 \%)$ e que buscam atitudes voltadas para o crescimento individual $(94,4 \%)$. Estes dados estão em consonância com os achados de SOUZA et al (45), e podem sugerir que os adolescentes, mesmo sofrendo de agravos ou de alguns sintomas depressivos, não consideram que estes chegam a influenciar a sua qualidade de vida. Em contrapartida, foram evidenciadas proporções elevadas de sintomas relacionados à baixa auto estima, uma vez que $81,4 \%$ dos jovens referiram que gostariam de se valorizar mais.

\subsection{DESCRIÇÃO DOS SINTOMAS DEPRESSIVOS}

Determinar a intensidade dos sintomas depressivos é importante para verificar o estágio da depressão e avaliar o seu desfecho, trazendo impactos positivos tanto para propósitos clínicos quanto de pesquisa.

No presente estudo, foi evidenciado que $32 \%$ dos adolescentes avaliados não apresentaram sintomas depressivos, ao passo que $45 \%$ apresentaram depressão leve, $19 \%$ depressão moderada e $4 \%$ depressão grave. Com relação à classificação por gênero, foi evidenciada uma maior prevalência de depressão moderada e grave no sexo feminino, com resultados de $25 \%$ e $6 \%$, respectivamente, do que no sexo masculino, cujas proporções foram de 13\% e 1\%, para as mesmas variáveis. Estes achados estão compatíveis com os estudos de BRAGA E DELL'AGLIO (40), LOPEZ 
et al. (36), DAMIÃO et al (23) e ARGIMON et al. (25). Todos esses autores também registraram maiores proporções de depressão no sexo feminino.

Além disso, os sintomas de depressão que receberam a maior pontuação no BDI foram mais prevalentes, em sua maioria, na população feminina. Esses achados estão possivelmente relacionados ao maior grau de sensibilidade das meninas na adolescência, e também à questões históricas do papel da mulher na sociedade, por séculos relegada a uma condição de inferioridade. Além disso, as adolescentes podem apresentar sintomas depressivos devido à baixa auto estima causada pelos estereótipos atuais de beleza desejável, que são, muitas vezes, difíceis ou impossíveis de serem alcançados visto que com a introdução do foto shop, os padrões de beleza passaram a ser ainda mais artificiais Tais resultados também são importantes para a tomada de decisões quanto às ações de prevenção do agravo e para o empoderamento feminino, que deve ser levado em consideração nas ações de promoção da saúde implantadas na atenção primária.

Para os resultados acima descritos, há alguns autores que registraram resultados semelhantes. BRAGA E DELL'AGLIO (40), por exemplo, justificam que as meninas investem mais do que os meninos em seus relacionamentos afetivos, como fonte de apoio emocional e de intensidade pessoal. Em decorrência disso, elas sentem, em maior intensidade, o estresse interpessoal como uma ameaça ao seu próprio bem estar. Nesse sentido, em situações de conflito com os pais e companheiros, as meninas experienciam níveis de estresse interpessoal mais alto do que os meninos, mostrando-se mais vulneráveis e reagindo, com maior frequência, com respostas depressivas ao estresse (25).

SOUZA et al (44) também apontam diferença entre os sexos, ao referir que há uma maior prevalência de desordens internalizantes, como a depressão, entre as meninas, e desordens externalizantes, como o uso da distração e expressão de sentimentos por meio de comportamentos agressivos e abuso de álcool e drogas, entre os meninos. Já os achados de LOPEZ et al (36) sugeriram que as adolescentes apresentaram quase 3 vezes mais probabilidade de depressão do que os jovens do gênero masculino. Para os autores, a prevalência de sintomas depressivos entre as meninas está relacionado ao modo específico do 
funcionamento neuro-hormonal feminino. Este autor sugere, também, que as meninas buscam, de um modo mais enfático, o auto conhecimento; e, por conseguinte, possuem maior consciência de seus estados internos.

Chama a atenção o fato da resposta "eu quero me matar" ter apresentado um resultado quase 3 vezes maior nas meninas $(2 \%)$ do que nos meninos (1\%), dentre os 19 adolescentes que marcaram esta questão. Trata-se de um aspecto preocupante, pois de acordo com SOUZA et al (44), o suicídio é a quarta principal causa de morte entre os adolescentes, perdendo apenas para os acidentes de trânsito e os homicídios. De acordo com BRAGA e DELL'AGLIO (40), o comportamento suicida pode ser dividido em três categorias: ideação suicida (pensamentos, idéias, planejamento e desejo de se matar), tentativa de suicídio e suicídio consumado. Nesse sentido, a ideação suicida é um importante preditor de risco para o suicídio, sendo considerado o primeiro passo para a sua completa efetivação (43), o que requer atenção especial da família e da escola para a tomada de consciência do fato, aliada a medidas preventivas.

Nesta pesquisa, foram encontrados sintomas depressivos relacionados à ideação suicida semelhantes ao de outros autores. São eles: sentimentos de tristeza $(20,1 \%)$, pessimismo $(3,7 \%)$, diminuição do interesse ou prazer $(2,0 \%)$, perda de apetite $(11,4 \%)$, problemas de sono $(6,3 \%)$ e baixa capacidade de concentração (24,6\%). Segundo os pesquisadores BRAGA E DELL'AGLIO (40), SENNA (5), LOPEZ et al (37) e DAMIÃO et al (23), a adolescência é considerada um período propício para as tentativas de suicídio. Estes autores referem, ainda, que um dos principais fatores de proteção contra as tentativas de suicídio foi o relacionamento satisfatório com os pais, aliado a níveis altos de autoestima. Nessa pesquisa, os achados referentes a esses sintomas (auto-aversão e baixa autoestima), em seus níveis mais graves, foram de $1,5 \%$ e $9,0 \%$, respectivamente. Dessa maneira é possível inferir que, ainda que o conceito de família tenha se pluralizado nas últimas décadas e que as configurações familiares atuais sejam mais diversificadas (famílias nucleares, monoparentais, reconstituídas, ou configuradas por genitores do mesmo gênero), a importância dessa instituição para o desenvolvimento adequado de seus membros ainda persiste. Portanto, o vínculo emocional entre os membros de uma 
família, seja ela nuclear ou não, continua apresentando a função protetora na adolescência, inclusive para o pensamento suicida (25).

No presente estudo, a prevalência de pais divorciados foi de $23,3 \%$ e, de falecidos, 3,7\%; o que sugere a necessidade um suporte social e familiar para os adolescentes que se encontraram nesta situação. De acordo com SENNA (5), a maioria dos estudos atuais sobre vínculos familiares defendem a ideia de que a configuração da família não é o que determina o desenvolvimento adequado de seus membros, e sim a sua dinâmica e a qualidade do vínculo familiar. Este autor referiu que adolescentes oriundos de famílias nucleares apresentaram menos incidência de tentativa de suicídio do que adolescentes oriundos de famílias de pais divorciados ou de famílias nas quais um membro importante já havia falecido.

Ainda com relação ao suicídio, BRAGA E DELL'AGLIO, (40) referem que, apesar de algumas divergências, é consenso que o suicídio é um fenômeno multideterminado, que está presente em todas as faixas etárias, culturais e sociais e constitui-se em um tema de grande complexidade, o que dificulta que os pesquisadores estabeleçam uma relação causal entre o ato (suicídio consumado) e um motivo causador. Tendo em vista que muitos indivíduos em risco de suicídio não são identificados ou, muitas vezes, a identificação ocorre em caráter tardio, são necessários esforços com 0 intuito de identificar e manejar fatores de risco referentes a esse comportamento (43).

De acordo com BRAGA E DELL'AGLIO (40), há alguns fatores protetores relacionados à menor ocorrência de suicídio consumado entre as mulheres, dentre os quais, destacam-se: a baixa prevalência de alcoolismo, as crenças religiosas e as atitudes flexíveis em relação às aptidões sociais e ao desempenho de papéis ao longo da vida. Soma-se a isso o fato de que as mulheres, de uma maneira geral, identificam os sintomas de depressão ou de outras doenças em caráter mais precoce e, por conseguinte, estão mais propensas a buscar ajuda em momentos de crise e possuem uma rede de apoio social e afetiva mais ampla do que a dos homens. 
Em contrapartida, os papéis atribuídos à masculinidade envolvem aspectos que podem predispor os homens a comportamentos suicidas. Tais aspectos podem incluir a competitividade, a impulsividade e o maior acesso a tecnologias letais e às armas de fogo. Além disso, os homens são mais sensíveis a aspectos relacionados ao trabalho, ao desemprego e ao empobrecimento, o que justifica, em parte, as maiores taxas de ideações suicidas no sexo feminino; já que, essas situações, em geral, ocorrem, com menor frequência no período da adolescência (BRAGA E DELL'AGLIO (40).

A maioria dos estudos sobre suicídio menciona a depressão como um dos fatores de risco ao suicídio em todas as faixas etárias. Desse modo, o estudo sobre depressão na adolescência torna-se relevante, principalmente por considerar que este transtorno desempenha um importante papel diante de vários agravos à saúde.

Observa-se que os resultados encontrados no presente estudo, comparados aos verificados na literatura mundial e brasileira, corroboram os aspectos sociais enfatizados nos modelos teóricos desenvolvidos por Erikson e os desenvolvidos posteriormente para explicar as mudanças encontradas na adolescência e muitos dos sintomas de depressão encontrados nessa fase da vida. 


\section{CONSIDERAÇÕES FINAIS E RECOMENDAÇÕES}

A depressão é uma doença do organismo como um todo, a qual compromete o funcionamento físico, o humor e, por conseguinte, o pensamento. Ela altera a maneira como o indivíduo enxerga o mundo e sente a realidade, entende as coisas, manifesta emoções, sente a disposição e o prazer com a vida. Portanto, a depressão é uma doença afetiva ou do humor, sendo classificada como um transtorno psiquiátrico que exige tratamento. No entanto, de acordo com os achados deste e de outros estudos, parece que determinantes sociais como o arranjo familiar, condição socioeconômica e outros influenciam o aparecimento e a intensidade dos sintomas depressivos ou o agravo propriamente dito. Esse fato requer uma atenção especial, visto que necessita da integração de vários setores e modificações estruturais intensas para o seu enfrentamento.

Dentre os fatores individuais que parecem fornecer um papel protetor para o surgimento de depressão em adolescentes destacam-se: o sucesso na vida escolar, o envolvimento em atividades extracurriculares, a competência social, a auto percepção positiva, a competência intelectual, as relações sociais confiantes e os suportes sociais adequados. Portanto, a maior ou menor probabilidade de surgimento de depressão pode ser vista como o resultado da interação de uma série de condições ambientais, de modo especial o estresse, as perdas e as predisposições individuais.

Adolescentes com transtorno depressivo apresentam, em geral, humor irritável e instável, com frequentes episódios de explosão e de raiva. Nessa pesquisa, os índices relacionados a esse sintoma foram de 20,4\%; o que pode sugerir a necessidade de intervenção de caráter multidisciplinar e acompanhamento deste grupo, por parte da família, da escola, do sistema de saúde e das instituições de suporte psicossocial. Tais medidas podem contribuir como importante ferramenta de prevenção ao desenvolvimento da depressão. 
Com relação aos aspectos preventivos e de tratamento da depressão na adolescência, destaca-se a necessidade de capacitação dos profissionais da área de educação e da área de saúde para a identificação precoce e o manejo dos sintomas. Destaca-se ainda a importância do aprimoramento e do avanço nos estudos sobre os medicamentos antidepressivos específicos para essa faixa etária, já que a maior disponibilidade desses medicamentos em serviços de saúde poderia auxiliar na redução dos agravos e dos casos de suicídio entre os adolescentes. Entretanto, é importante considerar, também, que a intervenção nos determinantes sociais poderia prevenir o agravo, sendo essa a ação mais importante para evitar a medicalização deste grupo etário.

Neste estudo foi destacada a importância da identificação dos sintomas depressivos e da gradação dos níveis de depressão; entretanto, é preciso considerar, também, que o conhecimento a respeito dos fatores de proteção à depressão na adolescência é de vital importância para que estratégias de prevenção sejam construídas e para que seja possível atenuar os efeitos dos principais fatores de risco para a instalação da sintomatologia depressiva. Ações que envolvam a família devem estar na pauta das intervenções de promoção da saúde e nas atividades das escolas.

A depressão na adolescência é preocupante devido à sua prevalência elevada e à tendência de o transtorno apresentar longa duração e recorrência, o que acarreta disfunções sociais e ocupacionais mais prolongadas, e envolve um alto grau de morbidade e risco dos indivíduos afetados atentarem contra a própria vida. Além disso, o desenvolvimento de transtornos mentais pode acarretar diversos danos psicossociais para o adolescente, extrapolando, inclusive, o âmbito individual, pois o aumento da depressão pode trazer danos à sociedade, visto que o agravo acomete jovens no início de sua entrada no mercado de trabalho, o que acarreta um aumento dos custos com a saúde e no sistema de previdência social.

O estudo foi conduzido de forma a atingir os objetivos propostos, com destaque para a identificação dos diferentes níveis de depressão, bem como a percepção do estado geral de saúde entre os adolescentes. O conhecimento desses fatores é relevante para o desenvolvimento de ações de proteção à depressão na 
adolescência, além de serem úteis para orientar ações de políticas públicas e de práticas promotoras da saúde. Entretanto, os achados desta pesquisa sugerem a necessidade de mais estudos, incluindo análises de triangulação metodológica sobre depressão em adolescentes, com abrangência nacional, a fim de aprofundar o conhecimento do agravo e possibilitar a proposição de estratégias de Saúde Coletiva mais amplas, com vistas à prevenção e intervenção neste transtorno junto a esta faixa etária da população brasileira.

Em um momento em que se discute a redução da maioridade penal, é possível que dados de saúde mental, como os apresentados, possam fortalecer a reflexão no sentido de mudar as condições dos jovens brasileiros e a mentalidade da população sobre a violência juvenil, visto que os adolescentes são vítimas e não culpados, uma vez que a sociedade que os marginaliza e não oferece opções de vida, é a mesma que os criminaliza, responsabilizando-os por eventos danosos à sociedade. Dessa forma, torna-se necessário o fortalecimento das redes de apoio a este grupo populacional, com envolvimento expressivo da família, grupos de pares e também da escola, a fim de que relacionamentos satisfatórios e de maior bem-estar sejam construídos, uma vez que as relações pessoais e a percepção de apoio por parte dos adolescentes é crucial nesta etapa da vida.

É preciso também que governos e políticos, que detém o poder de mudar, de fato, as condições dos jovens não enfatizem discursos eleitoreiros, ouvindo uma população cansada e desinformada, que projeta em inocentes a sua indignação por toda uma situação política e social resultante de gestão deficitária, decorrente de interesses pessoais e sede de poder. 


\section{REFERÊNCIAS:}

1. Eisenstein, E. 2005: Adolescência: Definições, conceitos e critérios. Revista Adolescência e Saúde; 2005; 2 (2), 6-10.

2. Davim, R.M.B; Germano, R.M.; Menezes, R.M.V.; Carlos, D.J.D. Adolescente/Adolescência: revisão teórica sobre uma fase crítica da vida. Rev. Rene Fortaleza;2009;10 (.2):131-140.

3. World Health Organization. Child and Adolescents Mental Health. WHO;2013. [Acesso em 24 de Maio de 2013] Disponível em:

http://www.who.int/mental health/maternal-child/child adolescent/en/

4. Presidência da República. Casa Civil. Subchefia para assuntos jurídicos. Lei 8069, de 13 de Julho de 1990: Dispõe sobre o Estatuto da Criança e do Adolescente e dá outras providências[Acesso em 24 de Maio de 2013] Disponível em: http://www.planalto.gov.br/ccivil 03/Leis/18069.htm

5. Senna, S.R.C.M.;Dessem, M.A. Contribuições das Teorias do Desenvolvimento Humano para a Concepção Contemporânea da Adolescência. Psicologia: Teoria e Pesquisa; 2012; 28 (1): 101-108.

6. Hall, G. S. Adolescence: Its psychology and its relations to physiology, anthropology, sociology, sex, crime, religion and education.New York, D. Appleton and Company, 1904.

7. Freud, S. Análise Terminável e Interminável. Edição Standard Brasileira das Obras Psicológicas Completas. Rio de Janeiro: Imago, 1996.

8. Erikson, E. H. Identidade, Juventude e Crise. Rio de Janeiro: Zahar Editores, 1976.

9. Mead, M. Adolescencia, sexo y cultura em Samoa.Paidos Studio,1928. 
10. Piaget, J.W.F. Teoria da Aprendizagem na Obra de Jean Piaget. São Paulo. UNESP, 2009.

11. Cairns, Robert B., Glen H. Elder, and E. Jane Costello. Developmental science. Cambridge University Press, 2001.

12. Dessen, M.A. \& Costa Júnior, A.L. (Orgs.): A Ciência do Desenvolvimento Humano: Tendências Atuais e Perspectivas Futuras. Porto Alegre: Artmed; 2005.

13. Elder Jr, G. H: Human lives in changing societies: Life course and developmental insights. Em R. B. Cairns, G. H. Elder \& E. J. Costello (Orgs.), Developmental science (pp. 31-62). New York: Cambridge University Press;1996

14. Bronfenbrenner, U. Toward an experimental ecology of human development. American Psychologist;1997. 32,513-531.

15. Bronfenbrenner, U:Ecological system theory. Em R. Vasta (Org.), Six theories of child development ;1992. London: Jessica Kingsley. P.187-243

16. Bronfenbrenner, U: Ecological models of human development. Em T. Husten \& T. N. Postelethwaite (Orgs.), International Encyclopedia of Education. New York: Elsevier Science; 1994; p.1643-1647.

17. Bronfenbrenner, U.: A ecologia do desenvolvimento humano: experimentos naturais e planejados. (M. A. Verríssimo, Trad.) Porto Alegre: Artes Médicas. (Trabalho original publicado em 1979)

18. Bronfenbrenner, U. \& Ceci, S.: Nature-Nurture reconceptualized in developmental perspective: A bioecological model. Psychological Review;1994. 101, 568-586.

19. Bronfenbrenner, U. \& Morris, P. A.: The ecology of developmental process. Em W. Damon \& R. M. Lerner (Orgs.), Handbook of child psychology: Vol. 1. Theoretical models of human development. New York: Wiley; 1998. P.992-1028 
20. Lerner, R. M., Phelps, E., Forman, Y., \& Powers, E. P.: Positive youth development. In R. M. Lerner, \& L. Steinberg (Eds.), Handbook of adolescent psychology. New York: Wiley; 2009. $3^{\mathrm{a}}$ ed;p.524-558.

21. Lerner, R. M., \& Steinberg, L.: The scientific study of adolescent development: Historical and contemporary perspectives. In R. M. Lerner, \& L. Steinberg (Eds.), Handbook of adolescent psychology. New Jersey: Wiley; 2009. $3^{\text {a }}$ ed.;p. 3-14.

22. Brown, B. B. (2005). Moving forward with research on adolescence: Some reflections on the state of JRA and the state of the field. Journal of Research on Adolescence; 2005. 15 a ed., p. 657-673.

23. Damião, N. F., Coutinho, M. P. I, Carolino, Z. C. G. \& ribeiro, k. C. S. "Representações sociais da depressão no ensino médio: um estudo sobre duas capitais" Psicologia \& Sociedade; 2011. 23 (1): 114-124.

24 World Health Organization. Depression. WHO, 2013. [Acesso em 24 de Maio de 2013]. Disponível em:

\section{http://www.who.int/mediacentre/factsheets/fs369/en/}

25. Argimon, I.I.L.; Terroso, L.B.; Barbosa, A. S.; Lopes, R. M. F. Intensidade de sintomas depressivos em adolescentes através da Escala de Depressão de Beck (BDI-II). Bol. Acad. Paulista de Psicologia, São Paulo, Brasil;2013;.33(85), p. 354372.

26. Oliveira, D.A.A.P.; Gomes, L.; Oliveira, R. F. Prevalência de depressão em idosos que frequentam centros de convivência. Rev. Saúde Pública 2006;40 (4): 734-6.

27. Molina, M.R.A.L.; Wiener, C.D.; Branco, J.C.;Jansen, K.; Souza, L.D.M.; Tomasi, E.; Silva, R.A.; Pinheiro, R.T. Prevalência de depressão em usuários de unidades de atenção primária. Arch. Clin. Psychiatry (São Paulo, Impr.); 201239 (6): 194-197.

28. Kessler RC, Ustun TB. The WHO World Mental Health Surveys: Global Perspectives on the Epidemiology of Mental Disorders. New York (NY): Cambridge University Press; 2011. 
29. Global, regional and national incidence, prevalence and years lived with disability for 301 acute and chronic diseases and injuries im 188 countries, 1990-2013: a systematic analysis for the Global Burden of Disease Study; The Lancet; 2013.

30. World Health Organization: Health Statistics and Information Systems: Metrics: Disability Adjusted Life Years (DALY).WHO, 2014. [Acesso em: 21 de Dezembro de 2014]. Disponível em:

http://www.who.int/healthinfo/global burden disease/metrics daly/en/

31.Chisholm, D. Diehr, M.K.; Patrick D.; Lia, M.T.; Simon, G. Depression status, medical comorbidity and resource costs. Evidence from an international study of major depression in primary care (LIDO). The British Journal os Psychiatry; 2003, 183(2) 121-131;

32. Castro, Stela Maris de Jezus; Trentini, Clarissa; Riboldi, João. Item response theory applied to the Beck Depression Inventory. Revista Brasileira de Epidemiologia; 2010; 13 (3), p. 487-501.

33. Viana, M.C.; Andrade, L.H. Lifetime Prevalence, Age and Gender Distribuition and Age-of-Onset Psychiatric Disorders in the São Paulo Metropolitan Area, Brazil: Results from the "São Paulo Megacity Mental Health Survey". Rev. Bras. Psiquiatr. 2012; 34: 249-260.

34. Patel, V., A. J. Flisher, S. Hetrick, and P. McGorry. Mental health of young people: a global public-health challenge.: The Lancet;2007 v. 369, p. 1302-1313

35. Associação Brasileira de Estudos Populacionais (ABEP). Taxa de Atividade Econômica e Saúde Mental: A Relação entre um choque na atividade econômica e a saúde mental das mulheres maduras. Luiza Pimenta Terra. Trabalho apresentado no XVI Encontro Nacional de Estudos Populacionais,Caxambu- MG - Brasil, 2008. 
36. Lopez, M.R.A.; Ribeiro, J.P.; Ores, L.C.; Jansen, K.; Souza, L.D.M.; Pinheiro, R.C.; Silva, R.A. Depressão e qualidade de vida em jovens de 18 a 24 anos no Sul do Brasil. Ver. Bras. Psiquiatr. Rio Gd Sul. 2011; 33 (2): 103-108.

37. Lopes, Paula, David Pires Barreira, and Ana Matos Pires. "Tentativa de suicídio na adolescência: avaliação do efeito de género na depressão e personalidade." Psicologia, Saúde \& Doenças ; 2001; 2 (1): 47-57.

38. Castro, Stela Maris de Jezus; Trentini Clarissa; Riboldi, João. "Teoria da resposta ao item aplicada ao Inventário de Depressão Beck." Rev. bras. Epidemiol; 2010; 13(3): 487-501.

39. Baptista, Makilim Nunes; Baptista, Adriana Said Daher; Dias, Rosana Righetto. Estrutura e suporte familiar como fatores de risco na depressão de adolescentes. Psicologia: ciência e profissão;2001: 21 (2):. 52-61.

40. Braga, Luiza de Lima; Dell'aglio, Débora Dalbosco. Suicídio na adolescência: fatores de risco, depressão e gênero. Contextos Clínicos;2013: 6 (1): 2-14.

41. Toro, Diana C. et al. Caracterización de adolescentes escolarizados con riesgo de suicidio, Medellín, 2006. Rev. Fac. Nac. Salud Pública;2009: 27, (3): 302-308.

42. Parente, Adriana da Cunha Menezes et al. Caracterização dos casos de suicídio em uma capital do Nordeste Brasileiro. Rev. bras. Enferm;2007: 60 (4): 377-381

43. Werlang, Blanca Guevara; BORGES, Vivian Roxo; Fensterseifer, Liza. Fatores de risco ou proteção para a presença de ideação suicida na adolescência. Revista interamericana de psicologia: Interamerican journal of psychology;2005: 39 (2): 259266.

44. Souza, Edinilsa Ramos; Minayo, Maria Cecília de Souza; Malaquias, Juaci Vitória. "Suicide among young people in selected Brazilian State capitals Suicídio de jovens nas principais capitais do Brasil."Cad. Saúde Pública 2002; 18.(3): 673-683.

45. Souza, Elza Maria; Da Silva Abrão, Fernanda Pires; Oliveira Almeida, Janayana. Desigualdade social, delinquencia e depressão: um estudo com adolescentes em conflito com a lei. Revista de Salud Pública;2011: 13 (1) p. 13-26 
46. American Psychiatric Association: DSM-IV, Diagnostic and Statistical Manual of Mental Disorders ( $4^{\mathrm{a}}$ ed.). Washington, DC:Author, 2000.

47. Organização Mundial da Saúde. CID-10: Classificação Estatística Internacional de Doenças com disquete Vol. 1. Edusp, 1994.

48. Pereira, Priscila Krauss; Lovisi, Giovanni Marcos. Prevalência da depressão gestacional e fatores associados. Rev Psiquiatr Clín;2008: 35 (4): 144-53

49. Silveira, DX da; Jorge, Miguel Roberto. "Propriedades psicométricas da escala de rastreamento populacional para depressão CES-D em populações clínica e nãoclínica de adolescentes e adultos jovens." Psiq Clin 25.5 (1998): 251-261. CES-D

50. Moreno, Ricardo A., Moreno Doris Hupfeld. "Escalas de depressão de Montgomery \& Asberg (MADRS) e de Hamilton (HAM-D)." Revista de Psiquiatria Clínica 25.5 (1998): 262-72. HAM-D

51. Salle, Emilio, et al. "Depression rating scales as screening tools for depression in high school students." Archives of Clinical Psychiatry39.1 (2012): 24-27.

52. Schardosim, Juliana Machado, and Elizeth Heldt. "Escalas de rastreamento para depressão pós-parto: uma revisão sistemática." Rev. Gaúcha Enferm.(Online), Porto Alegre 32.1 (2011).

53. Argimon, I. L. \& Werlang, B. S. G.. Manual do Inventário de Depressão de Beck BDI-II. São Paulo: Casa do Psicólogo, 2011.

54. Beck, A. T., Steer, R. A., \& Brown, G. K. Beck depression inventory-II. San Antonio, 1996.

55. ONU, Conselho de Segurança das Nações. Unidas. Direitos da população jovem: um marco para o desenvolvimento; v.2; 2013.

56. World Health Organization. Child and Adolescents Mental Health. WHO;2013. [Acesso em 24 de Maio de 2013] Disponível em:

http://www.who.int/mental health/maternal-child/child adolescent/en/ 
57. Instituto Brasileiro de Geografia e Estatística: Síntese de indicadores Sociais: Uma análise das condições de vida da população brasileira: IBGE,2013. [Acesso em 24 de Maio2013.].Disponível em:

:http://www.ibge.gov.br/home/estatistica/populacao/condicaodevida/indicadoresmini mos/sinteseindicsociais2008/indic sociais2008.pdf.

58. Companhia de Planejamento do Distrito Federal: Criança e Adolescente no Distrito Federal: CODEPLAN-DF, 2013. [Acesso em 24 de Maio2013.] Disponível em:

http://www.codeplan.df.gov.br/images/CODEPLAN/PDF/Pesquisas\%20Socioecon\% C3\%B4micas/POL\%C3\%8DTICAS\%20SOCIAIS/CriancaeAdolescentenoDF.pdf 


\section{APËNDICE A - QUESTIONÁRIO}

Depressão em adolescentes: um estudo de prevalência no Distrito Federal.

ESTA É UMA PESQUISA DO PROGRAMA DE INICIAÇÃO CIENTÍFICA DA ESCOLA SUPERIOR DE CIÊNCIAS DA SAÚDE/FEPECS/SES-DF. NÓS ESTAMOS INTERESSADOS EM SABER UM POUCO SOBRE COMO SE SENTEM OS ADOLESCENTES E SUA RELAÇÃO COM A FAMÍLIA E A COMUNIDADE. PARA TANTO, GOSTARÍAMOS DE CONVIDAR VOCÊ A RESPONDER ALGUMAS PERGUNTAS. O CARÁTER DAS QUESTÕES É EXTRITAMENTE CONFIDENCIAL, A SUA IDENTIDADE NÃO SERÁ DIVULGADA.

SUA OPINIÃO É EXTREMAMENTE IMPORTANTE. NÓS LHE AGRADECEMOS PELA PARTICIPAÇÃO NESSE ESTUDO!

NOME DA ESCOLA

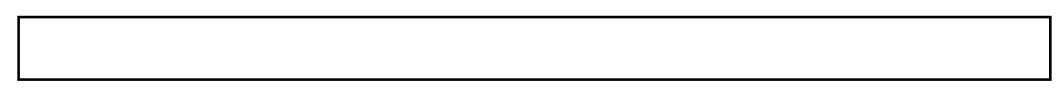

SÉRIE

TURMA

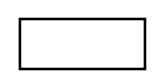

PERÍODO

$\square$ MANHÃ

TARDE

INÍCIO DA ENTREVISTA

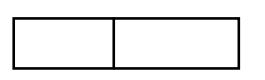

TÉRMINO DA ENTREVISTA

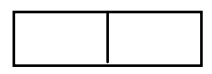

TEMPO DE ENTREVISTA

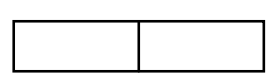


NOME DO ENTREVISTADO

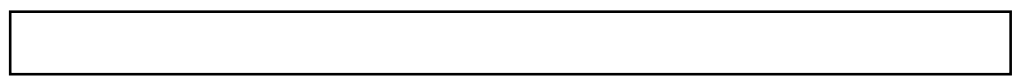

ENDEREÇO DO ENTREVISTADO

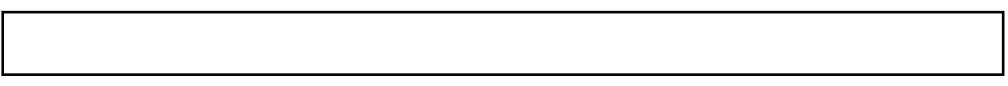

TELEFONE DO ENTREVISTADO

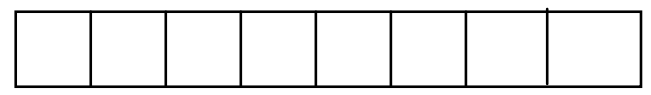

(Se tiver) 
1) Sexo:
1

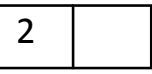
Masculino
Feminino

2) Idade:

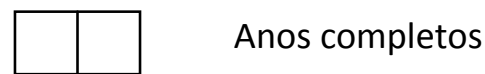

3) Data de nascimento:

4)Naturalidade (Estado onde nasceu):
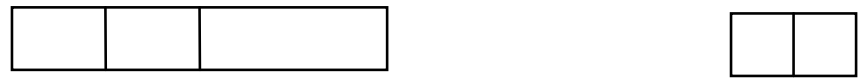

5) Com quem você vive no momento? (Marque apenas uma alternativa)

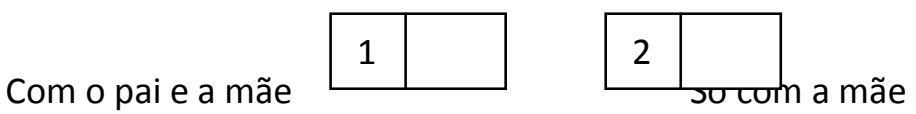

Só com o pai
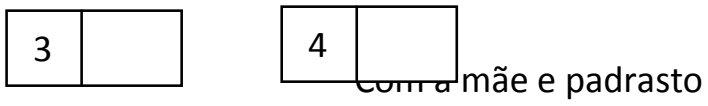

Com o pai e

\begin{tabular}{|l|l|}
\hline 5 & \\
\hline
\end{tabular}

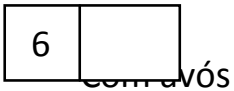

madrasta

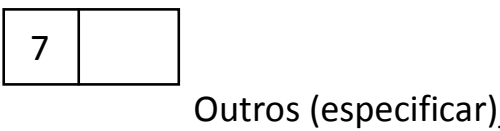


6) Qual a escolaridade do seu pai ou responsável (especifique o responsável)

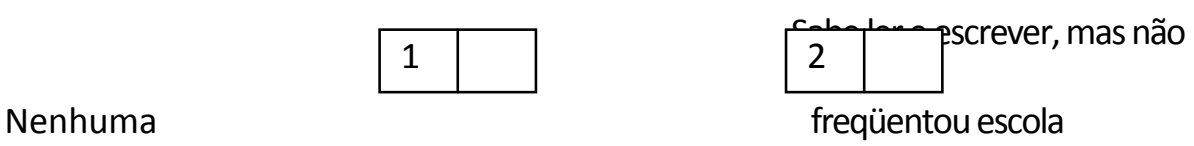

Ensino fundamental

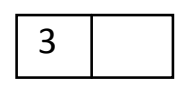

completo

4

incompleto

(primeiro grau)

Ensino médio

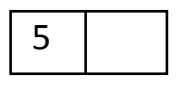

completo

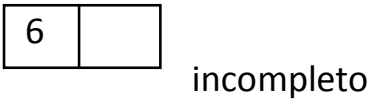

(segundo grau)

Ensino superior

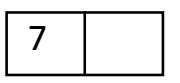

completo

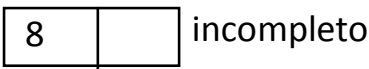

(faculdade)

Não sei

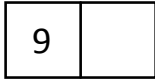

\begin{tabular}{|l|l|}
\hline 10 & \\
\hline
\end{tabular}

7) Qual a escolaridade de sua mãe?

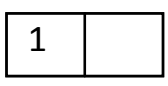

Nenhuma

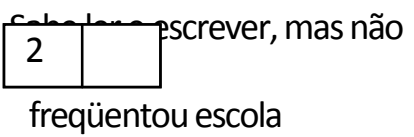

Ensino fundamental

$$
3
$$

completo

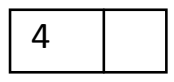

incompleto

(primeiro grau)

$$
5
$$

6 
Ensino médio

completo

incompleto

(segundo grau)

Ensino superior

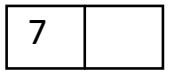

completo

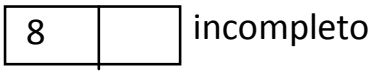

(faculdade)

Não sei

9

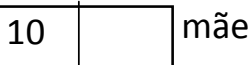

8) Qual é a ocupação do pai ou responsável:

\section{1}

Não está trabalhando

2

Está trabalhando

(especifique o tipo de trabalho)

9) Qual é o estado conjugal dos seus pais?

Solteiros, nunca

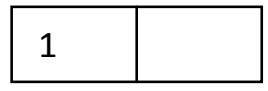

2

viveram juntos

Unidos consensualmente
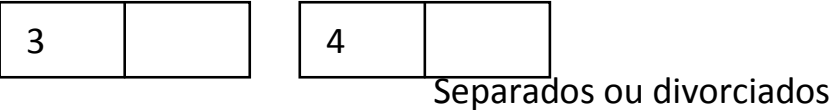

(moram juntos e não são casados)

Viúvo(a)

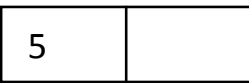

6

Ambos falecidos 
Outros (especificar)

\begin{tabular}{|l|l|}
\hline 7 & \\
\hline
\end{tabular}

II-RECURSOS DE SAÚDE

AGORA GOSTARÍAMOS DE SABER UM POUCO SOBRE VOCÊ E A SUA SAÚDE - (Marque apenas uma alternativa)

10) Como você diria que está a sua saúde no momento?

Muito boa

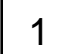

Boa

$$
2
$$

3

Ruim

Muito ruim

$$
4
$$

5

Não sei

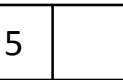


11) Sinto que sou uma pessoa digna de respeito.

Concordo totalmente

1

Concordo

3

Discordo

Discordo totalmente

4

12) Creio que tenho várias qualidades boas.

Concordo totalmente

1

3

Discordo

Discordo totalmente

4

Concordo

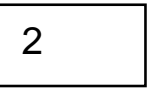


13) Creio que tenho motivos para sentir orgulho de quem sou.

Concordo totalmente

\section{1}

Concordo

\section{2}

3

Discordo

Discordo totalmente

4

14) Tenho uma atitude positiva em relação a mim mesmo.

Concordo totalmente

1

2

3

Discordo

Discordo totalmente

4

15) Em geral, sou satisfeito comigo mesmo.

Concordo totalmente

1 
Concordo

Discordo

Discordo totalmente

16) Gostaria de me valorizar mais.

1

Concordo totalmente

2

Concordo

3

Discordo

Discordo totalmente

4

ESCOLHA AS FRASES ABAIXO QUE MELHOR DESCREVEM SEUS SENTIMENTOS NAS ÚLTIMAS DUAS SEMANAS (MARQUE APENAS UMA ALTERNATIVA)

17)

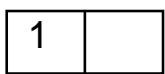

Eu fico triste de vez em quando

2

Eu fico triste muitas vezes

3

Eu fico triste o tempo todo 
18)

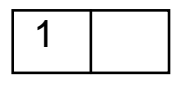

2

3

19)

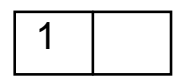

2

3

20)
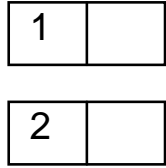

3

21)
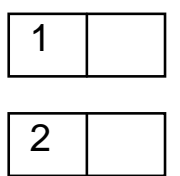

3

22)

1

2
Nada nunca vai dar certo para mim

Não tenho certeza se as coisas vão dar certo para mim

Vai dar tudo certo para mim

Eu faço quase tudo certo

Muitas coisas eu faço errado

Eu faço tudo errado

Eu me divirto com muitas coisas

Eu me divirto com algumas coisas

Não me divirto com nada

Eu sou ruim o tempo todo

Muitas vezes eu sou ruim

Eu sou ruim uma vez ou outra

Eu penso que coisas ruins possam acontecer comigo uma vez ou outra

Eu fico preocupado que coisas ruins aconteçam comigo 
23)

3

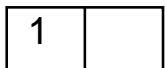

2

3

24)

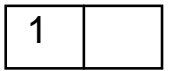

2

3

25)

$$
1
$$$$
2
$$

$$
3
$$

26)
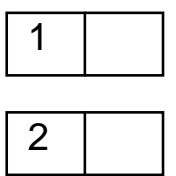

3

27)$$
1
$$

$$
2
$$

Eu tenho certeza que coisas horríveis vão acontecer comigo

Eu me detesto

Eu não gosto de mim

Eu gosto de mim

Todas as coisas ruins acontecem por minha culpa

Muitas coisas ruins acontecem por minha culpa

As coisas ruins geralmente não acontecem por minha culpa

Eu não penso em me matar

Eu penso em me matar, mas não faria isso

Eu quero me matar

Tenho vontade de chorar todos os dias

Muitos dias eu tenho vontade de chorar

Tenho vontade de chorar uma vez ou outra

Tem sempre uma coisa me aborrecendo

Muitas vezes tem uma coisa me aborrecendo 
Uma vez ou outra tem alguma coisa me aborrecendo

28)

\section{1}

2

\begin{tabular}{|l|l|}
\hline 3 & \\
\hline
\end{tabular}

29)

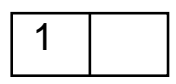

2

$$
3
$$

30)

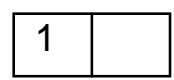

2

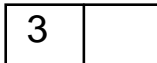

31)
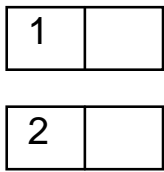

3

32)

1
Eu gosto de estar com outras pessoas

Muitas vezes eu não gosto de estar com outras pessoas

Eu não tenho vontade de estar com ninguém

Eu não consigo me decidir sobre nada

É difícil tomar decisões

Eu me decido sobre as coisas facilmente

Minha aparência é legal

Tem umas coisas que eu não gosto na minha aparência

Eu sou feio(a)

Eu tenho sempre que me forçar a fazer minhas tarefas escolares

Muitas vezes eu tenho que me forçar a fazer minhas tarefas escolares

Não tenho problemas para fazer as tarefas escolares

Tenho problema para dormir todas as noites 


$$
2
$$$$
3
$$

33)

$$
1
$$

\begin{tabular}{|l|l|}
\hline 2 & \\
\hline
\end{tabular}

3

34)

$$
1
$$$$
2
$$

\begin{tabular}{|l|l|}
\hline 3 & \\
\hline
\end{tabular}

35)

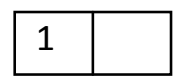

$$
2
$$

$$
3
$$

36)
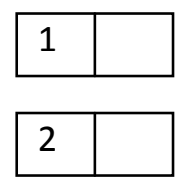$$
3
$$$$
3
$$

Muitas vezes tenho problema para dormir

Eu durmo bem

Eu fico cansado uma vez ou outra

Muitos dias eu fico cansado

Estou sempre cansado

Na maioria dos dias eu não estou a fim de comer

Muitos dias eu não estou a fim de comer

Eu como bem

Não me preocupo com dores

Muitas vezes eu me preocupo com dores

Eu sempre me preocupo com dores

Eu não me sinto sozinho(a)

Muitas vezes eu me sinto sozinho(a)

Eu sempre me sinto sozinho(a)

37) 


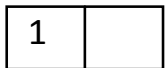

2 3

38)
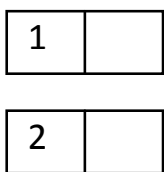

3

39)

$$
1
$$

$$
2
$$$$
3
$$

40)

$$
1
$$

\begin{tabular}{|l|l|}
\hline 2 & \\
\hline
\end{tabular}

\begin{tabular}{|l|l|}
\hline 3 & \\
\hline
\end{tabular}

41)
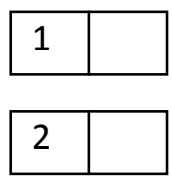

$$
3
$$

42)
Nunca me divirto na escola

Só me divirto na escola uma vez ou outra

Muitas vezes eu me divirto na escola

Eu tenho muitos amigos

Eu tenho muitos amigos, mas queria ter mais

Eu não tenho amigos

Meu rendimento na escola está bom

Meu rendimento na escola não está tão bom quanto antes

Estou indo mal em matérias nas quais eu ia bem

Nunca vou ser tão bom quanto os outros

Se eu quiser posso ser tão bom quanto os outros

Sou tão bom quanto os outros

Ninguém me ama de verdade

Não tenho certeza se alguém me ama

Tenho certeza que alguém me ama 

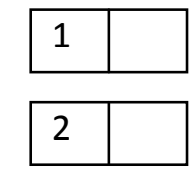

3

43)

$$
1
$$

\begin{tabular}{|l|l|}
\hline 2 & \\
\hline
\end{tabular}

3
Eu geralmente faço o que me mandam fazer

Eu geralmente não faço o que me mandam fazer

Eu nunca faço o que me mandam fazer

Eu me dou bem com as pessoas

Muitas vezes eu me meto em brigas

Eu me meto em brigas o tempo todo

III - RECURSOS SOCIAIS

A - AGORA GOSTARÍAMOS DE SABER UM POUCO SOBRE A SUA CONVIVÊNCIA COM A SUA FAMÍLIA E COM OS SEUS (SUAS) AMIGOS (AS) - (Marque apenas uma alternativa)

44)Você diria que a convivência que você tem com a sua família é: (Família são as pessoas com quem você mora mesmo que não sejam parentes ou os pais, irmão e avós mesmo que não morem juntos)

Muito boa
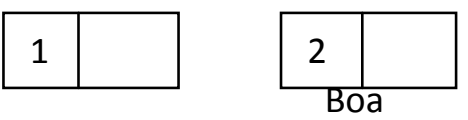

Ruim

\begin{tabular}{|l|l|}
\hline 3 & \\
\hline
\end{tabular}

\begin{tabular}{|l|l|}
\hline 4 & \\
\hline IVIutto rurm
\end{tabular}

Não sei 
45) Com que freqüência você conversa sobre assuntos relacionados a sexo (namoro, relações sexuais, doenças sexualmente transmissíveis, gravidez, casamento, etc.) com seus pais ou responsáveis?

Freqüentemente
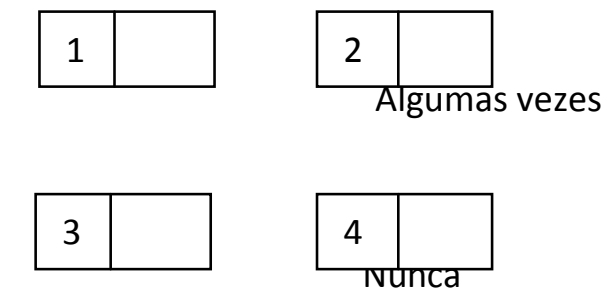

Raramente

INunca

Não sei

46) Com que freqüência você conversa sobre drogas, criminalidade e violência com seus pais ou responsáveis?

Freqüentemente
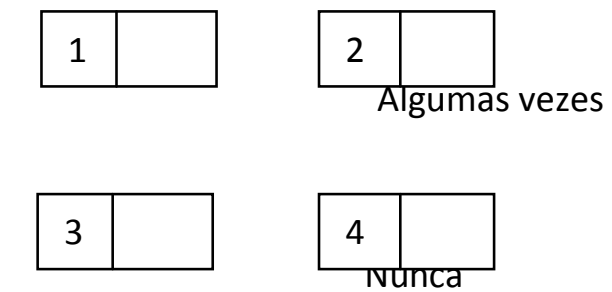

Raramente

ivunca

Não sei

\section{5}

47) Como você se sente para conversar com seus pais ou responsáveis sobre assuntos diversos do cotidiano, tais como vida escolar, saídas com amigos, projetos de vida, suas satisfações e insatisfações de um modo geral?

Muito à vontade

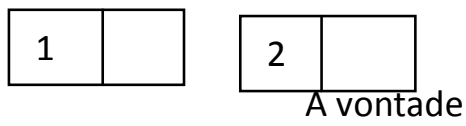

Embaraçado

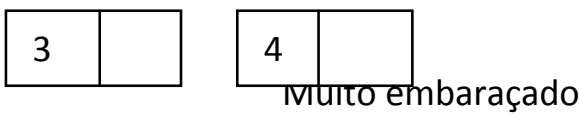

Não costuma conversar

5

6 
48) Com quem você mais conversa sobre os seus problemas? (Marque apenas uma alternativa)

Com o pai

Com a mãe

Com avós

Com parentes

Com amigos

Com o(a) namorado(a)

Com professor(a) ou

funcionário(a) da escola

Outros especificar

Ninguém

Não sei
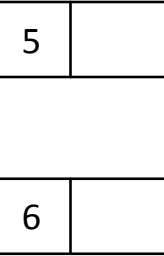

7

\section{1}

2

3

4

8$$
9
$$

$$
10
$$


49) Com quem você mais conversa sobre as suas alegrias? (Marque apenas uma alternativa)

Com o pai

1

Com a mãe

2

Com avós

$$
3
$$

Com parentes

$$
4
$$

Com amigos$$
5
$$

Com o(a) namorado(a)

$$
6
$$

Com professor(a) ou

funcionário(a) da escola

Outros especificar

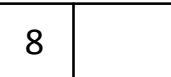

9

Ninguém

\begin{tabular}{|l|l|}
\hline 9 & \\
\hline
\end{tabular}

Não sei

50)Você confia na sua família?

Para todos os assuntos 
Para alguns assuntos

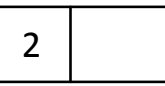

Para poucos

assuntos

Para nenhum assunto

Não sei

51)Você acha que sua família confia em você?

Para todos os assuntos

1

2

Para alguns assuntos

assuntos

Para nenhum assunto

Não sei 
52) Você acha que de um modo geral a sua família está satisfeita com você?

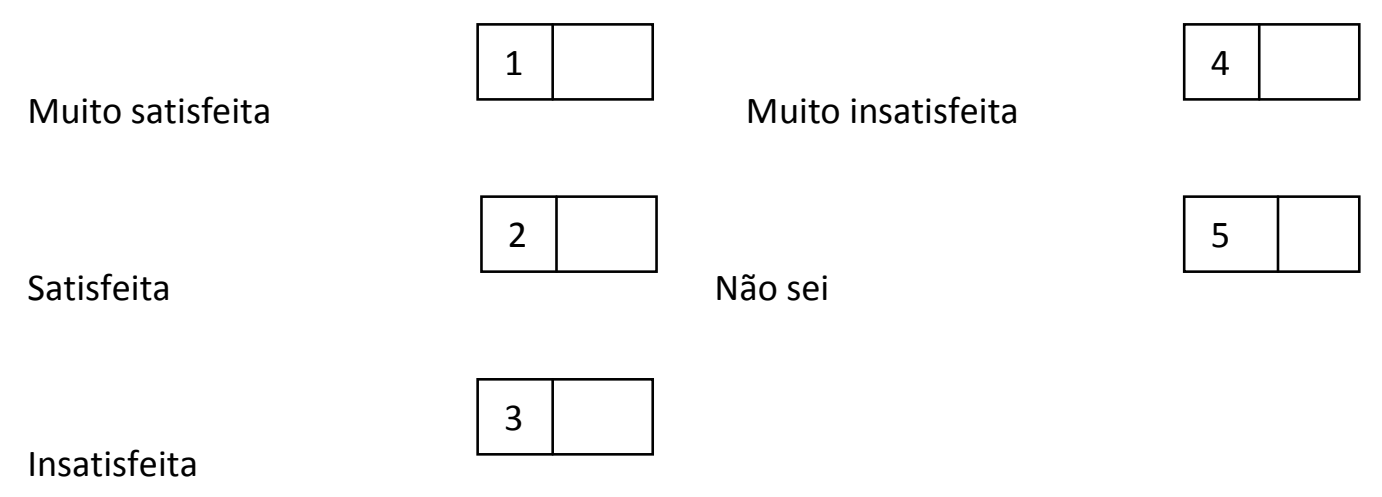

53) Você acha que sua família tem admiração por você?

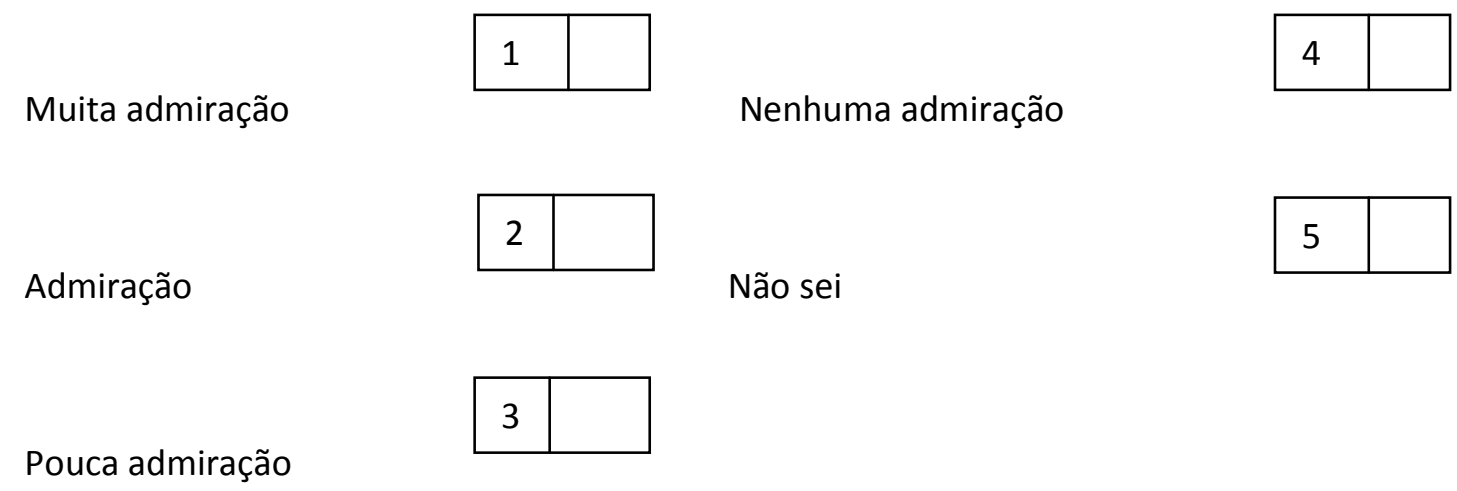

54)Você costuma participar das decisões da sua família?

Em todos os assuntos

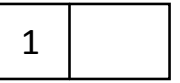

Em alguns assuntos

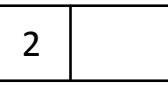

Em poucos assuntos 
Em nenhum assunto

Não sei

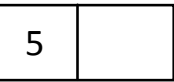

55) Quantos(as) amigos(as) você tem para sair ou conversar? (Amigo(a) é aquele(a) com quem você compartilha qualquer situação).

Um ou dois

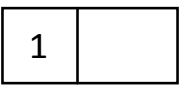

Três ou quatro

$$
2
$$

Cinco ou mais

Nenhum ...

$$
\begin{aligned}
& \text { 4 } \quad \text { arcou “nenhum" vá para a questão } 59 \text { e } \\
& \text { marque “Não se aplica" nas questões } 56 \text { a } 58 .
\end{aligned}
$$

Não sei

56) De um modo geral você está satisfeito(a) com os seus (suas) amigos(as)?

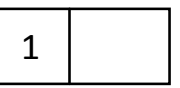

Muito satisfeito

Satisfeito

Insatisfeito

\section{Muito insatisfeito}

\begin{tabular}{|l|l|}
\hline 2 & \\
\hline
\end{tabular}

Não sei

\begin{tabular}{|l|l|}
\hline 3 & \\
\hline
\end{tabular}

Não se aplica

\section{4}

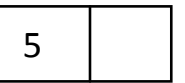

6

(não tenho amigos) 
57) Com que freqüência você saiu, visitou ou foi visitado pelos seus(suas) amigos(as) nos últimos dois meses?

Freqüentemente
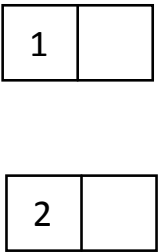

Raramente

Nenhuma vez

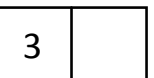

$$
4
$$

5

Não se aplica

(não tenho amigos)

58) Você diria que você confia nos seus(suas) amigos(as)?

Para todos os assuntos

1

$$
2
$$

Para alguns assuntos

assuntos

Para nenhum assunto

4 
Não sei

\begin{tabular}{|l|l|}
\hline 5 & \\
\hline
\end{tabular}

Não se aplica

(não tenho amigos)

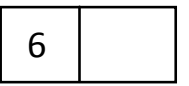

59) Em um momento de grande necessidade ou crise com quem você pode realmente contar para te ajudar? (Marque apenas uma alternativa)

Com o pai

Com a mãe

Com avós

Com parentes

Com amigos

Com o(a) namorado(a)

\begin{tabular}{|l|l|}
\hline 6 & \\
\hline
\end{tabular}

Com professor(a) ou

funcionário(a) da escola

Outros especificar

$$
1
$$$$
2
$$

$$
3
$$

4

$$
5
$$


Ninguém

Não sei

B - AGORA GOSTARÍAMOS DE SABER UM POUCO SOBRE A SUA RELAÇÃO COM AS PESSOAS EM

GERAL E A SUA PARTICIPAÇÃO COMUNITÁRIA - (Marque apenas uma alternativa)

60) Você participa de alguma atividade ou projeto, tais como grupo de esportes, grupos de igreja ou outras associações?

$\operatorname{Sim}$

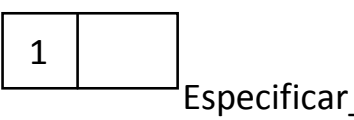

Não

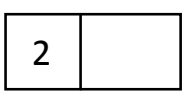

61) Você faz algum trabalho voluntário para escolas, igrejas, asilos, creches ou outras instituições?

Sim

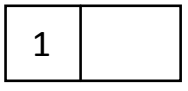

Especificar

Não

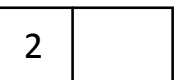


62) Você acha que as pessoas de um modo geral tentam tirar vantagem umas das outras (passar a perna) quando têm chance?

Todas

$$
1
$$

A maioria

\section{2}

3

Poucas

Ninguém

4

5

Não sei

63) Você acha que as pessoas de um modo geral são honestas e justas umas com as outras?

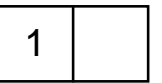

Todas são

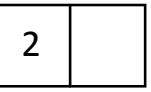

A maioria é

$$
3
$$

\section{4}

Nenhuma é

5

Não sei

Poucas são

64) Você diria que as pessoas de um modo geral são preocupadas e solidárias umas com as outras?

Todas são

$$
1
$$

A maioria é

2 
Poucas são

Nenhuma é

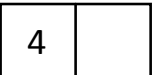

Não sei

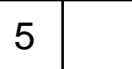

65) Você acha que as pessoas de um modo geral são egoístas e não se preocupam umas com as outras?

Todas são

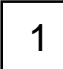

A maioria é

2

3

Poucas são

Nenhuma é

$$
4
$$

5

Não sei

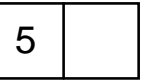

66)Você acha que as pessoas em geral respeitam os adolescentes?

Todas

$$
1
$$

A maioria

2 
Poucas

Nenhuma

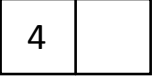

5

Não sei

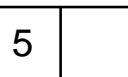

67) Você acha que as pessoas em geral valorizam os adolescentes?

Todas

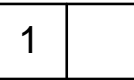

A maioria

2

3

Poucas

4

Nenhuma

5

Não sei

68) Você acha que as pessoas em geral consideram os adolescentes úteis?

1

Todas

2

A maioria 
Poucas

Nenhuma

Não sei

69) Você acha que as pessoas em geral pensam que os adolescentes fazem as coisas tão bem quanto os adultos?

\section{1}

Todas

2

A maioria

Poucas

Nenhuma

4

Não sei

Se você tiver algum comentário a mais para fazer, por favor, utilize o verso da folha. Nós agradecemos a sua participação. 


\section{ANEXO A- QUESTIONÁRIO DO INVENTÁRIO DE DEPRESSÃO DE BECK}

Este questionário consiste em 21 grupos de afirmações. Depois de ler cuidadosamente cada grupo, faça um círculo em torno do número $(0,1,2$ ou 3) diante da afirmação, em cada grupo, que descreve melhor a maneira como você tem se sentido nesta semana, incluindo hoje. Se várias afirmações num grupo parecerem se aplicar igualmente bem, faça um círculo em cada uma. Tome o cuidado de ler todas as afirmações, em cada grupo, antes de fazer a sua escolha.

1. 0 Não me sinto triste.

1 Eu me sinto triste.

2 Estou sempre triste e não consigo sair disso.

3 Estou tão triste ou infeliz que não consigo suportar.

2. 0 Não estou especialmente desanimado quanto ao futuro.

1 Eu me sinto desanimado quanto ao futuro.

2 Acho que nada tenho a esperar.

3 Acho o futuro sem esperança e tenho a impressão de que as coisas não podem melhorar.

3. 0 Não me sinto um fracasso.

1 Acho que fracassei mais do que uma pessoa comum.

2 Quando olho para trás, na minha vida, tudo o que posso ver é um monte de fracassos.

3 Acho que, como pessoa, sou um completo fracasso.

4. 0 Tenho tanto prazer em tudo como antes.

1 Não sinto mais prazer nas coisas como antes.

2 Não encontro um prazer real em mais nada.

3 Estou insatisfeito ou aborrecido com tudo.

5. 0 Não me sinto especialmente culpado.

1 Eu me sinto culpado às vezes.

2 Eu me sinto culpado na maior parte do tempo.

3 Eu me sinto sempre culpado.

6. 0 Não acho que esteja sendo punido.

1 Acho que posso ser punido.

2 Creio que vou ser punido.

3 Acho que estou sendo punido.

7. 0 Não me sinto decepcionado comigo mesmo.

1 Estou decepcionado comigo mesmo.

2 Estou enojado de mim.

3 Eu me odeio.

8. 0 Não me sinto de qualquer modo pior que os outros.

1 Sou crítico em relação a mim devido a minhas fraquezas ou meus erros. 
2 Eu me culpo sempre por minhas falhas.

3 Eu me culpo por tudo de mal que acontece.

9. 0 Não tenho quaisquer idéias de me matar.

1 Tenho idéias de me matar, mas não as executaria.

2 Gostaria de me matar.

3 Eu me mataria se tivesse oportunidade.

10. 0 Não choro mais que o habitual.

1 Choro mais agora do que costumava.

2 Agora, choro o tempo todo.

3 Costumava ser capaz de chorar, mas agora não consigo mesmo que o queira.

11. 0 Não sou mais irritado agora do que já fui.

1 Fico molestado ou irritado mais facilmente do que costumava.

2 Atualmente me sinto irritado o tempo todo.

3 Absolutamente não me irrito com as coisas que costumavam irritar-me.

12. 0 Não perdi o interesse nas outras pessoas.

1 Interesso-me menos do que costumava pelas outras pessoas.

2 Perdi a maior parte do meu interesse nas outras pessoas.

3 Perdi todo o meu interesse nas outras pessoas.

13. 0 Tomo decisões mais ou menos tão bem como em outra época.

1 Adio minhas decisões mais do que costumava.

2 Tenho maior dificuldade em tomar decisões do que antes.

3 Não consigo mais tomar decisões.

14. 0 Não sinto que minha aparência seja pior do que costumava ser.

1 Preocupo-me por estar parecendo velho ou sem atrativos.

2 Sinto que há mudanças permanentes em minha aparência que me fazem parecer sem atrativos.

3 Considero-me feio.

15. 0 Posso trabalhar mais ou menos tão bem quanto antes.

1 Preciso de um esforço extra para começar qualquer coisa.

2 Tenho de me esforçar muito até fazer qualquer coisa.

3 Não consigo fazer nenhum trabalho.

16. 0 Durmo tão bem quanto de hábito.

1 Não durmo tão bem quanto costumava.

2 Acordo uma ou duas horas mais cedo do que de hábito e tenho dificuldade para voltar a dormir.

3 Acordo várias horas mais cedo do que costumava e tenho dificuldade para voltar a dormir.

17. 0 Não fico mais cansado que de hábito.

1 Fico cansado com mais facilidade do que costumava.

2 Sinto-me cansado ao fazer quase qualquer coisa.

3 Estou cansado demais para fazer qualquer coisa. 
18. 0 Meu apetite não está pior do que de hábito.

1 Meu apetite não é tão bom quanto costumava ser.

2 Meu apetite está muito pior agora.

3 Não tenho mais nenhum apetite.

19. 0 Não perdi muito peso, se é que perdi algum ultimamente.

1 Perdi mais de $2,5 \mathrm{Kg}$.

2 Perdi mais de $5,0 \mathrm{Kg}$.

3 Perdi mais de $7,5 \mathrm{Kg}$.

Estou deliberadamente tentando perder peso, comendo menos: SIM ( ) NÃO ( )

20. 0 Não me preocupo mais que o de hábito com minha saúde.

1 Preocupo-me com problemas físicos como dores e aflições ou perturbações no estômago ou prisão de ventre.

2 Estou muito preocupado com problemas físicos e é difícil pensar em outra coisa que não isso. 3 Estou tão preocupado com meus problemas físicos que não consigo pensar em outra coisa.

21. 0 Não tenho observado qualquer mudança recente em meu interesse sexual.

1 Estou menos interessado por sexo que costumava.

2 Estou bem menos interessado em sexo atualmente.

3 Perdi completamente o interesse por sexo. 